\title{
A Study of Drought Characteristics over the Canadian Prairies
}

\author{
By \\ Erin Roberts \\ Department of Atmospheric and Oceanic Sciences \\ McGill University, Montréal \\ December 2004
}

A thesis submitted to the Faculty of Graduate Studies and Research in partial fulfillment of the requirements of the degree of Master of Science

CErin Roberts, December 2004 


$\begin{array}{ll}\begin{array}{l}\text { Library and } \\ \text { Archives Canada }\end{array} & \begin{array}{l}\text { Bibliothèque et } \\ \text { Archives Canada }\end{array} \\ \begin{array}{l}\text { Published Heritage } \\ \text { Branch }\end{array} & \begin{array}{l}\text { Direction du } \\ \text { Patrimoine de l'édition }\end{array} \\ \begin{array}{l}\text { 395 Wellington Street } \\ \text { Ottawa ON K1A 0N4 }\end{array} & \begin{array}{l}\text { 395, rue Wellington } \\ \text { Ottawa ON K1A ON4 } \\ \text { Canada }\end{array} \\ \end{array}$

Your file Votre référence ISBN: 978-0-494-12528-1 Ourfile Notre référence ISBN: 978-0-494-12528-1

NOTICE:

The author has granted a nonexclusive license allowing Library and Archives Canada to reproduce, publish, archive, preserve, conserve, communicate to the public by telecommunication or on the Internet, loan, distribute and sell theses worldwide, for commercial or noncommercial purposes, in microform, paper, electronic and/or any other formats.

The author retains copyright ownership and moral rights in this thesis. Neither the thesis nor substantial extracts from it may be printed or otherwise reproduced without the author's permission.
AVIS:

L'auteur a accordé une licence non exclusive permettant à la Bibliothèque et Archives Canada de reproduire, publier, archiver, sauvegarder, conserver, transmettre au public par télécommunication ou par l'Internet, prêter, distribuer et vendre des thèses partout dans le monde, à des fins commerciales ou autres, sur support microforme, papier, électronique et/ou autres formats.

L'auteur conserve la propriété du droit d'auteur et des droits moraux qui protège cette thèse. $\mathrm{Ni}$ la thèse ni des extraits substantiels de celle-ci ne doivent être imprimés ou autrement reproduits sans son autorisation.
In compliance with the Canadian

Privacy Act some supporting forms may have been removed from this thesis.

While these forms may be included in the document page count, their removal does not represent any loss of content from the thesis.
Conformément à la loi canadienne sur la protection de la vie privée, quelques formulaires secondaires ont été enlevés de cette thèse.

Bien que ces formulaires aient inclus dans la pagination, il n'y aura aucun contenu manquant. 


\begin{abstract}
Typically, drought occurs once every three years across the Canadian Prairies. Most research addressing such droughts has concentrated on the large scale conditions associated with this form of extreme weather whereas little research has been conducted on its smaller scale characteristics. The present research begins to address the latter issue.

Several datasets (surface observations, drought indices, and re-analysis products) were used to identify and analyze the 11 most severe droughts occurring over the Prairies since 1953. Warm season hourly surface observations (temperature, moisture, clouds, and precipitation) from 10 observational sites were then compared for extreme drought, drought, non-drought, and extreme wet conditions. When compared to non-drought or extreme wet conditions, drought and extreme drought conditions are associated with warmer temperatures and drier conditions and there is little change in the amount of total cloud cover but cloud bases are higher. As well, the maximum temperature and highest cloud base both occur 1-2 $\mathrm{h}$ later in the afternoon during drought and extreme drought conditions as compared to non-drought and extreme wet conditions. Such factors act to extend the drought conditions. For example, the higher cloud bases during drought and extreme drought conditions lead to greater evaporation of falling precipitation and this prevents significant precipitation from occurring thereby reinforcing the dry conditions.
\end{abstract}




\section{Résumé}

Une sécheresse se produit en moyenne tous les trois ans au-dessus des Prairies Canadiennes. La plupart des recherches concernant de telles sécheresses se sont concentrées sur les caractéristiques à grande échelle de ces désastres naturels, alors que peu de recherches ont été conduites sur les caractéristiques à petite échelle. La présente étude se concentre sur ce dernier problème.

Plusieurs ensembles de données (observations à la surface, indices de sécheresse, et produits de ré - analyse) ont été utilisés pour identifier et analyser les 11 sécheresses les plus importantes qui se sont produites au dessus des Prairies depuis 1953. Des données horaires d'observations à la surface (température, humidité, nuages et précipitations), en saison chaude, à 10 stations d'observation, ont été comparées pour des épisodes d'extrême humidité, de non sécheresse, de sécheresse et d'extrême sécheresse. Si l'on compare les épisodes d'extrême humidité et de non - sécheresse avec les épisodes de sécheresse et d'extrême sécheresse, on constate que ces derniers sont associés à des températures plus chaudes et une plus basse humidité de l'air; par ailleurs, il y a peu de différence concernant la couverture nuageuse totale mais la base des nuages est plus haute pour les épisodes de sécheresse et d'extrême sécheresse. De plus, pendant les périodes de sécheresse et d'extrême sécheresse, le moment où la température et l'altitude de la base des nuages sont maximales se produit 1 à 2 heures plus tard que pendant les périodes de non - sécheresse et d'extrême humidité. De tels facteurs tendent à prolonger la durée des sécheresses. Ainsi, le fait que la base des nuages soit plus haute pendant les périodes de sécheresse et d'extrême sécheresse contribue à produire un plus haut taux d'évaporation de l'eau de pluie avant qu'elle ne touche le sol, et donc de moindres précipitations à la surface, ce qui finalement renforce les conditions de sécheresse. 


\section{Table of Contents}

Abstract $\quad$ ii

Résumé

Table of Contents iv

List of Figures viii

List of Tables $\quad$ xi

Acknowledgements $\quad$ xii

\section{CHAPTER 1}

INTRODUCTION 1

1.1 Motivation behind the Study of Drought 1

1.2 Defining Drought 3

1.3 Drought Indices 4

1.4 The Study of Drought - A Review of the Literature 5

1.5 Climatology of the Prairies 9

$\begin{array}{lll}\text { 1.6 Main Thesis Objectives and Structural Outline } & 11\end{array}$

\section{CHAPTER 2}

DATA AND METHODOLOGY 14

$\begin{array}{ll}2.1 & \text { Description of Data Sets Used in Research } \\ \end{array}$

$\begin{array}{lll}2.1 .1 & \text { Surface Observations } & 14\end{array}$

$\begin{array}{lll}2.1 .2 & \text { Calculated Indices } & 16\end{array}$

$\begin{array}{ll}\text { 2.2 } & \text { Methodology of Research } \\ \end{array}$ 
$\begin{array}{lll}2.3 & \text { Selected Years } & 18\end{array}$

$\begin{array}{lll}2.3 .1 \text { Overview } & 18\end{array}$

$\begin{array}{ll}\text { 2.3.2 Methodology of Selection } & 19\end{array}$

\section{CHAPTER 3}

CHARACTERISTICS OF TEMPERATURE, MOISTURE, AND CLOUDS

3.1 Surface Observations 26

3.2 Averages and Deviations 28

3.3 Analysis of the Diurnal Cycle 29

$\begin{array}{llr}3.3 .1 & \text { Temperature } & 29\end{array}$

$\begin{array}{ll}\text { 3.3.2 Dew Point } & 30\end{array}$

$\begin{array}{lll}\text { 3.3.3 Dew Point Depression } & 31\end{array}$

3.3.4 Relative Humidity $\quad 32$

3.3.5 Wind Speed 33

$\begin{array}{ll}\text { 3.3.6 Cloud Tenths } & 34\end{array}$

$\begin{array}{lll}3.3 .7 & \text { Cloud Type } & 38\end{array}$

3.3.8 Convective Clouds $\quad 42$

3.3.9 Ceiling $\quad 44$

3.4 Synopsis $\quad 45$

$\begin{array}{lll}3.5 & \text { Statistical Significance } & 46\end{array}$

$\begin{array}{lll}3.6 & \text { Discussion } & 48\end{array}$ 


\section{CHAPTER 4}

\section{CHARACTERISTICS OF THE OCCURRENCE OF PRECIPITATION}

4.1 Average Characteristics of Precipitation $\quad 52$

4.2 Diurnal Cycle of Precipitation $\quad 55$

$\begin{array}{lll}4.2 .1 \quad \text { Rain } & 55\end{array}$

$\begin{array}{lll}\text { 4.2.2 Thunderstorms } & 56\end{array}$

$\begin{array}{lll}\text { 4.2.3 Drizzle } & 57\end{array}$

4.3 Duration of Events and Time between Events $\quad 58$

4.3.1 Duration of Rain Events $\quad 58$

$\begin{array}{ll}\text { 4.3.2 Time between Rain Events } & 60\end{array}$

$\begin{array}{lll}4.4 & \text { Synopsis } & 62\end{array}$

4.5 Discussion $\quad 64$

CHAPTER 5

ADDITIONAL FEATURES OF DROUGHT 66

5.1 Evaporation below Cloud Base 66

$\begin{array}{lll}5.2 & \text { Reduction of Visibility } & 70\end{array}$

$\begin{array}{lll}5.2 .1 & \text { Introduction } & 70\end{array}$

5.2.2 Analysis 70

5.3 The Correlation between Cold Season and Warm Season Precipitation 73

$\begin{array}{lll}\text { 5.3.1 Previous Studies } & 74\end{array}$

$\begin{array}{lll}\text { 5.3.2 Current Study } & 75\end{array}$ 
5.3.3 Factors Influencing the Correlation between Cold Season and Warm Season Precipitation

\section{CHAPTER 6}

\section{CONCLUSIONS}

$\begin{array}{llr}6.1 & \text { Thesis Summary } & 80\end{array}$

6.2 Concluding Remarks $\quad 86$

$\begin{array}{ll}\text { Appendix I } & 89\end{array}$

$\begin{array}{ll}\text { Bibliography } & 95\end{array}$ 


\section{List of Figures}

Figure 1-1: The atmospheric and oceanic anomalies commonly associated with Canadian Prairie droughts. The anomalous high pressure area is formed in part due to a pocket of cold water in the Pacific Ocean (Bonsal et al., 1993).

Figure 1-2: A map of Canada with the shaded region representing the Canadian Prairies

Figure 1-3: Possible positive feedback processes associated with drought. ...... 12

Figure 2-1: The map above is of the three provinces, Alberta, Saskatchewan, and Manitoba, which encompass the Canadian Prairies (Natural Resources Canada, 2004). The location and name of the observing sites are marked.

Figure 2-2: NCEP Re-analysis map of the average warm season PDI for 1988. A -7 indicates the most extreme drought conditions and a +7 indicates the most extreme wet conditions

Figure 2-3: NCEP Re-analysis map of the average warm season PDI for 1984. Negative values indicate regions of extreme drought and positive values indicate regions that are not afflicted by drought 20

Figure 2-4: Histogram of the warm season PDI value for the 10 observing stations between 1953 and 2001. 21

Figure 2-5: Histogram of the warm season precipitation anomalies for the ten observing stations between 1953 and 2001 .

Figure 3-1: Deviation of the temperature and dew point from the 49 year warm season average.

Figure 3-2: The average diurnal cycle of temperature for the specified condition.

Figure 3-3: The diurnal cycle of dew point for the specified condition.

Figure 3-4: The diurnal cycle of the dew point depression for the indicated condition.

Figure 3-5: The diurnal cycle of relative humidity for the indicated condition. 33 
Figure 3-5: The diurnal cycle of relative humidity for the indicated condition. 33

Figure 3-6: The average diurnal cycle of the wind speed in $\mathrm{km} / \mathrm{h}$ for the condition specified.

Figure 3-7: Percent of time during each condition with the indicated degree of cloudiness between 00-23 LST. 35

Figure 3-8: Percent of time during each condition with the indicated degree of cloudiness between 08-20 LST. 36

Figure 3-9: Percent of time during each condition with the indicated degree of cloudiness between 00-07 and 21-23 LST.

Figure 3-10: The percentage of time during each condition with the indicated lowest cloud type from 00-23 LST. 39

Figure 3-11: The percentage of time with the indicated lowest cloud type for each condition from 08-20 LST.

Figure 3-12: The percentage of hours that the specified cloud was reported as the lowest cloud from 21-07 LST for each condition. 41

Figure 3-13: The percentage of time that the individual convective cloud types occurred between 00-23 LST. 42

Figure 3-14: The percentage of time for each drought condition that the individual types of convective clouds from 08-20 LST were observed...... 43

Figure 3-15: The percentage of time with the specified convective clouds occurring between 21-07 LST. 44

Figure 3-16: The diurnal cycle of ceiling. 45

Figure 4-1: Average number of hours over the warm season with reports of drizzle, thunderstorms, and rain. 54

Figure 4-2: The diurnal cycle of rain for the specified condition with the average number of occurrences for each hour. The values refer to the average number of occurrences at a given location. 56 
Figure 4-3: The diurnal cycle of thunderstorms with the average number of occurrences for each hour and the specified condition at a given site.

Figure 4-4: The diurnal cycle of drizzle with the average number of occurrences per hour for the specified condition at a given site.

Figure 4-5: Average number of rain events as a function of their duration at a given location during the warm season.

Figure 4-6: Average number of days between rain events at a given location during the warm season.

Figure 5-1: The diurnal cycle of the diameter a raindrop must exceed to reach the surface in the specified condition. .69

Figure 5-2: Average number of observations of smoke, dust, and haze during the warm season for each of the four conditions. 71

Figure 6-1: Positive feedback process associated with drought. The figure is similar to Figure 1-3; however it has been updated with the some results from this thesis. 84

Figure A-1: Sounding at 18 LST on May 26, 2004 for Edmonton, Alberta . .88

Figure A-2: Sea level pressure and $1000-500 \mathrm{hPa}$ thickness at $12 \mathrm{LST}$ on May 26,2004 . Edmonton, Alberta is identified by a red dot.

Figure A-3: Observed cloud field at 12 LST ...............................90

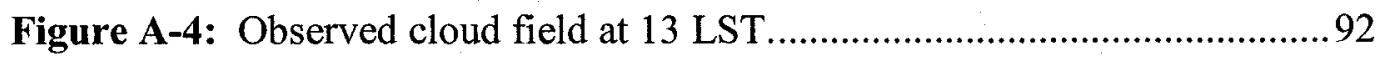

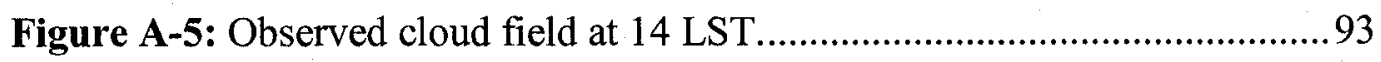

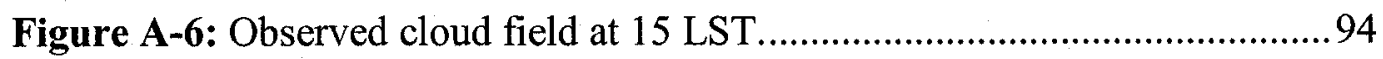




\section{List of Tables}

Table 2-1: Criteria used to determine drought severity......................23

Table 2-2: The eleven chosen drought years are shown as well as the years that qualified as extreme wet and extreme drought. A D marks a station that had both a negative PDI and a negative precipitation anomaly. An $E$ marks a station that had extreme drought conditions and a $\mathrm{W}$ marks a station that had extreme wet conditions. A dash indicates that a station had non-drought conditions...................... 25

Table 3-1: Overall warm season averages for the four conditions studied......28

Table 3-2: The number of hours that the deviations between the diurnal cycles of drought and non-drought were significant.........................48

Table 4-1: Overall warm season averages for the four conditions studied......62

Table 5-1: The average mixing ratio difference between the surface and the cloud base, the ceiling, and the minimum diameter that the drop diameter must exceed to allow a drop to reach the surface...........68

Table 5-2:Correlation coefficients between cold season and warm season precipitation anomalies for the 49 year period..................... 76

Table 5-3: Correlation coefficients between cold season and warm season precipitation anomalies during drought years.................. 77

Table 6-1: Overall warm season averages for the four conditions studied......85 


\section{Acknowledgements}

I am very grateful to my advisors Dr. Stewart and Dr. Lin. Their cheerful guidance and patience throughout this research was endless. In addition, their encouragement and enthusiasm made this truly a rewarding experience.

I would like to express thanks to Bob Kochtubajda and Monique Lapalme from the Hydrometeorology and Arctic Laboratory of the Meteorological Service of Canada, who aided in the retrieval of much of the data utilized in this study. In addition, discussions with Bob Kochtubajda provided drought expertise and he was of great guidance during the field experiment.

I am grateful to William Henson for the many statistical discussions and to both William Henson and Kevin Carrillo for contributing computer programs which enabled further analysis of the hourly precipitation data. In addition, I would like to thank the NOAA Climate Diagnostics Center (http://www.cdc.noaa.gov) for the PDI Re-Analysis data.

Finally, I would like to thank my family and friends, to whom I owe so much. I would like thank my parents and my sister for their love and support. I would like to thank Anne-Sophie for the multitude of advice, for the common love of caffeine and cinema, and for translating the abstract. I would like to thank Julie for the advice and good times we had, including the many hours at the Second Cup and the time spent touring Canada. Thank you to Jen for her editing assistance and the many late afternoon runs up Mt. Royal. To Andy, the fellow Penn Stater and roommate, thank you for telling me about McGill and the wonderful city of Montréal. A final thanks to Iriola, Steve, and Brian. 


\section{Chapter 1}

\section{Introduction}

\subsection{Motivation behind the Study of Drought}

Drought is an increasingly recurrent focus of news headlines around the world. Images of parched land, shriveled crops, and dried riverbeds and lakes are frequent. The impacts of drought are enormous and span many sectors including agriculture, water resources, and the environment.

In simple terms, drought can be defined as a precipitation deficit adversely affecting the economy, society, and the environment (AES, 1986). While drought is well recognized once it has firmly taken hold, it is not as well understood at which point the string of sunny days will begin to negatively affect the water budget (Tannehill, 1947). Scientific research to better understand the phenomenon of drought has become more common.

In recent years, the presence of drought has been felt worldwide. As much as $20 \%$ of the Earth's land mass was under drought conditions in 2002. Areas in Australia, Africa, China, Scandinavia, and North America were affected by four year precipitation deficits totaling as much as $300 \mathrm{~mm}$ between 1998 and 2002, causing widespread drought (Hoerling and Kumar, 2003). In 2002, China estimated losses of 1.2 billion dollars due to the most severe one year drought the 
area had experienced in over 100 years and the United States experienced the worst drought conditions since the Dust Bowl in the 1930's (Worldwatch, 2003).

In North America, the Canadian Prairies are one area particularly susceptible to drought. Drought is common over the region and the occurrence of at least one catastrophic drought per century can be seen in records dating back to the seventeenth century (Nkemdirim and Weber, 1998). As well, there were 38 years between 1900 and 1993 during which the Canadian Prairies were afflicted by drought that was severe enough to have a significant effect on crop production (Wilhite, 2000).

Much of the Prairies have been affected by a major drought since 1999. Even in the spring of 2004 the prospects for the moderation of the drought over the Canadian Prairies was bleak. Substantial precipitation deficits across much of the Prairies following the growing season in 2003 coupled with deficits in winter precipitation resulted in dry soil and well below normal ground water levels. The effects of the precipitation deficits were evident in the spring of 2004. Low water levels had left the area with decreased ability to produce hydroelectric power. Environment Canada indicated that there was a moderate risk for drought to continue through the 2004 growing season in Alberta with improving conditions further east towards Manitoba. In reality however, the drought was alleviated over much of the Prairies during the summer of 2004. This also points out the current poor capability of prediction.

The economic cost of drought over the Canadian Prairies, particularly in the agricultural, environmental, and hydroelectric sectors, is enormous. Environment Canada (EC, 2003) has listed Canada's most costly natural disasters in history and drought accounts for four of the six disasters, all four having their major impact on the Prairie region. By the end of 2003, the economic impact of the drought that has affected the Prairie region since 1999 reached 12-15 billion dollars. 
The large economic impact of drought and the knowledge that drought repeatedly occurs over the Canadian Prairies makes the study of Canadian Prairie drought essential. As well, with future climate warming, a shift to the hydrologic cycle may cause fluctuations in precipitation and atmospheric water vapor. Some climate models have suggested that enhanced evaporation will lead to more severe and longer lasting droughts in regions prone to drought (Dai and Trenberth, 1998). Other models have shown variable changes in future precipitation and this leads to considerable uncertainty whether there is a possibility of increased drought over the Canadian Prairies (Gan, 1998).

\subsection{Defining Drought}

The definitions of drought are specific to drought's impact and the local climate of the afflicted region. Wilhite et al. (1987) identified and reviewed over 150 definitions for drought and found a common idea that all droughts are characterized by a water shortage that originated from a deficiency in precipitation. The definitions of drought are classified into one of four categories depending on whom or what is affected by the water shortage. The four categories include meteorological, agricultural, hydrologic, and socioeconomic drought. The four categories are arranged in the order in which their effects are noticed.

Meteorological drought is defined as the degree and duration of a dry period as compared to climate records. When the precipitation deficits affect soil moisture the conditions can then be classified as agricultural drought. Agricultural drought is defined as a precipitation shortage resulting in soil moisture deficits, plant stress, and changes in evapotranspiration. A hydrologic drought is declared when precipitation deficits affect surface and subsurface water supplies. Socioeconomic drought encompasses features of meteorological, 
agricultural, and hydrologic drought (Heim, 2002) and is defined by the impact of drought on human and economic activities, such as hydroelectric power.

Precipitation normals are different from one climate region to the next. This combined with differences in land type and land use make it almost impossible to have one definition for drought and as Wilhite commented in 1987, "There cannot (and should not) be a universal definition of drought." The notion that there can never be one universal definition of drought makes the study of drought that much more difficult. Because no concrete definition of drought exists frequent discrepancies concerning the severity of drought occur. This often leads to governmental indecisiveness as to the action that must be taken.

\subsection{Drought Indices}

The lack of a common definition of drought also makes it difficult to have one universally accepted drought index. However, several drought indices have been developed which to some extent provide a magnitude as to the severity of drought. Incorporating a variable to account for climate variations in different regions of the world allows for comparisons of drought conditions. The indices serve to detect and monitor drought conditions. Among the more common drought indices are the Standardized Precipitation Index (SPI), the Crop Moisture Index (CMI), and the Palmer Drought Index (PDI).

The Standardized Precipitation Index quantifies precipitation deficits on multiple time scales. This allows scientists and decision makers to examine the effects of drought on different sectors since agricultural drought may become apparent long before the impact would be seen in the hydrologic sector (Heim, 2002). Positive values indicate greater than normal precipitation.

The Crop Moisture Index best details agricultural drought, reflecting weekly moisture changes in the soil. The crop moisture index is based on a water balance model that incorporates both precipitation and temperature (Heim, 2002). 
The Palmer Drought Index is dependent both on temperature and precipitation and is based on a supply and demand model. Precipitation and soil moisture are accounted for in the supply and the loss of moisture from the soil is accounted for in the demand. Two-thirds of the PDI value is determined by antecedent conditions in comparison with one-third that is dependent on the current month's data (Quiring and Papakryiakou, 2003). The calculation of the PDI results in either a negative or a positive value, with negative values indicating drought conditions and positive values indicating wet conditions. Values around zero are considered normal whereas values below -4 indicate extreme drought conditions and values above +4 indicate extreme wet conditions.

In North America, of these three indices, the Palmer Drought Index is perhaps the most extensively used and has gained the widest acceptance (Akinremi et al., 1996). The Palmer Drought Index (PDI) is commonly used for drought monitoring and detection over the Canadian Prairies and the PDI will be utilized later in this thesis (Maybank et al., 1995; Nkemdirim and Weber, 1998).

\subsection{The Study of Drought - A Review of the Literature}

With the knowledge of how drought is defined and monitored, it becomes important to discuss the overall known causes and factors, both atmospheric and oceanic, which allow drought to develop and persist. Past research has focused on the teleconnections between the ocean and the atmosphere which are correlated with drought. Other work has focused on paleoclimate data and the impacts of drought on various sectors.

While a small amount of research has primarily focused on the Canadian Prairies a large amount has focused on the Great Plains of the United States. However, due to the close proximity of the Great Plains to the Prairies, much of the research completed on the Great Plains can also be applied to the Canadian Prairies. 
The study of the atmospheric circulation is integral to the study of drought. Deviations from normal atmospheric circulation are a common cause of dry conditions. The deviations include a large shift of the jet stream and storm track or a blocking high pressure area. The presence of a blocking high pressure area results in large scale subsidence which acts as a deterrent to both large scale and convective precipitation. Wilhite (2000) details the resultant effects of subsidence that inhibits the precipitation, including low-level stabilization and suppressed horizontal moisture convergence. Shifts in the jet stream and storm track also direct precipitation patterns away from their normal location. This was one important factor in the 1988 drought (Trenberth and Guillemot, 1996; Trenberth and Branstator, 1992).

The anomalous area of subsidence can be correlated with a large blocking high pressure area and a meridional flow pattern. Bonsal et al. (1999) showed that during dry periods there was a deepening of the trough over eastern Canada and an amplification of the west coast ridge. The anomalous ridge and trough pattern associated with meridional flow allowed cyclones to be diverted north thus missing the Prairie region. Dey (1982) showed that droughts over the Canadian Prairies were typically associated with a quasi-stationary midtropospheric ridge which blocked precipitation.

Bonsal et al. (1993) found a significant correlation between North Pacific sea surface temperatures and the occurrence of growing season dry spells over the Canadian Prairies. An anomalously cold pool over the central North Pacific and warm water off of the coast of British Columbia affect the upper level wave pattern (Figure 1-1). The resultant $500 \mathrm{mb}$ ridging over the Canadian Prairies drives subsidence and suppresses precipitation. However, these sea surface temperature patterns are not the sole driver of dry spells over the Prairies as several dry spells have occurred without the presence of this pattern. 


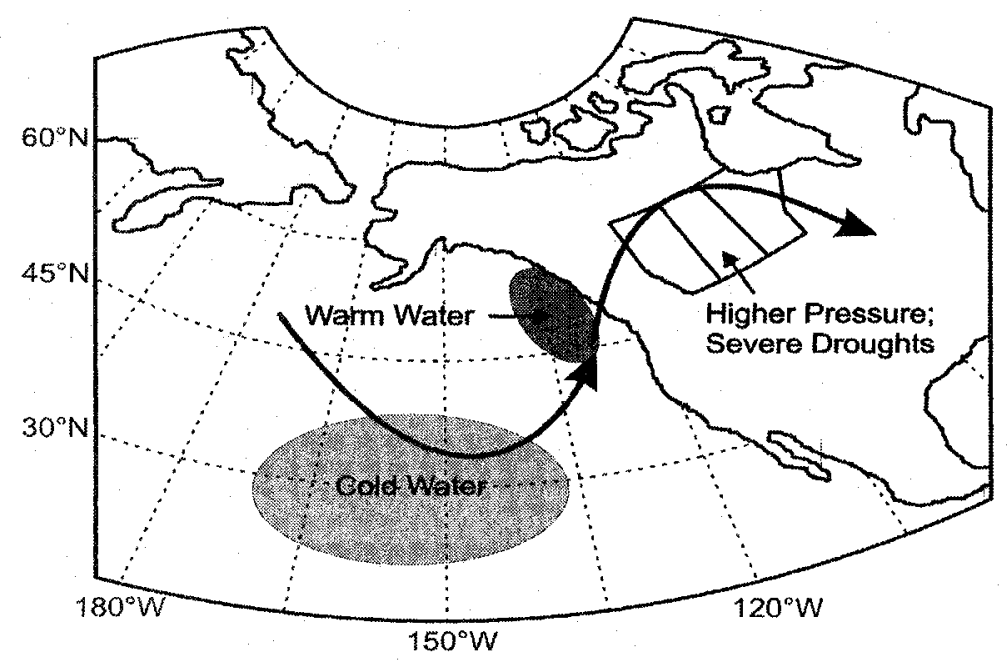

Figure 1-1: The atmospheric and oceanic anomalies commonly associated with Canadian Prairie droughts. The anomalous high pressure area is formed in part due to a pocket of cold water in the Pacific Ocean (Bonsal et al., 1993).

Bonsal and Lawford (1999) extended the study of the tropical forcing and examined the correlation of tropical sea surface temperature forcing and atmospheric circulation over the Canadian Prairies. It was found that the Canadian Prairies tend to experience an increased number of summer dry spells and decreased precipitation during the second summer after the mature stage of El Niño. Connections have since been made on the correlation between the tropical forcings, El Niño, a positive Pacific North Atlantic pattern, a strong Aleutian Low, warm sea surface anomalies in the North Atlantic, and dry periods over the Canadian Prairies. Other work has shown similar results. Shabbar et al. (1997) determined that the strongest correlations between negative precipitation anomalies and tropical forcing occurred during the winter following the onset of the El Niño event. Trenberth et al. (1988) correlated the 1988 drought with the 1986-1987 El Niño event.

However, others have also correlated specific droughts with the tropical forcing of La Niña. Hoerling and Kumar (2003) used model simulations to verify that the 1998-2002 drought which affected many parts of the Northern Hemisphere was forced by ocean temperature and correlated with the presence of La Niña. The 1988 La Niña event could have also initiated circulation anomalies 
that led to the 1988 drought across much of North America (Trenberth and Guillemot, 1996).

Other drought research has focused on the impact to the agricultural sector as well as the hydrological sector and the environment. Studies have been conducted on the applicability of drought indices to parts of the globe and which index is best for monitoring agricultural drought and the crop production. Quiring and Papakryiakou (2003) determined that the Palmer Z-Index, a moisture anomaly index based on temperature and precipitation, is best for monitoring wheat production across the Canadian Prairies. The Palmer Z-Index calculates the monthly departure from normal of the moisture conditions (Heim, 2002).

In order to study drought, data depicting temperature, pressure, precipitation, and other parameters is necessary. In North America, the most severe droughts of the twentieth century occurred in the 1930's and the 1980's. Instrumental records are available for the study of such $20^{\text {th }}$ century droughts. However, to study droughts prior to this time paleoclimate records are required. In-depth studies have been conducted on the paleoclimate records over the last 2000 years to find the full range of drought variability over the Great Plains of the United States. Tree rings, lake sediments, and historical documents have shown that even more severe droughts occurred prior to 1900. A drought with a magnitude similar to that of the dust bowl years occurred once or twice a century for the past 300-400 years (Woodhouse and Overpeck, 1998). In addition, paleoclimate data has shown evidence of abrupt changes within drought regimes across the Prairies (Laird et al., 2003).

In addition, research has focused on the use of satellite derived products, in particular the vegetation condition index, to monitor and study drought (Kogan, 1995; Gutman, 1990). The satellite derived products detect changes to vegetation which can then be correlated to precipitation and temperature trends. Studies have shown that this method compares well with surface-based observations (Kogan, 1995). 
Chapter 1 - Introduction

Further research has focused on the correlation between solar activity and drought. Major drought periods have come during minima in solar activity following minor solar peaks (PFRA, 1998). Earlier work by Tannehill (1947) showed that there were overall correlations between temperature, rainfall, and sunspots. Tannehill (1947) correlated higher temperatures and a likelihood of drought over the Great Plains with minima in solar activity.

Limited work has focused on the local characteristics of drought. As indicated above, most research has focused on the large scale forcing associated with drought conditions. This thesis will focus on the former issue, the local characteristics of drought.

\subsection{Climatology of the Prairies}

The Canadian Prairies span $520,000 \mathrm{~km}^{2}$ of central and western Canada, and include the provinces of Alberta, Saskatchewan, and Manitoba (Figure 1-2). The Prairies are bounded by the Rocky Mountains on the western edge and extend eastward almost to the Great Lakes. Height above sea level ranges from $200 \mathrm{~m}$ in Manitoba to $1800 \mathrm{~m}$ in the foothills of the Rocky Mountains near Calgary. The vegetation is predominantly grassland. The Canadian Prairies are an agricultural area containing $3 / 4$ of all Canadian farmland. In the northern parts, there is a shift from agriculture to boreal forest, tundra, and parkland (Longley, 1972).

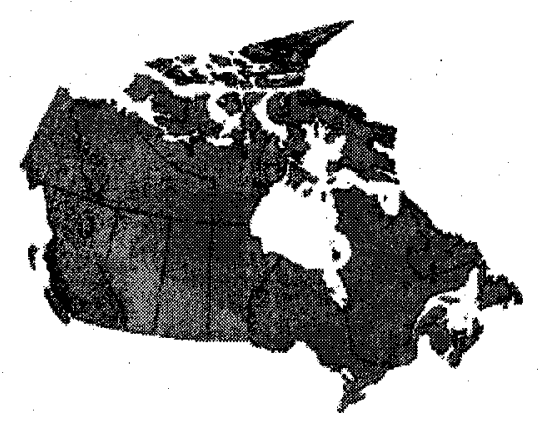

Figure 1-2: A map of Canada with the shaded region representing the Canadian Prairies. 
The location of the Canadian Prairies has a profound influence on its climate. Without the moderating effects of a large body of water, the Prairies experience both extremely cold winters and extremely warm summers. The Prairie climate is classified as cold temperate having a mean annual temperature ranging from $2-6^{\circ} \mathrm{C}$. Western parts of the Prairies lie in the rain shadow of the Rocky Mountains which prevents significant amounts of Pacific Ocean moisture from reaching the Prairies. As a result precipitation amounts to less than $350 \mathrm{~mm}$ per year in western parts of Alberta. Precipitation amounts increase towards the eastern Prairies, to more than $500 \mathrm{~mm}$ a year in Manitoba, as there is less influence from the Rocky Mountains and a greater chance for southerly flow to bring moisture from the Gulf of Mexico (Phillips, 1990; Wilhite, 2000). Twothirds of the precipitation falls during the growing season, spanning May through August, with the largest amounts falling during the months of June and July (Longley, 1972). The growing season rainfall is a result of both synoptic scale systems and local convection. Deep convection is a significant component of summer rainfall events (Raddatz, 2000). However, rainfall from summer thunderstorms is very sporadic; one part of the Prairies may receive substantial precipitation while a neighboring area does not receive any precipitation.

Fundamentally there are two sources of moisture that lead to precipitation over the Canadian Prairies. These include the advection of water vapor, mainly originating from the Pacific Ocean or the Gulf of Mexico, and water vapor supplied within the region via evapotranspiration (Liu et al., 2004). Raddatz (2000) showed that over the Canadian Prairies summer precipitation is dominated by water vapor that is advected into the region. However, it was shown that evapotranspiration does have a significant role.

The general atmospheric circulation over the Canadian Prairies during the summer months is typified by the polar jet which splits over the area with one branch to the south of the Prairies and one branch along the $55^{\text {th }}$ parallel on the northern edge of the Prairies. The more northern branch, from which the Alberta 
storm track originates, is a more reliable source of precipitation than the southern branch (Nkemdirim and Weber, 1998).

\subsection{Main Thesis Objectives and Structural Outline}

There are two questions one can ask concerning the study of drought. First, given the large scale atmospheric conditions, will there be a drought? Second, given a drought, what are the drought's characteristics and small scale structure? To date, a majority of the research of drought has focused on the first question, the correlation of the larger scale conditions and drought. Such studies encompass large scale teleconnections which force circulation anomalies and finally have impacts on hydrology, agricultural, and other areas. Details concerning several of these studies were previously discussed. Thus far, few studies have focused specifically on the small scale characteristics associated with drought over the Canadian Prairies.

One possible small scale forcing for drought is a positive feedback between drought and precipitation. This summertime feedback process associated with small scale drought characteristics is detailed in Figure 1-3. An initial water shortage, a consequence of a precipitation deficit, results in drier soil. The drier soil then influences the surface parameters. Warmer temperatures and lower dew points are associated with reduced latent heat flux and drier soil and consequently with drought conditions. The warmer temperatures and drier surface impact the ceiling, forcing a higher lifting condensation level, reducing the amount of cloud cover. The reduction of clouds and higher ceiling reduce precipitation production and serve to prolong drought conditions. With continued drying of the surface and thus warmer temperatures the cycle will continue by way of a positive feedback.

This cycle continues until precipitation is produced over the drought area thus eliminating the precipitation deficit. This typically occurs at the time that the anticyclone, typical of droughts as discussed in Section 1.5, moves (AES, 
Chapter 1 - Introduction

1986). In addition, precipitation may be produced as the dry soils can enhance buoyant energy because of the enhanced surface temperature. With sufficient atmospheric moisture it can alleviate the drought if substantial clouds can be produced (Giorgi et al., 1996).

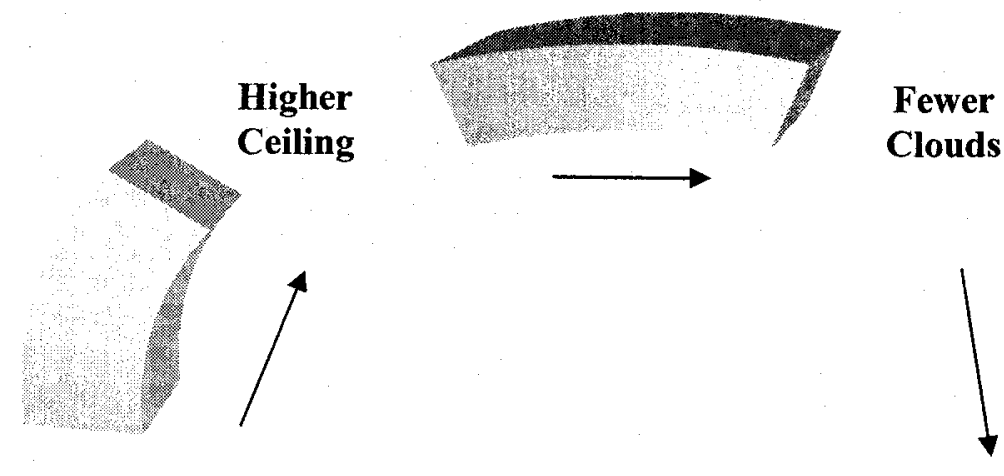

Warmer

Temperatures

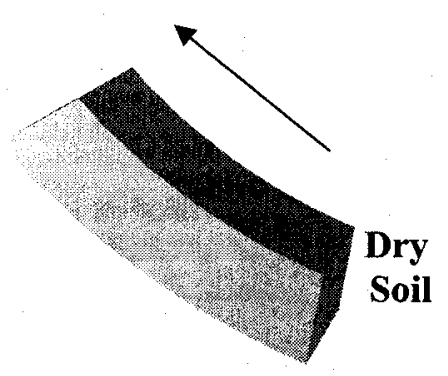

Clouds

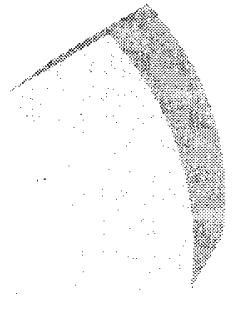

Less

Precipitation

Figure 1-3: Possible positive feedback processes associated with drought.

Given the impacts of drought, the importance of its study, and the lack of attention to its small scale aspects, the main objectives of the thesis are to investigate the small scale aspects of drought, and to identify and compare these characteristics across varying degrees of drought severity.

The general approach for this thesis will be to quantify key aspects of Figure 1-3 and other associated features. Through the analysis of surface temperature and moisture, variations between drought and non-drought conditions may become apparent. Such varying conditions will in turn affect the 
Chapter 1 - Introduction

properties of clouds, in particular their type, coverage, and height. Finally the impact of the temperature, moisture, and cloud fields will be correlated with both the pattern and intensity of precipitation.

This thesis investigating the small scale aspects of drought is structured in the following way. Chapter 2 discusses the data and methodology utilized in this study. Chapter 3 focuses on the characteristics of Prairie drought determined by the surface-based observations. Significance tests are applied to the results found in Chapter 3 and the methods and analysis of the significance tests are discussed. Chapter 4 focuses on the characteristics of the occurrence of precipitation, including the occurrence of thunderstorms and drizzle. In Chapter 5 the small scale features of drought are discussed further, including the impacts of both higher ceilings and obstructions to visibility on precipitation, and the correlation between cold season (October through April) and warm season (May through September) precipitation. The conclusions are presented in Chapter 6. 


\section{Chapter 2}

\section{Data and Methodology}

\subsection{Description of Data Sets Used in Research}

A number of data sets were utilized for the purpose of this thesis, including surface observations and calculated indices. The data sets are described in the following section. It should be noted that the results are reported in local standard time (LST) throughout this thesis.

\subsubsection{Surface Observations}

Hourly surface observations were obtained from Environment Canada for the period from 1953 through 2001. The surface observations included temperature, wind speed, relative humidity, ceiling, dew point, total cloud amount (cloud tenths), and lowest cloud type.

The cloud type, based on the International Cloud Atlas, is identified by the surface observer. Ceiling height is determined by a ceilometer; a device that uses a laser beam to estimate the height of the ceiling in both light and dark conditions (EC, 1977). If the reporting station is not equipped with a ceilometer, a ceiling balloon may be used to estimate the height of the ceiling. 
All of the hourly surface observations are subjected to quality control measures to account for instrumental errors, and errors in the recording and transmission of the data.

It should be noted that despite quality control methods, observations of cloud type and cloud cover may contain errors. This is true particularly during the nighttime hours when light is inadequate and cloud cover is generally underestimated (Hahn et al., 1995). Studies have shown that nighttime observations of clouds are more accurate over large cities due to artificial lighting (WMO, 1956). In a more recent study, Hahn et al. (1995) found that with a moon at least $1 / 2$ full, there is enough light to correctly identify cloud cover and cloud type.

Environment Canada also provided precipitation data which was utilized in this thesis. Monthly precipitation amounts were obtained for the period from 1953 through 2001 and were subsequently used as a basis to compute warm season (May through September) and cold season (October through April) precipitation anomalies. Quality control and correction methods have been applied to the monthly precipitation data to account for wind, evaporation, and rain gauge type (Mekis and Hogg, 1999).

Hourly precipitation data were used in determining the diurnal cycle of precipitation. The data included the hours during which precipitation occurred, its type, frozen or liquid, and its character (showery or continuous). Hourly reports of thunderstorms, haze, smoke, and dust were also available. Hourly precipitation amounts were not utilized in this thesis as they were only available from the mid 1990's to present. Prior to the installation of the automatic weather stations in the mid 1990's, hourly precipitation amounts were only recorded during the summer months and this data has not been quality controlled.

Observations of precipitation and reductions to visibility are made in accordance to the MANOBS, the Manual of Surface Weather Observations, (EC, 1977). A thunderstorm is reported at the observing station when thunder or 
lightning were observed in the $15 \mathrm{~min}$ prior to the observation time. Thunderstorms are reported with precipitation if at the time of observation precipitation is falling at the observing station. Liquid precipitation is defined as any product of condensation of atmospheric water vapor that is observed at the surface with a diameter greater than $0.50 \mathrm{~mm}$. Liquid precipitation with a diameter less than $0.50 \mathrm{~mm}$ is reported as drizzle. Smoke is defined as the result of combustion where small particles are suspended in the air. Haze is defined as a suspension of extremely small particles that give the sky an opalescent appearance. Dust is a suspension of dust or small sand particles.

\subsubsection{Calculated Indices}

Monthly values of the Palmer Drought Index, hereafter referred to as only the PDI, were provided by Environment Canada and covered the period from 1953 to 2001. The calculation of the PDI is based on climatological data from 1950 through 1996. PDI values were used to determine drought severity.

PDI data were also obtained from the National Centers for Environmental Protection (NCEP) Re-analysis. The NCEP Re-analysis incorporates monthly surface air temperature and precipitation data into the PDI calculation (Dai and Trenberth, 1998). Soil moisture included in the calculation of the PDI is fixed to soil-holding climatological maps on a $1^{\circ} \times 1^{\circ}$ grid (Webb et al., 1993). The NCEP Re-analysis was used to formulate plots of the average PDI between May and September covering the area between $140 \mathrm{~W}$ and $60 \mathrm{~W}$ and $25 \mathrm{~N}$ and $60 \mathrm{~N}$.

The PDI data from both Environment Canada and NCEP allowed for the analysis of the extent and severity of wet and dry spells and this represented one method used to determine the specific years to study. An examination of the PDI results for the Prairies revealed that its value varied between -7 and +7 . Negative values indicate drought conditions and positive values indicate wet conditions. 


\subsection{Methodology of Research}

Ten observational sites, located in cities across the Prairies, were selected for this study. The 10 sites were chosen on the basis of the quality of the data as well as on their location (Figure 2-1). The observing sites cover a wide area of the Prairies, from the foothills of the Rocky Mountains to central Manitoba. All but two stations, Brandon and Edmonton, had climatological data available from 1953 to the present. Brandon and Edmonton have climate data available beginning in 1959 and 1961, respectively. It is also noted that due to errors in the data, cloud data for Lethbridge was not used after 1993.

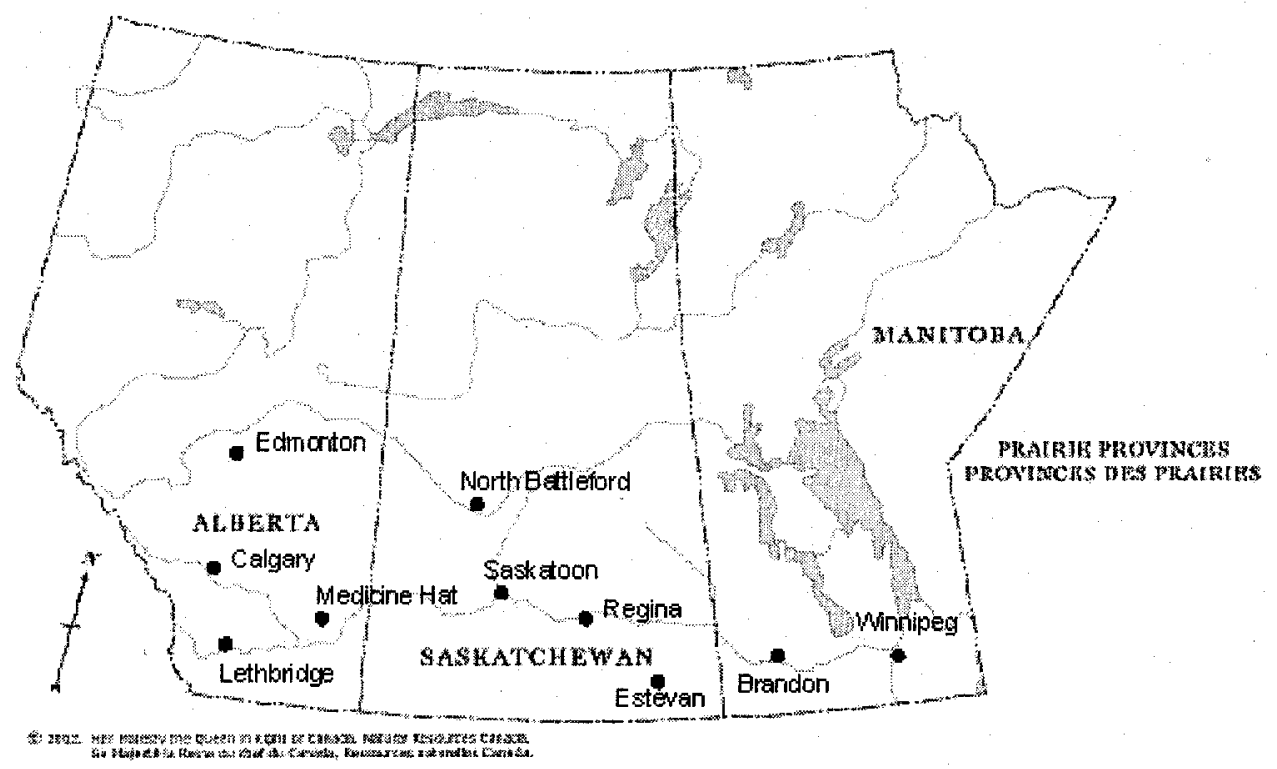

Figure 2-1: The map above is of the three provinces, Alberta, Saskatchewan, and Manitoba, which encompass the Canadian Prairies (Natural Resources Canada, 2004). The location and name of the observing sites are marked.

Over the Canadian Prairies, drought has the largest economic impact during the growing season, mid May through August, when agriculture is most susceptible to moisture deficits. Therefore this drought study focuses mainly on 
the warm season, May through September. However, the cold season (October through April) is also analyzed in connection with some aspects of drought.

\subsection{Selected Years}

The study of the small scale characteristics of drought required specific drought years to be identified. In the following section discussion will be presented concerning how the drought years were selected. An overview of the methodology will first be presented. This will be followed by a more in-depth discussion of the process and subsequent results of the characterization of drought, non-drought, extreme drought, and extreme wet years.

\subsubsection{Overview}

Initially, the classification of drought and non-drought years was based on an analysis of NCEP Re-analysis plots of the average warm season PDI from 1953-2001. The entire Prairie region was classified as being influenced by either severe drought (11 years) or non-drought conditions (38 years). Upon further analysis it was determined stronger criteria was needed. The PDI data obtained from Environment Canada in Edmonton, Alberta and precipitation data were used to determine if drought conditions, defined as having a PDI and precipitation anomaly $<0$, or non-drought conditions, defined as having either a PDI or precipitation anomaly $>0$, impacted each individual station during the 11 regional drought years. In addition, for each station a drought year could be additionally categorized as having extreme drought conditions, defined as having a $\mathrm{PDI}<-4$, and each non-drought condition could be additionally categorized as having extreme wet conditions, defined as having a PDI $>+4$. 


\subsubsection{Methodology of Selection}

Both the PDI data obtained from Environment Canada in Edmonton, Alberta and the NCEP Re-analysis PDI plots were used to distinguish the most severe drought years between 1953 and 2001.

NCEP Re-analysis plots of the average warm season PDI were studied. Drought years were chosen based on the criteria of both the severity and extent of the drought as evident in the Re-analysis plots of the average warm season PDI. Eleven years met the criteria of having severe drought over a large area of the Canadian Prairies. These years include 1958, 1960, 1961, 1969, 1979, 1980, $1984,1987,1988,2000$, and 2001. Most of these years correspond with drought years determined by Environment Canada (EC, 2004). The remaining 38 years, categorized as non-drought years, were analyzed and served as a basis of comparison against the eleven drought years.

Illustrative NCEP Re-analysis plots for the two of the drought years chosen, 1988 and 1984, are shown in Figures 2-2 and 2-3. For each figure, the PDI scale extends from negative values, shaded red, to positive values, shaded blue. More severe drought conditions are indicated by increasingly negative values and the more extreme wet values are indicated by increasingly positive values.

The plots of the PDI show considerable variations in the structure and severity of the drought across the Canadian Prairies. Figure 2-2 shows the average warm season PDI for the 1988 drought year. The severity of the drought ranges from -6 to -1 across the Prairies. There are also several areas where severe drought regions were surrounded by areas of less severe drought. A different drought pattern is observed in Figure 2-3, which shows the 1984 drought was less severe and spatially it covered a different area across the Prairies. 


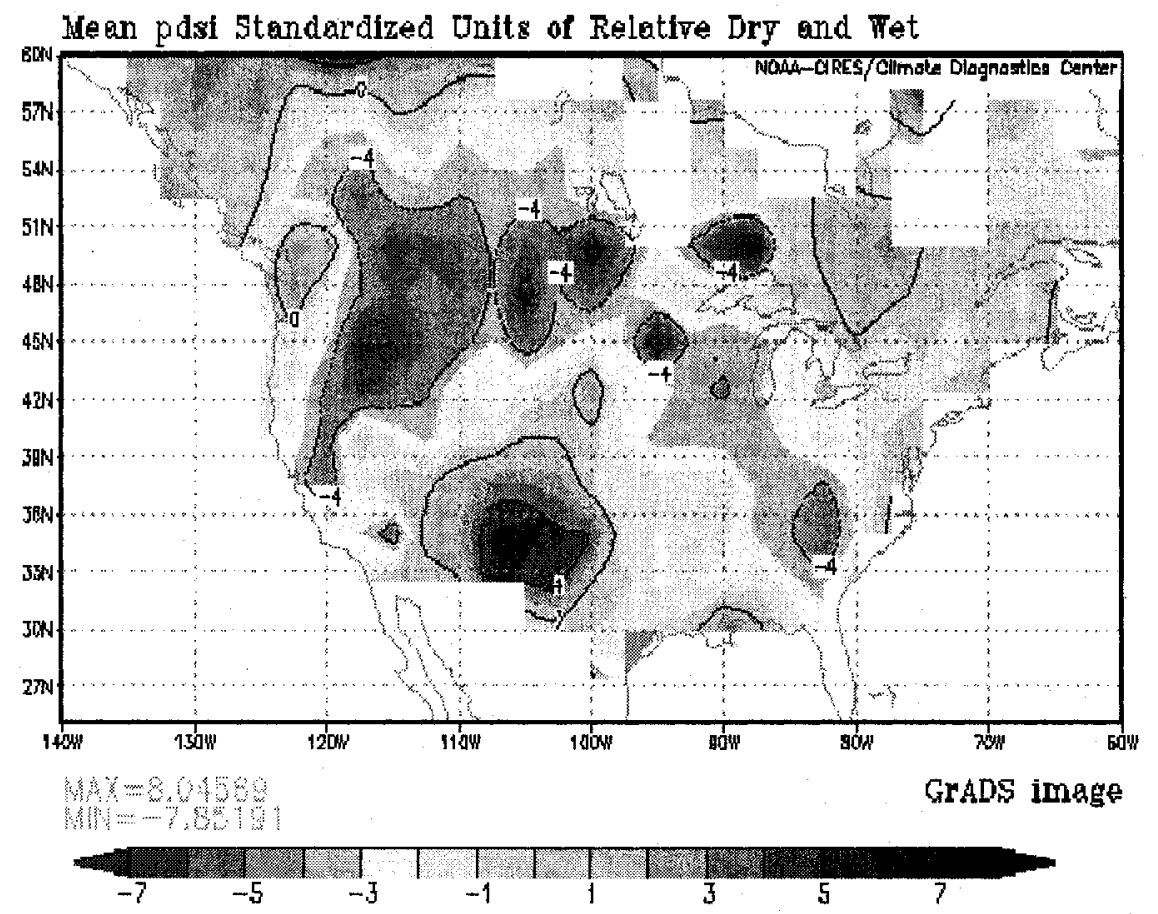

Figure 2-2: NCEP Re-analysis map of the average warm season PDI for 1988. A -7 indicates the most extreme drought conditions and $\mathrm{a}+7$ indicates the most extreme wet conditions.

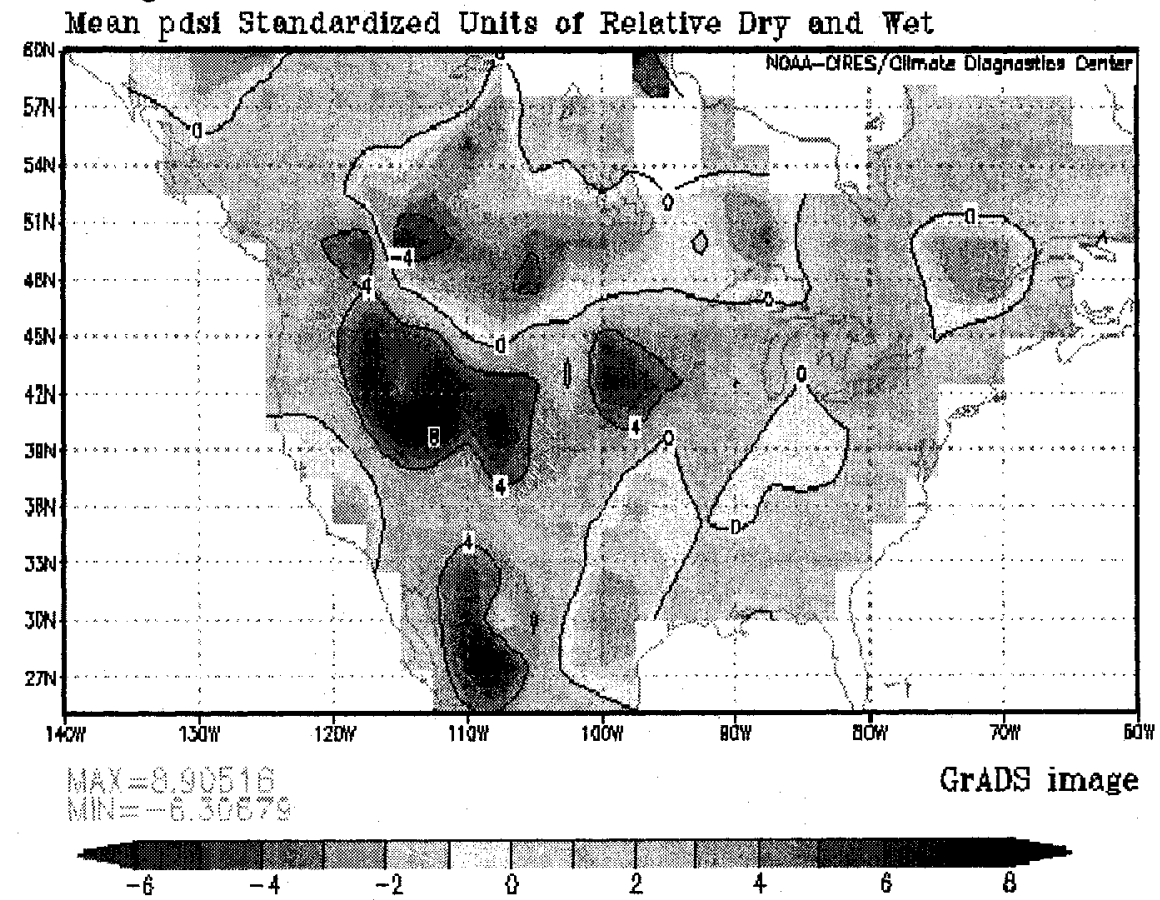

Figure 2-3: NCEP Re-analysis map of the average warm season PDI for 1984. Negative values indicate regions of extreme drought and positive values indicate regions that are not afflicted by drought. 
Chapter 2 - Data and Methodology

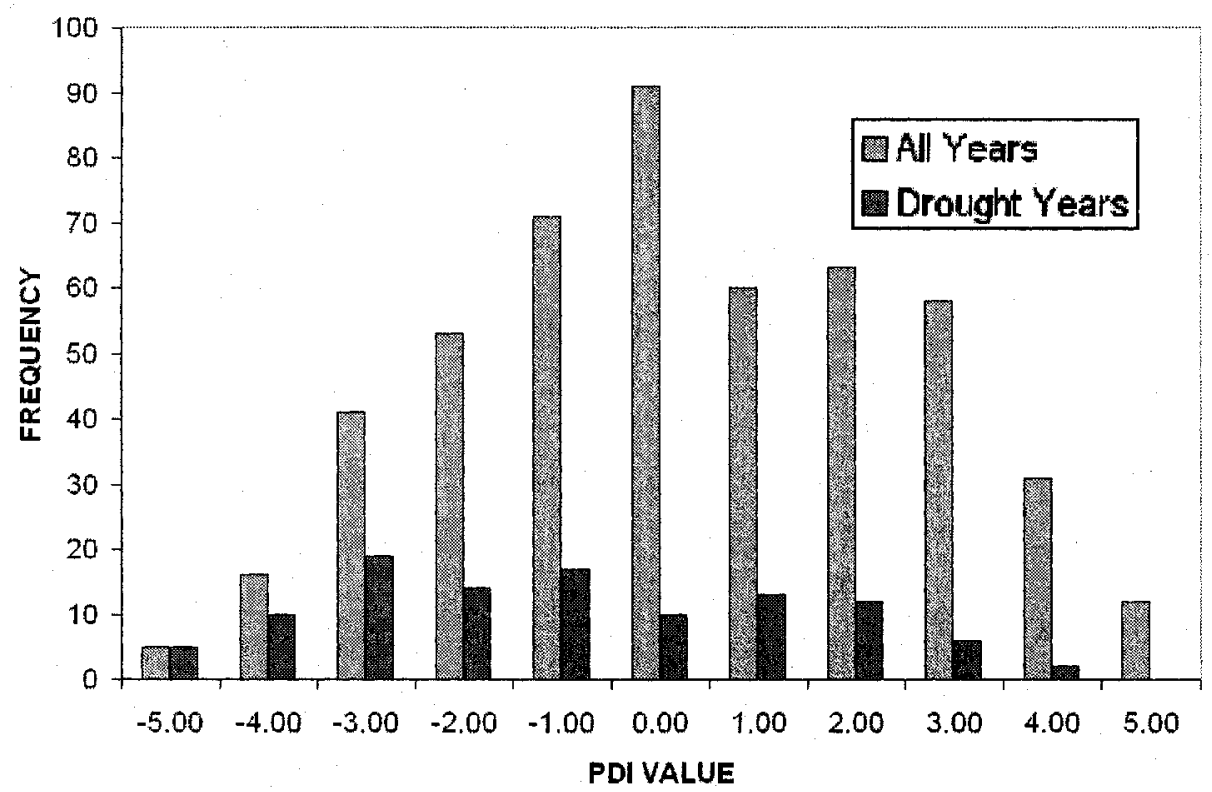

Figure 2-4: Histogram of the warm season PDI value for the 10 observing stations between 1953 and 2001.

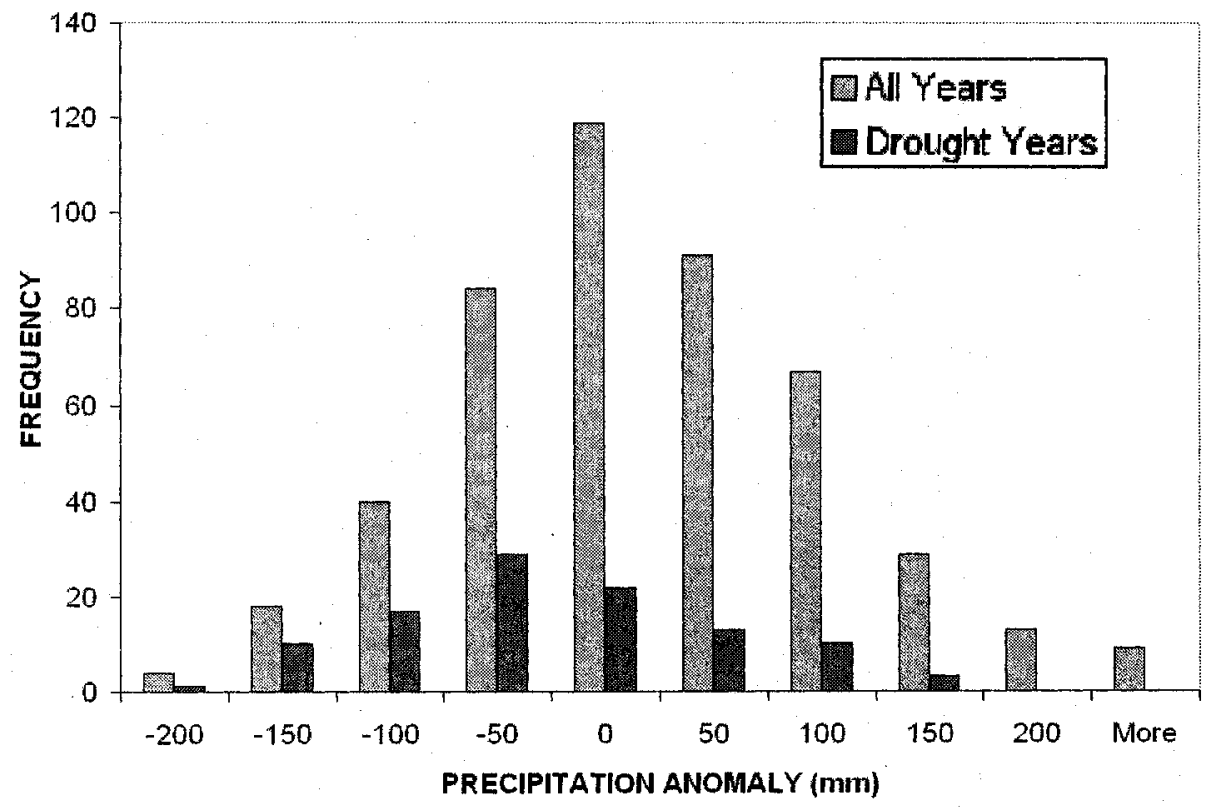

Figure 2-5: Histogram of the warm season precipitation anomalies for the 10 observing stations between 1953 and 2001 . 
To further emphasize the spatial variations of drought an analysis was conducted comparing the warm season precipitation anomalies and PDI values. Both monthly precipitation data and PDI values were obtained from Environment Canada for the 10 stations for the 11 selected drought and all 49 years between 1953 and 2001. Histograms were produced to demonstrate this comparison and are shown in Figures 2-4 and 2-5.

The histograms prove that, overall, the Prairies have been plagued by both extremely dry and extremely wet conditions. A near normal distribution is noted for both the PDI and the precipitation anomalies when focusing on data from all 49 years. Focusing on the drought years, the histograms reveal that drought over the Prairies has a high spatial variability. While there are stations reporting PDI values and precipitation anomalies less than 0 , simultaneously there are stations observing PDI values greater than 0 .

Throughout the 11 drought years, not all of the 10 stations PDI values and precipitation anomalies were always below zero. In fact, during the previously categorized 11 drought years, $29 \%$ of the drought cases reported PDI values greater than zero (33 times) and $25 \%$ of the drought cases reported positive precipitation anomalies (26 times). This reemphasizes the spatial variability observed on the two NCEP Re-analysis PDI plots, Figures 2-2 and 2-3. Although a large portion of the Prairies was afflicted by dry conditions, other stations within the Prairies during the same year were simultaneously affected by wet conditions.

To sharpen the selected information for subsequent studies, the criteria determining whether the warm season was characterized as drought or as nondrought were redefined. New criteria were established to distinguish drought versus non-drought years and these were applied to the 11 drought years. The PDI values and precipitation anomalies were studied for the eleven drought years. It was determined that the station would be included within the drought year dataset only if, for the warm season, that station had below average 
precipitation, indicated by a negative precipitation anomaly, as well as a PDI less than zero.

To further quantify the differences between drought and non-drought conditions two additional categories, extreme drought and extreme wet, were defined for this thesis. The extreme wet and extreme drought conditions were defined through the use of the PDI values obtained from Environment Canada. If during one of the eleven drought years, an observing station recorded an average PDI less than -4 during the warm season the location was considered to be afflicted by extremely dry conditions. This station was included in the extreme drought analysis in addition to the drought analysis. For the cases when the average warm season PDI for an observing station was greater than +4 for any of the 38 non-drought years, the station was classified as extremely wet in addition to the non-drought classification. For this study, such a threshold meant that only $3 \%$ of all cases were classified as extreme drought and $3 \%$ were classified as extreme wet. More specifically, $21 \%$ of the drought conditions were also considered to be an extreme drought while $4 \%$ of the non-drought conditions were also considered as extreme wet conditions. The results of the final criteria used to differentiate between the 49 years are shown in Table 2-1.

\begin{tabular}{|c|c|c|c|c|}
\hline & $\begin{array}{c}\text { Extreme } \\
\text { Drought }\end{array}$ & Drought & Non-drought & Extreme Wet \\
\hline Criteria & $\begin{array}{c}\text { PDI }<-4 \\
\text { Precipitation } \\
\text { Anomaly }<0\end{array}$ & $\begin{array}{c}\text { PDI }<0 \\
\text { Precipitation } \\
\text { Anomaly }<0\end{array}$ & $\begin{array}{c}\text { PDI }>\text { or }<0 \\
\text { Precipitation } \\
\text { Anomaly }>\text { or } \\
<0\end{array}$ & $\begin{array}{c}\text { PDI }>+4 \\
\text { Precipitation } \\
\text { Anomaly }>0\end{array}$ \\
\hline Designation & E & D & - & W \\
\hline
\end{tabular}

Table 2-1: Criteria used to determine drought severity.

Table 2-2 lists the stations in each Prairie province that were utilized in this study. Below each station is a list of the years for which each station had a 
Chapter 2 - Data and Methodology

warm season which fit the criteria of both a negative PDI and a negative precipitation anomaly, indicated with a D. The extreme wet and extreme dry conditions are indicated with an $\mathrm{E}$ and a $\mathrm{W}$ respectively. The remaining years, which may have positive or negative PDI values and positive or negative precipitation anomalies, were categorized as non-droughts and are indicated by a dash. It is noted that non-drought conditions were observed for each of the 10 stations for the remaining years that are not listed in Table 2-2.

With the categorization of the 1953 through 2001 data, an in-depth study of the small scale characteristics of drought over the Canadian Prairies was carried out including comparisons between extreme drought, drought, nondrought, and extreme wet conditions. 


\begin{tabular}{|c|c|c|c|c|c|c|c|c|c|c|c|}
\hline & \multicolumn{4}{|c|}{ Alberta } & \multicolumn{5}{|c|}{ Saskatchewan } & \multicolumn{2}{|c|}{ Manitoba } \\
\hline & 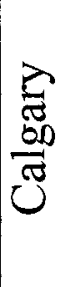 & 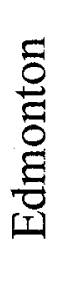 & 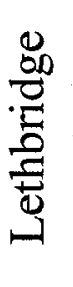 & 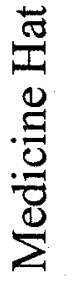 & 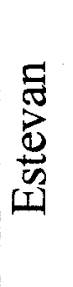 & 量 & 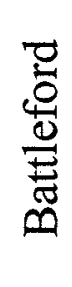 & 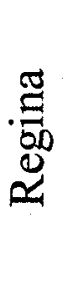 & 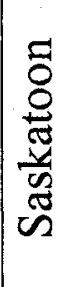 & 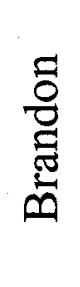 & 每 \\
\hline 1953 & $\mathbf{W}$ & - & - & $\mathbf{W}$ & - & & - & - & - & - & - \\
\hline 1954 & $\mathbf{W}$ & - & - & $\mathbf{W}$ & - & & - & $\mathbf{W}$ & - & - & - \\
\hline 1955 & - & - & - & $\mathbf{W}$ & - & & $\mathbf{W}$ & $\mathbf{W}$ & - & - & - \\
\hline 1956 & - & - & - & - & - & & $\mathbf{W}$ & $\mathbf{W}$ & - & - & - \\
\hline 1958 & - & - & - & D & $\begin{array}{l}\mathbf{D} \\
\mathbf{E}\end{array}$ & & D & D & D & - & D \\
\hline 1960 & & & & D & - & & D & - & - & - & - \\
\hline 1961 & D & D & D & D & D & & $\mathbf{D}$ & D & D & D & D \\
\hline 1968 & - & - & $\mathbf{W}$ & - & - & & - & - & - & - & - \\
\hline 1969 & D & - & - & D & - & & D & D & - & - & - \\
\hline 1974 & - & $\mathbf{W}$ & - & - & - & & $\mathbf{W}$ & - & $\mathbf{W}$ & - & - \\
\hline 1979 & - & - & - & - & - & & D & D & D & D & - \\
\hline 1980 & - & - & - & D & D & & - & $\begin{array}{l}\text { D } \\
\text { E }\end{array}$ & D & - & $\begin{array}{l}\mathbf{D} \\
\mathbf{E}\end{array}$ \\
\hline 1984 & D & - & $\mathbf{D}$ & $=$ & D & & - & D & D & D & - \\
\hline 1987 & D & - & D & - & D & & - & D & D & D & D \\
\hline 1988 & - & - & $\begin{array}{l}\mathbf{D} \\
\mathbf{E}\end{array}$ & $\begin{array}{l}\mathbf{D} \\
\mathbf{E}\end{array}$ & $\begin{array}{l}\mathbf{D} \\
\mathbf{E}\end{array}$ & & - & $\begin{array}{l}\mathbf{D} \\
\mathbf{E}\end{array}$ & $\begin{array}{l}\mathbf{D} \\
\mathbf{E}\end{array}$ & D & $\begin{array}{l}\mathbf{D} \\
\mathbf{E}\end{array}$ \\
\hline 1997 & - & $\mathbf{W}$ & - & - & - & & - & - & - & - & - \\
\hline 2000 & - & - & $\begin{array}{l}\mathbf{D} \\
\mathbf{E}\end{array}$ & $\begin{array}{l}\mathbf{D} \\
\mathbf{E}\end{array}$ & - & & D & - & - & - & - \\
\hline 2001 & D & D & $\begin{array}{l}\text { D } \\
\text { E }\end{array}$ & $\begin{array}{l}\mathbf{D} \\
\mathbf{E}\end{array}$ & - & & D & D & - & - & - \\
\hline
\end{tabular}

Table 2-2: The eleven chosen drought years are shown as well as the years that qualified as extreme wet and extreme drought. A D marks a station that had both a negative PDI and a negative precipitation anomaly. An $\mathrm{E}$ marks a station that had extreme drought conditions and a W marks a station that had extreme wet conditions. A dash indicates that a station had nondrought conditions: 


\section{Chapter 3}

\section{Characteristics of Temperature, Moisture, and Clouds}

The main objectives of this thesis are to investigate the small scale characteristics of drought and to identify and compare these features over varying degrees of drought severity. There will be a focus on the surface-based parameters in this chapter.

An initial discussion of the basic surface observations and the overall average of the parameters will first be given. Overall averages of the surface observations for extreme drought, drought, non-drought, and extreme wet conditions will be analyzed. It should be noted that the two extreme conditions are subsets of the drought and non-drought conditions. The surface observations will be further studied and the variations of the diurnal cycle for the four conditions will be given. A synopsis of the results of the chapter will then be presented. The difference of two means test will be applied to the data to find the significance of the observed deviations between the drought and non-drought conditions. Finally, a discussion of the data presented in the chapter will be provided.

\subsection{Surface Observations}

To place the examination of extreme drought, drought, non-drought, and extreme wet conditions into perspective, overall average conditions over all stations were first determined for the May through September period from 1953 
Chapter 3 - Characteristics of Temperature, Moisture, and Clouds

to 2001. The surface observations that were used in this analysis include temperature, dew point, relative humidity, wind speed, ceiling height, lowest cloud type, and total cloud amount (cloud tenths).

The average warm season (May through September) temperature is $15.0^{\circ} \mathrm{C}$ and the average dew point is $7.0^{\circ} \mathrm{C}$. The average wind speed is 16.2 $\mathrm{km} / \mathrm{h}$ and the average ceiling height is $2500 \mathrm{~m}$. Clear skies are reported $13 \%$ of the time and overcast skies are reported $18 \%$ of the time during the warm season. More often skies are reported as "broken" or 7/10 - 9/10 covered by clouds. Convective clouds are most frequently reported as the lowest cloud type. During the warm season approximately $29 \%$ of the lowest cloud reported is convective.

Figure 3-1 shows the deviation from the long-term mean for both temperature and dew point. Several years are notable. 1961 and 1988, two of the most severe drought years over the Prairie region, had both a warmer than average temperature and a lower than average dew point. Other years, including the early 1950's, had a different character. For these cases, the temperature was lower than the 49 year average and the dew point was higher than the 49 year average. The early 1950's coincide with several of the most extreme wet conditions defined in Chapter 2.

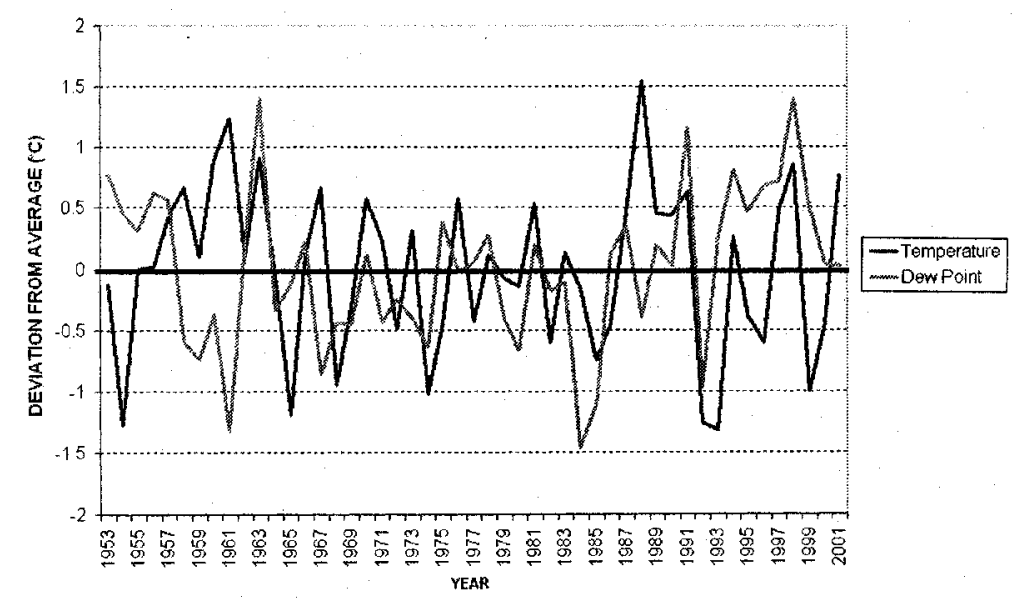

Figure 3-1: Deviation of the temperature and dew point from the 49 year warm season average. 


\subsection{Averages and Deviations}

Table 3-1 shows the overall warm season averages, including all observations between 00-23 LST, for the extreme drought, drought, non-drought, and extreme wet conditions. For each case, the percentage of hours for each condition during which the specified cloud type was observed as the lowest cloud type is also shown.

\begin{tabular}{|c|c|c|c|c|}
\hline & $\begin{array}{c}\text { Extreme } \\
\text { Drought }\end{array}$ & Drought & Non-drought & $\begin{array}{c}\text { Extreme } \\
\text { Wet }\end{array}$ \\
\hline Temperature & $17.0^{\circ} \mathrm{C}$ & $16.0^{\circ} \mathrm{C}$ & $15.0^{\circ} \mathrm{C}$ & $14.0^{\circ} \mathrm{C}$ \\
\hline Dew Point & $6.0^{\circ} \mathrm{C}$ & $6.0^{\circ} \mathrm{C}$ & $7.0^{\circ} \mathrm{C}$ & $7.0^{\circ} \mathrm{C}$ \\
\hline Wind & $17.7 \mathrm{~km} / \mathrm{h}$ & $16.5 \mathrm{~km} / \mathrm{h}$ & $16.0 \mathrm{~km} / \mathrm{h}$ & $17.0 \mathrm{~km} / \mathrm{h}$ \\
\hline Ceiling & $3000 \mathrm{~m}$ & $2700 \mathrm{~m}$ & $2500 \mathrm{~m}$ & $2200 \mathrm{~m}$ \\
\hline High Clouds & $14 \%$ & $12 \%$ & $10 \%$ & $9 \%$ \\
\hline Middle Clouds & $29 \%$ & $28 \%$ & $26 \%$ & $24 \%$ \\
\hline Low Clouds & $18 \%$ & $20 \%$ & $24 \%$ & $25 \%$ \\
\hline Convective Clouds & $22 \%$ & $25 \%$ & $28 \%$ & $26 \%$ \\
\hline
\end{tabular}

Table 3-1: Overall warm season averages for the four conditions studied.

Deviations are noted within the surface observations between extreme drought, drought, non-drought, and extreme wet conditions. Temperatures are warmest during extreme drought conditions, averaging $2.0^{\circ} \mathrm{C}$ warmer than the average non-drought temperature and $3.0^{\circ} \mathrm{C}$ warmer than the average temperature during extreme wet conditions. Comparable deviations between non-drought and extreme wet conditions are noted in the dew point temperature as drier nearsurface moisture conditions are observed during both extreme drought and drought conditions. Winds are stronger during extreme drought and drought conditions as compared to non-drought conditions. However, strong winds are also noted during extreme wet conditions. 
Chapter 3 - Characteristics of Temperature, Moisture, and Clouds

Convective and middle level clouds are observed as the lowest cloud layer most often during each of the four conditions. Low clouds are observed for $7 \%$ fewer hours during extreme drought conditions than during extreme wet conditions. As well, large differences are noted in the occurrence of high clouds as extreme drought conditions experience a greater percentage of hours with high clouds reported than extreme wet conditions.

\subsection{Analysis of the Diurnal Cycle}

The surface parameters are further analyzed in this section. An analysis of the diurnal cycle of surface parameters (temperature, dew point, relative humidity, wind speed, lowest cloud type, ceiling, and cloud tenths) measured at each station is presented. The results are based on the hourly observations.

\subsubsection{Temperature}

The diurnal cycle of temperature is depicted in Figure 3-2. The four curves follow a similar trend with the minimum temperature observed early in the morning and the maximum temperature recorded during the late afternoon. It is evident that warmer temperatures are correlated with drier surface conditions, as the warmest temperatures are observed during extreme drought conditions and the coolest temperatures are observed during extreme wet conditions.

A lag of one hour is observed when comparing the time of the maximum temperature during extreme wet conditions and extreme drought conditions. The daily high temperature occurs earlier in the day during extreme wet conditions in comparison with extreme drought conditions. Temperatures reach a maximum of $22.8^{\circ} \mathrm{C}$ at $16 \mathrm{LST}$ during extreme drought conditions whereas they reach a maximum of $19.4^{\circ} \mathrm{C}$ at 15 LST during extreme wet conditions. 


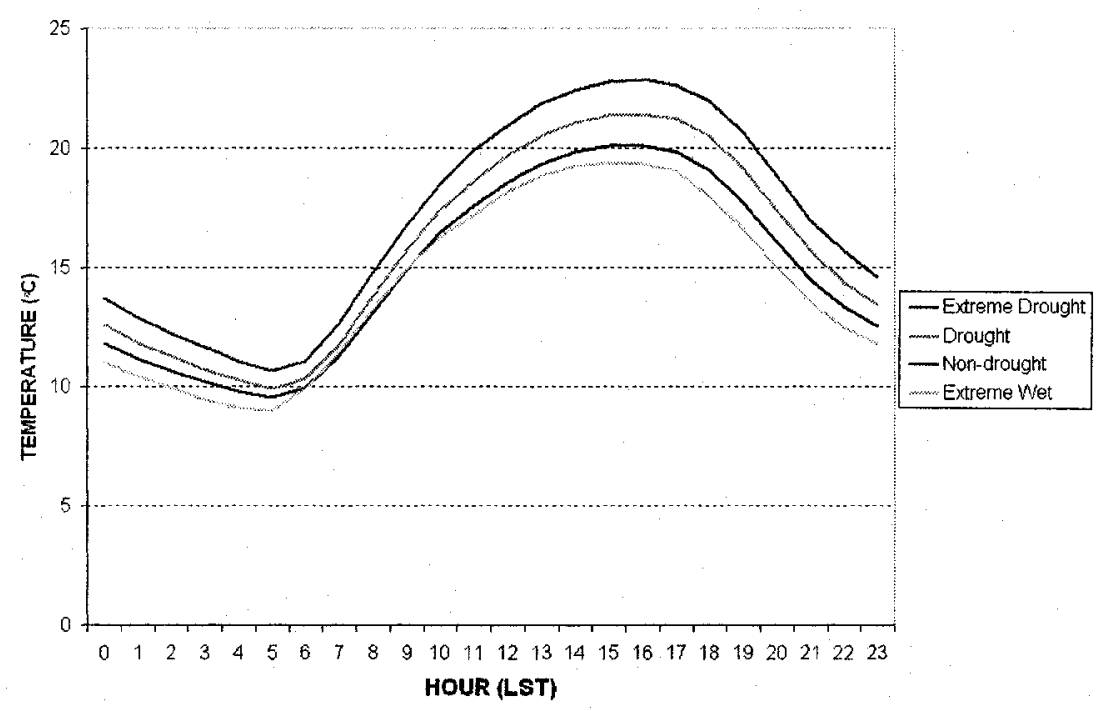

Figure 3-2: The average diurnal cycle of temperature for the specified condition.

\subsubsection{Dew Point}

The dew point is a measure of atmospheric moisture at the surface. Figure 3-3 shows systematic variations of the dew point between the four conditions. To first order there are no points where the curves cross and each of the four curves follow a similar trend. The lowest dew points occur in the early morning hours. As expected, extreme wet conditions have the largest dew point or the highest amount of atmospheric moisture and extreme drought conditions have the lowest dew point or the least amount of atmospheric moisture.

There are two peaks within the diurnal cycle of the dew point. The increase from 05 to 09 LST correlates with an increase in moisture. The dew point then decreases from 09 to 18 LST coinciding with the formation and decay of the atmospheric boundary layer and associated mixing of low level air. The rate of decrease from 09 to 18 LST depends on both advective and evapotranspirative processes (Stewart and Burford, 2002). A larger decrease is noted between 09 and 18 LST for extreme drought conditions which coincides 
with a decrease in evapotranspiration. Evapotranspiration would add additional moisture to the atmosphere as seen with the smaller decrease in dew point associated with extreme wet conditions.

The surface observations from the extreme wet conditions show an earlier peak in the dew point than do the extreme drought years. The late day peak of dew point for extreme wet conditions occurs at $19 \mathrm{LST}$ and is $8.1^{\circ} \mathrm{C}$ whereas during extreme drought conditions the late day dew point peak of $5.9^{\circ} \mathrm{C}$ is at 20 LST.

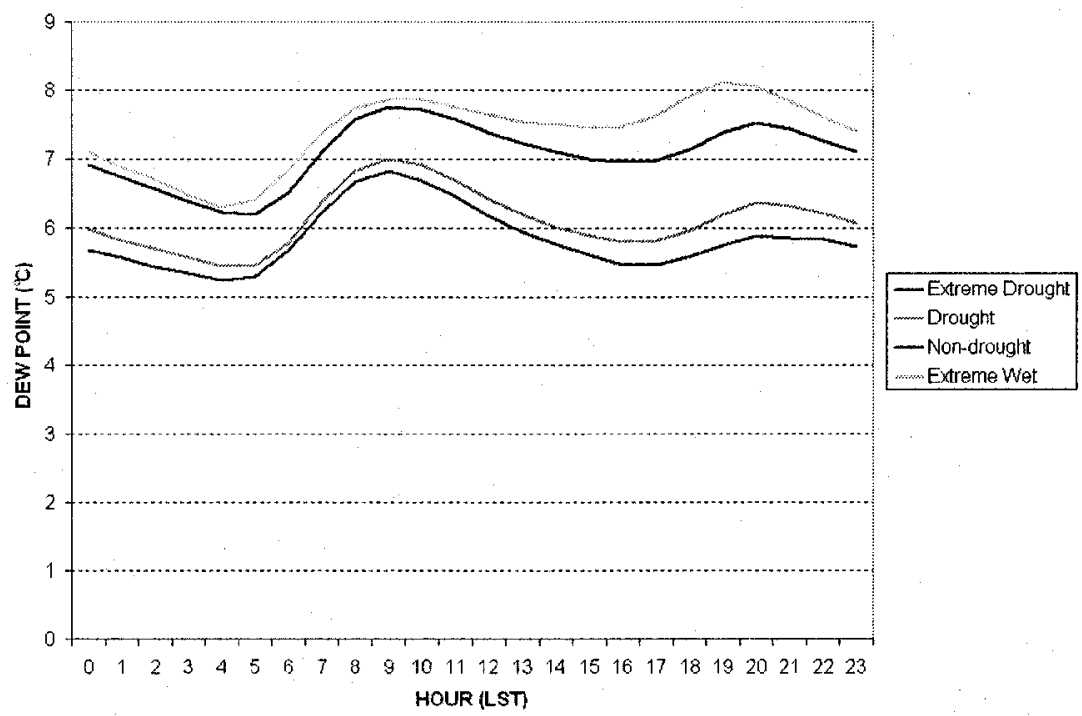

Figure 3-3: The diurnal cycle of dew point for the specified condition.

\subsubsection{Dew Point Depression}

The dew point depression, calculated by taking the difference between the dew point and the temperature, is an indicator of how close the atmosphere is to saturation. The diurnal cycle of dew point depression, shown in Figure 3-4, is similar to the diurnal cycle of temperature depicted in Figure 3-2. A small diurnal range, less than $2^{\circ} \mathrm{C}$, is observed in the hourly dew point data, whereas a much larger range, more than $10^{\circ} \mathrm{C}$, is noted in the hourly temperature data. This 
results in the diurnal cycle of the dew point depression resembling the diurnal cycle of temperature. The lowest dew point depression is observed early in the morning and the largest dew point depression is observed late in the day for each of the four conditions shown. A larger dew point depression is observed during extreme drought conditions and the dew point depression is smaller for increasingly moist surface conditions. The dew point depression is approximately $6.0^{\circ} \mathrm{C}$ larger during extreme drought conditions than during extreme wet conditions, indicating the dryness of the atmosphere.

There is a lag of approximately $1 \mathrm{~h}$ between the peak of the dew point depression for extreme wet conditions $\left(11.9^{\circ} \mathrm{C}\right.$ at $\left.15 \mathrm{LST}\right)$ compared to extreme drought conditions $\left(17.4^{\circ} \mathrm{C}\right.$ at $\left.16 \mathrm{LST}\right)$. This is consistent with the lag observed in both the diurnal cycle of dew point and temperature.

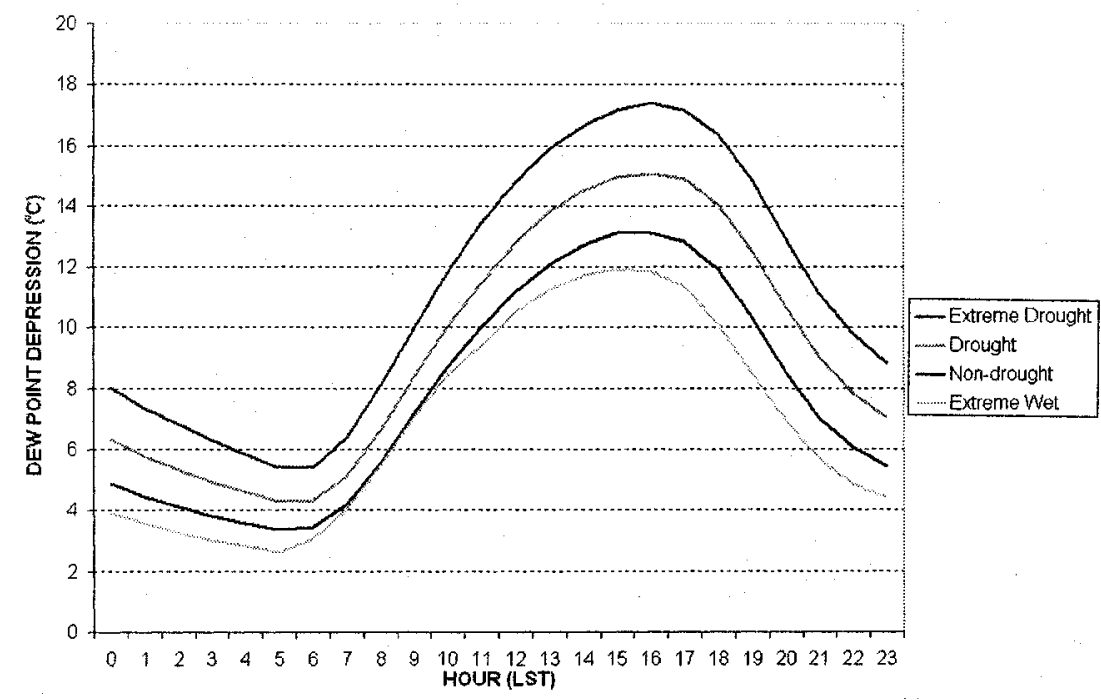

Figure 3-4: The diurnal cycle of the dew point depression for the indicated condition.

\subsubsection{Relative Humidity}

Relative humidity, Figure $3-5$, is a mirror image of the dew point depression and is typically lowest during the late afternoon hours. Extreme wet 
conditions have higher indices of relative humidity than the other three conditions. The relative humidity decreases as drought conditions become more severe. Extreme drought conditions have an average relative humidity of $40 \%$ during the late afternoon as compared to a relative humidity of $50 \%$ observed during extreme wet conditions.

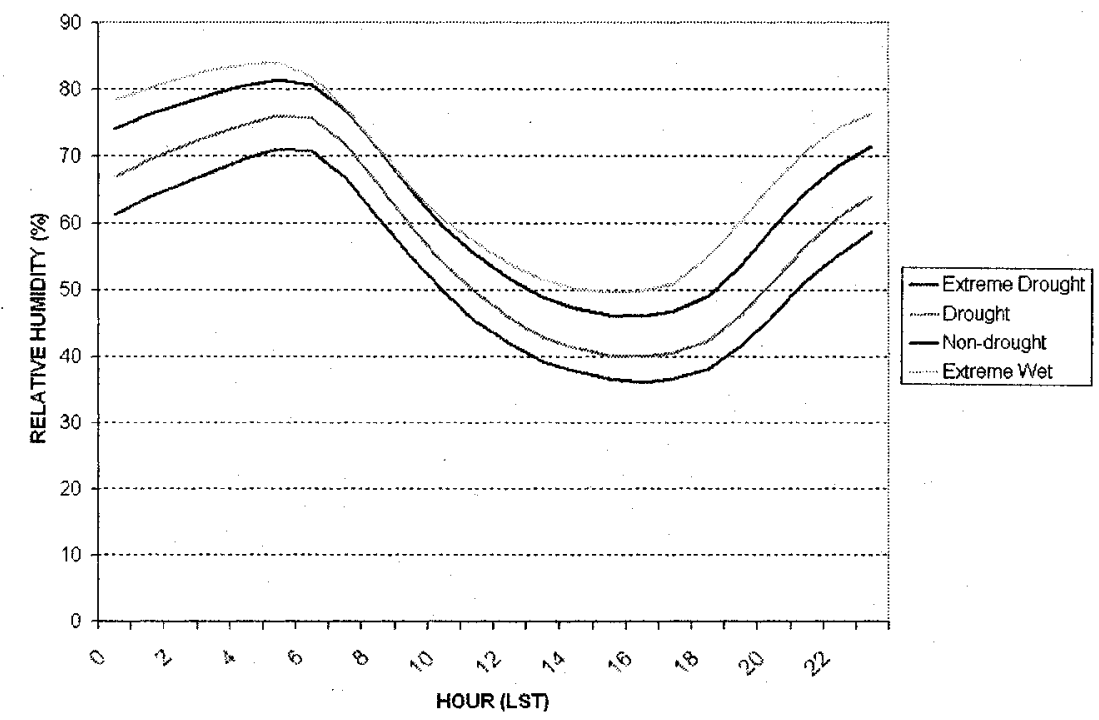

Figure 3-5: The diurnal cycle of relative humidity for the indicated condition.

\subsubsection{Wind Speed}

The diurnal cycle in wind speed, recorded in $\mathrm{km} / \mathrm{h}$, is shown in Figure 3-6. Overall the wind speed tends to increase as the day progresses with a peak average wind speed observed in the late afternoon around 16 LST. The strongest average wind speeds are reported during extreme drought and extreme wet conditions.

The timing of the peak wind speed of $22.3 \mathrm{~km} / \mathrm{h}$ occurring at $16 \mathrm{LST}$ during extreme drought conditions is delayed by $2 \mathrm{~h}$ when compared to the peak wind speed of $20.2 \mathrm{~km} / \mathrm{h}$ which occurs at 14 LST during extreme wet conditions. 
Chapter 3 - Characteristics of Temperature, Moisture, and Clouds

The peak wind is delayed during drought conditions due to a deeper convective boundary layer and thus a longer period is needed for the higher winds aloft to mix down to the surface.

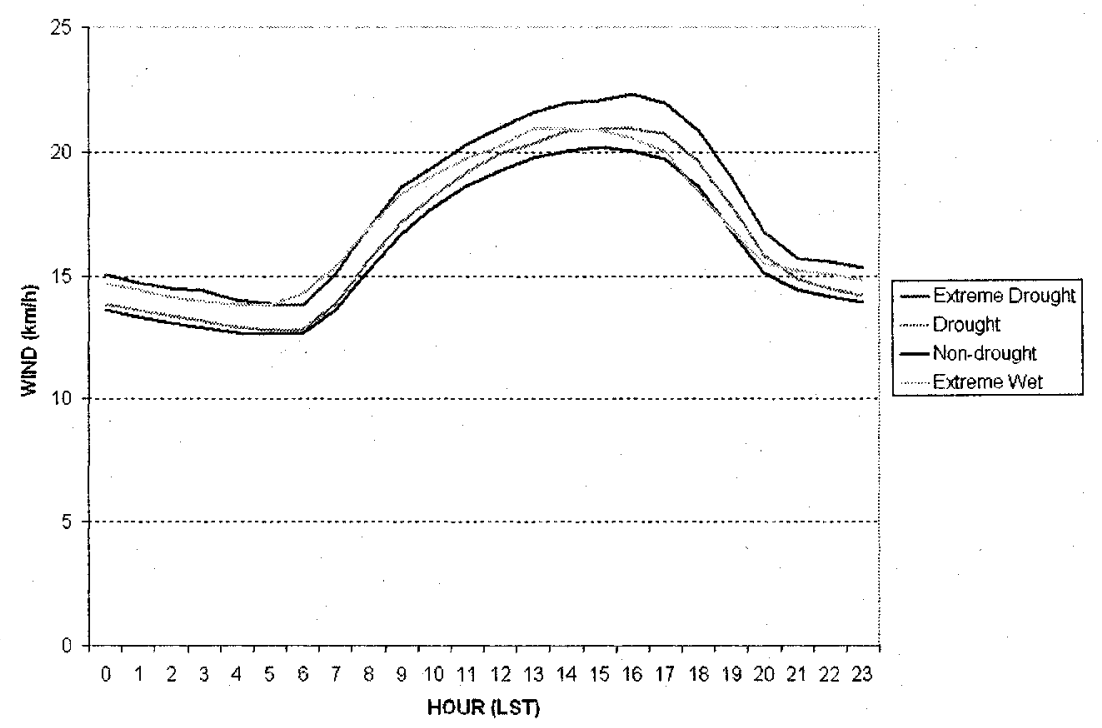

Figure 3-6: The average diurnal cycle of the wind speed in $\mathrm{km} / \mathrm{h}$ for the condition specified.

\subsubsection{Cloud Tenths}

The cloud tenths surface observation reports the percentage of sky that is covered by clouds. Observations are reported as a value from $0 / 10$, clear skies, to $10 / 10$, overcast skies, the latter of which indicates that the sky is $100 \%$ covered by clouds. For this analysis the observations were grouped as follows: 0/10, $1 / 10-3 / 10,4 / 10-6 / 10,7 / 10-9 / 10$, and 10/10 which indicates clear, "few", "scattered", "broken", and overcast conditions respectively.

The total number of occurrences of each cloud tenth between $0 / 10-10 / 10$ was calculated for each station and each warm season. The data were combined for all stations and grouped into the four conditions. The total number of hours observed during each condition was calculated. Finally, a percentage was 
calculated to determine the amount of time a certain sky condition was reported for each condition.

An overall analysis of the cloud tenths reported between 00-23 LST was completed. Figure 3-7 shows the percentage of time with the indicated degree of cloudiness for extreme drought, drought, non-drought, and extreme wet conditions. The figure shows that there still are clouds present during extreme drought and drought conditions as $84 \%$ of the observations for extreme drought conditions and $86 \%$ of the observations for drought conditions indicate that clouds were present at the time of observation. This signals that there is certainly moisture in the atmosphere.

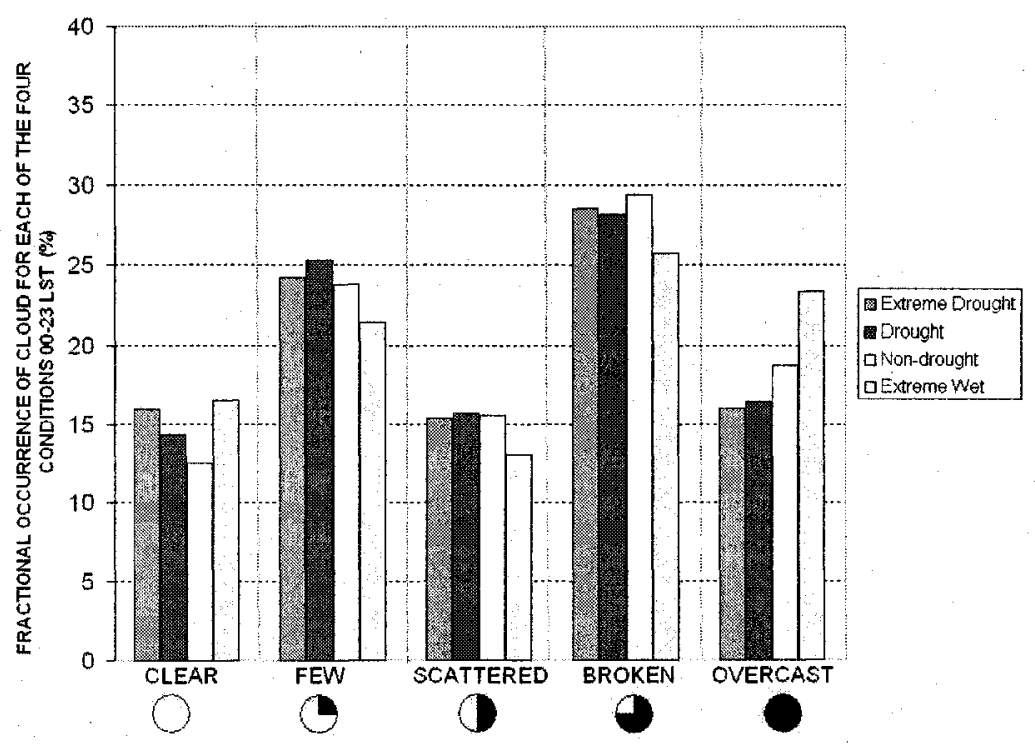

Figure 3-7: Percent of time during each condition with the indicated degree of cloudiness between 00-23 LST.

From Figure 3-7 it is observed that, overall, "broken" cloud tenths are reported most frequently accounting for over $25 \%$ of the total observations for each of the four conditions. Approximately the same percentage of the "few", "scattered", and "broken" cloud tenths were reported for extreme drought, drought, non-drought, and extreme wet conditions. 
Overcast skies are reported most frequently during extreme wet conditions when compared to the three other conditions. Skies are overcast approximately $22 \%$ of the time during extreme wet conditions while skies are reported overcast $16 \%$ of the time during both extreme drought and drought conditions and $19 \%$ of the time during non-drought conditions.

A study was then conducted to find whether variations were present between the cloud tenths reported during the day and the cloud tenths reported at night. The cloud tenths were divided into two groups, those that were observed between 08-20 LST and those that were observed between 21-07 LST. The cloud tenths observed between the hours of 08 LST to 20 LST are shown in Figure 3-8 whereas those observed between 21 LST to 07 LST are shown in Figure 3-9.

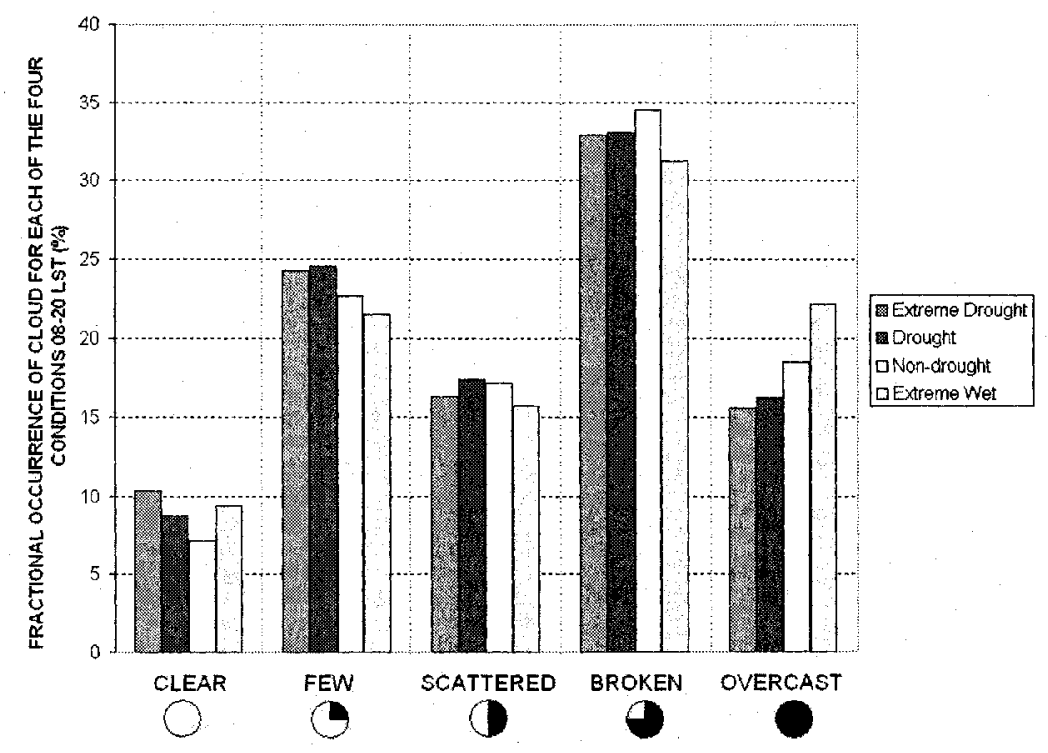

Figure 3-8: Percent of time during each condition with the indicated degree of cloudiness between 08-20 LST.

Figure 3-8 shows the clouds tenths recorded between 08 LST and 20 LST. Clear skies are infrequently reported between 08-20 LST indicating that a majority of the time there are clouds observed. Clear skies are reported the most often during extreme drought conditions, $10 \%$ of the time, when compared to the 
three other conditions. "Broken" cloud coverage is reported most frequently, accounting for approximately one-third of all observations for all conditions. Overcast conditions are observed more often during extreme wet conditions, accounting for $23 \%$ of the total observations. During extreme drought conditions overcast skies are observed only $16 \%$ of the time.

Figure 3-9 shows the cloud tenths reported between the hours of 21 LST and 07 LST. Clear skies are reported more frequently during the nighttime hours than during the daytime hours. Large differences in the percent of time that the "few", "scattered", and "broken" cloud tenths are reported are not observed when comparing the cloud tenths for extreme drought, drought, non-drought, and extreme wet conditions. Extreme wet conditions see not only the most frequent clear skies, $25 \%$ of the time, but also the most frequent overcast skies, $24 \%$ of the time when compared to extreme drought, drought, and non-drought conditions.

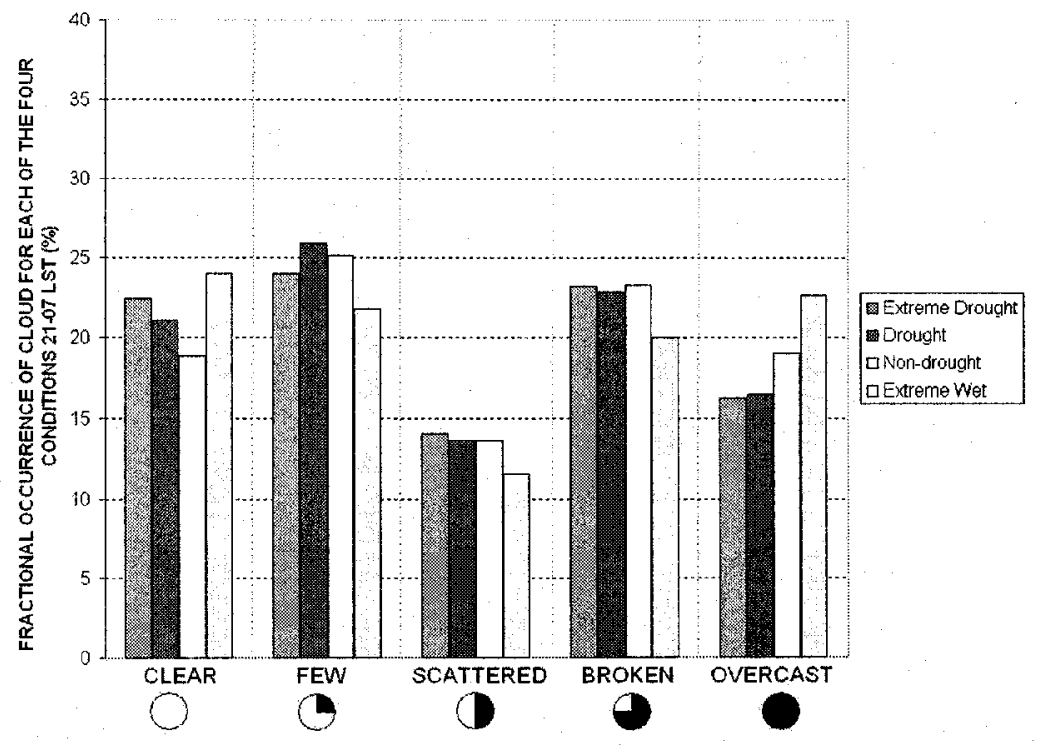

Figure 3-9: Percent of time during each condition with the indicated degree of cloudiness between 00-07 and 21-23 LST. 


\subsubsection{Cloud Type}

At the time of observation, clouds are reported as being one of four layers, the lowest layer, the second layer, the third layer, and the fourth layer. In this section the lowest cloud layer is analyzed. The lowest cloud is reported as one of seventeen types.

A method similar to that used in Section 3.3.6 was used to calculate the percentage of time that a certain cloud type was observed. For each warm season the total number of observations of each cloud type was calculated. The data were then divided into each of the four conditions and a percentage was calculated by dividing the total number of occurrences by the total number of hours during which cloud types were reported for each of the four conditions. The results for each of the four conditions are expressed as a percentage.

For this thesis the clouds were grouped into classes based on their characteristics. The first category incorporated the high clouds including cirrus, cirrostratus, and cirrocumulus clouds. Middle level clouds were grouped into the second category and include altostratus, altocumulus, and altocumulus castellanas clouds. The cloud types including stratus, stratocumulus, stratus fractus, and nimbostratus clouds were grouped together to form the low cloud category. Convective clouds included cumulus, cumulonimbus, cumulus fractus, and towering cumulus clouds. The final grouping included fog and other obscurities to vision.

The cloud types that were reported as the lowest layer cloud and observed between 00-23 LST are shown in Figure 3-10. The clouds were again separated depending on the time of day during which they were observed. Figure 3-11 shows the percent of time the various cloud types occurred from 08-20 LST and Figure 3-12 shows the percent of time the various cloud types occurred from 2107 LST. 
Chapter 3 - Characteristics of Temperature, Moisture, and Clouds

Overall, when analyzing the lowest cloud type reported between 00-23 LST, Figure 3-10, extreme drought and drought conditions observe fewer low clouds when compared to drought and non-drought conditions. Low clouds are observed $18 \%, 20 \%, 24 \%$, and $25 \%$ of the time during extreme drought, drought, non-drought, and extreme wet conditions respectively. Middle level clouds are observed the most during extreme drought and drought conditions accounting for $29 \%$ and $28 \%$ of the lowest clouds observed for each respectively. High clouds are observed a greater percent of the hours during extreme drought and drought conditions than during non-drought and extreme wet conditions. Finally, approximately the same percentage of convective clouds is observed regardless of whether the Prairies are afflicted by extreme drought, drought, non-drought, or extreme wet conditions although extreme drought is slightly less than the other conditions.

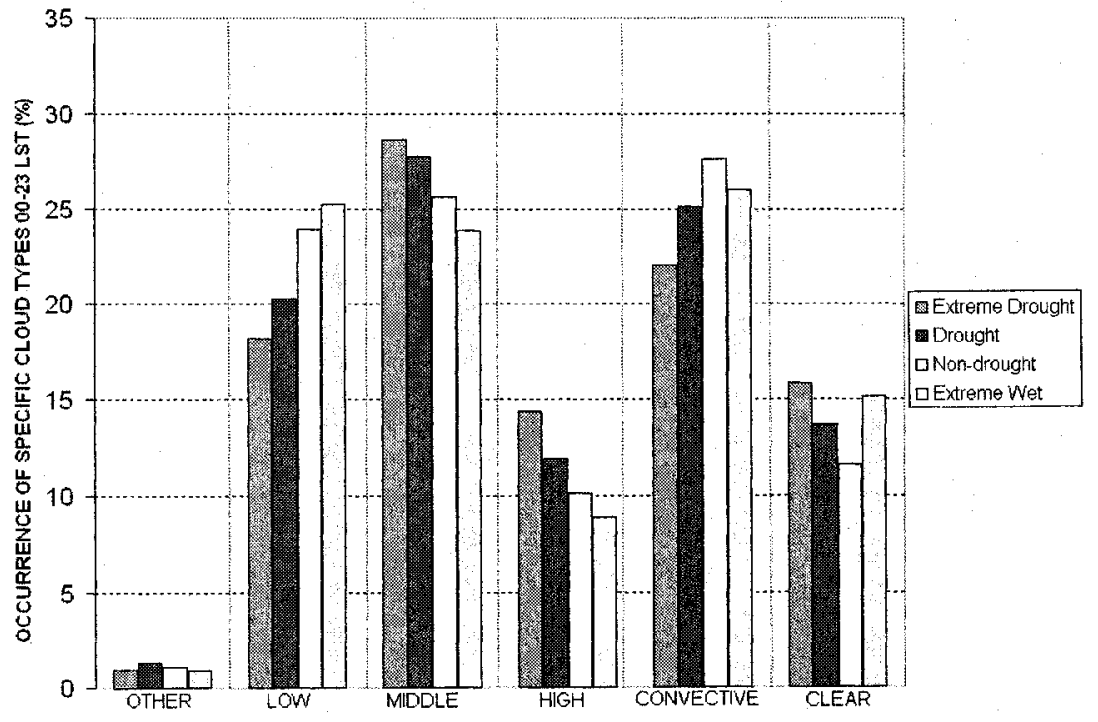

Figure 3-10: The percentage of time during each condition with the indicated lowest cloud type from 00-23 LST

Figure 3-11 shows the percentage of the various cloud types reported between the hours of 08-20 LST for the four conditions. To the first order, it is evident that convective clouds are most frequently observed for each of the four 
conditions. More than one-third of the lowest cloud types observed during the warm season are convective clouds. Only a slight decrease is noted in the occurrence of convective clouds during extreme drought conditions as convective clouds account for $37 \%$ of all lowest cloud observations as compared to $42 \%$, $45 \%$, and $43 \%$ for drought, non-drought, and extreme wet conditions respectively.

Focusing on the upper level or high clouds, more high clouds are observed during extreme drought and drought conditions than non-drought and extreme wet conditions. Similar observations are noted when analyzing the percent of time middle clouds are observed. Once again, middle level clouds are observed more frequently during extreme drought and drought than during nondrought and extreme wet conditions.

Figure 3-11 shows that low clouds are reported fewer hours during extreme drought conditions as compared to drought, non-drought, and extreme wet conditions. During extreme wet conditions low clouds are observed $22 \%$ of the time indicating a better likelihood for stratiform precipitation.

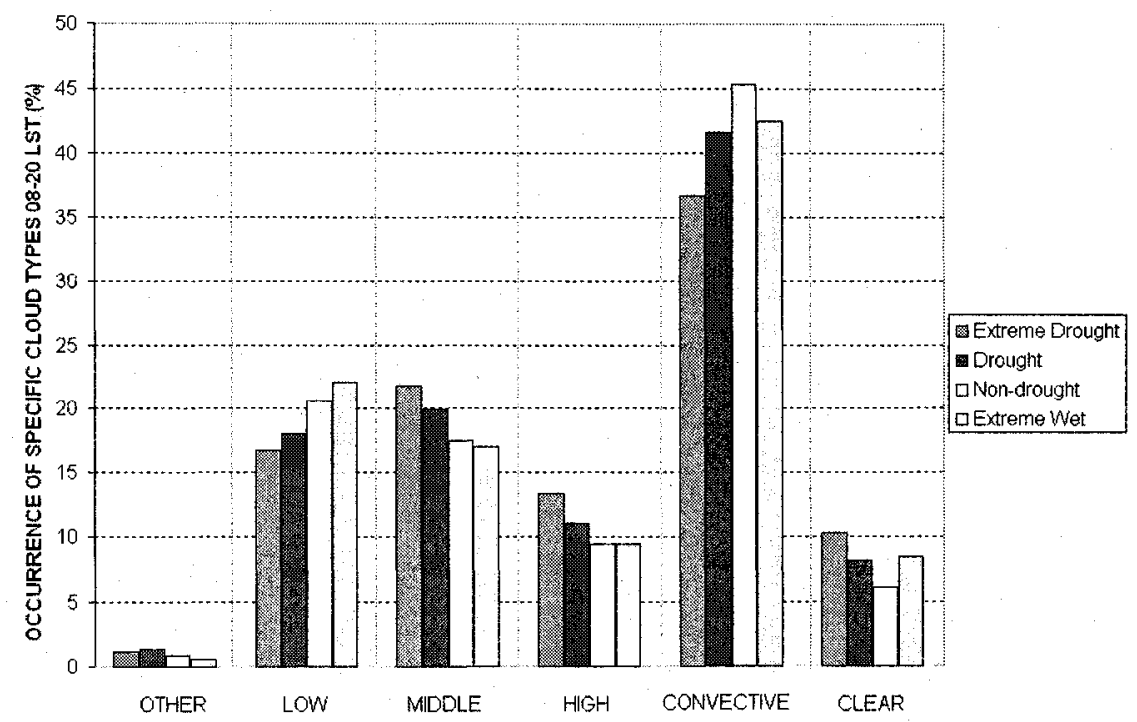

Figure 3-11: The percentage of time with the indicated lowest cloud type for each condition from 08-20 LST. 
The increase in reports of clear skies for extreme drought, drought, and extreme wet conditions confirms the data from Section 3.3.6. Reports of fog and other obscurities to vision are rarely reported. Only $1 \%$ of observations during the warm season are of fog and other obscurities for the four conditions.

A different trend is observed in the analysis of Figure 3-12, the percentage of time with the indicated lowest cloud type from 21-07 LST. In this figure, the percentage of lowest clouds that are convective and high account for much fewer of the observations than these clouds did when the hours from 08-20 LST were analyzed. The percentage of low clouds observed is again fewest during extreme drought conditions. Low clouds account for $20 \%$ of the lowest cloud type during extreme drought conditions while $29 \%$ of the lowest cloud type during extreme wet conditions. Middle clouds are observed more than one-third of all the hours for each of the four conditions.

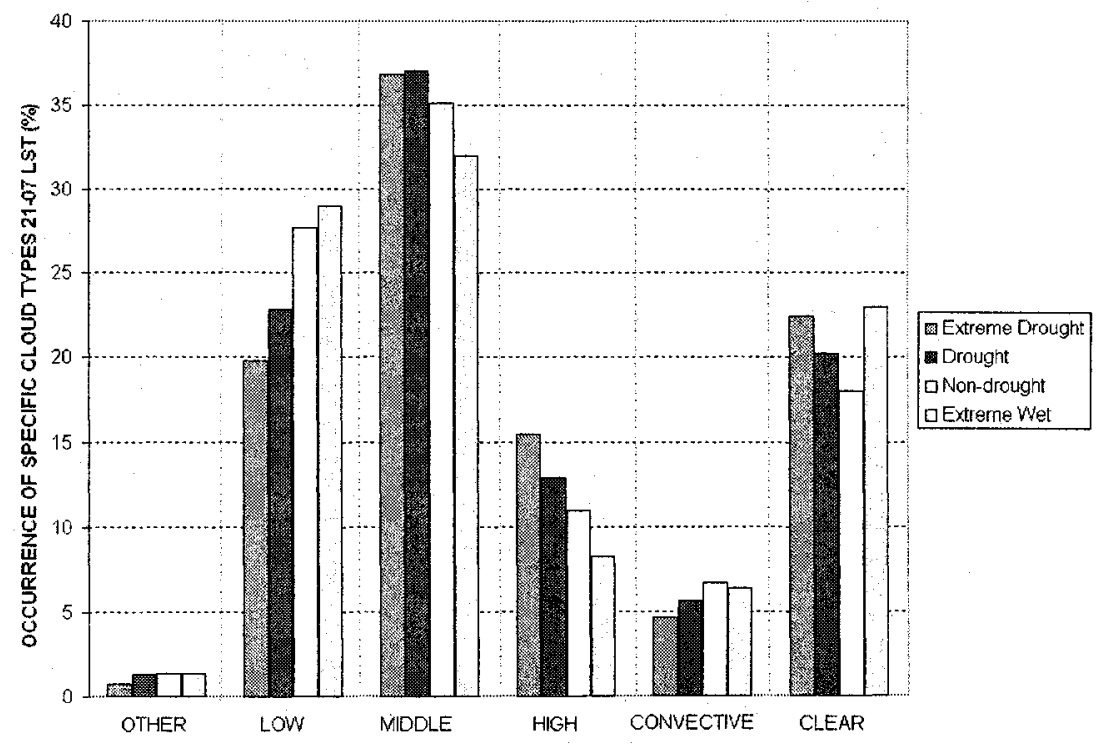

Figure 3-12: The percentage of hours that the specified cloud was reported as the lowest cloud from 21-07 LST for each condition. 
Chapter 3 - Characteristics of Temperature, Moisture, and Clouds

\subsubsection{Convective Clouds}

In Figure 3-10, little variation was noted in the percent of time between each of the four conditions during which convective clouds were observed. Therefore, in order to gain better insight into the convective clouds, each of the convective cloud types including cumulus, towering cumulus, cumulus fractus, and cumulonimbus clouds, was analyzed individually. The percent of time that each of the convective clouds were observed between 00-23 LST is first shown (Figure 3-13). Figure 3-14 shows the percent of time that the convective clouds were observed between 08-20 LST and.Figure 3-15 shows the percent of time that the convective clouds were observed between 21-07 LST.

Figure 3-13 shows that cumulus clouds are most frequently observed when convective clouds are reported. Deep convection, typified by cumulonimbus and towering cumulus clouds, is observed less frequently during extreme drought and drought conditions than during non-drought and extreme wet conditions.

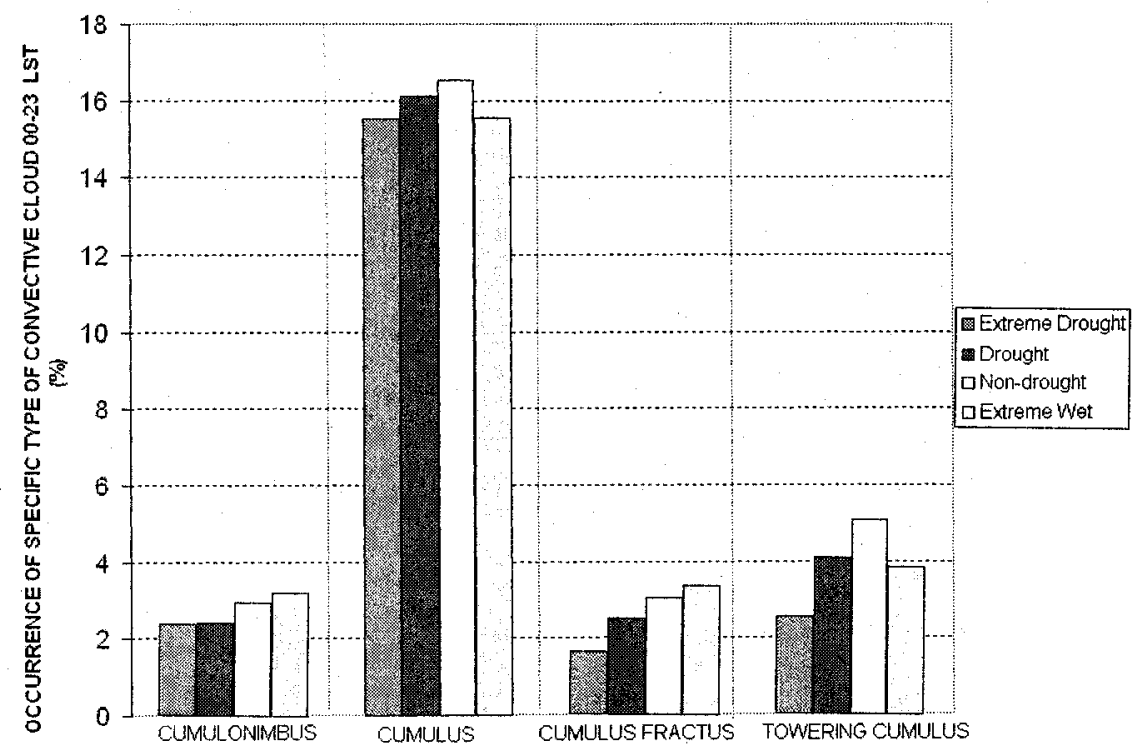

Figure 3-13: The percentage of time that the individual convective cloud types occurred between 00-23 LST. 
Figure 3-14 illustrates that cumulus clouds account for a majority of the convective clouds reported during extreme drought, drought, non-drought, and extreme wet conditions between 08-20 LST. Cumulus clouds account for approximately $30 \%$ of the observed convective clouds for each of the four conditions. Cumulonimbus clouds are rarely observed as less than $5 \%$ of the reported convective clouds are cumulonimbus. Cumulus fractus and towering cumulus clouds are observed a few percent more hours than the cumulonimbus clouds. Fewer hours with reports of cumulus fractus and towering cumulus clouds are observed during extreme drought and drought conditions.

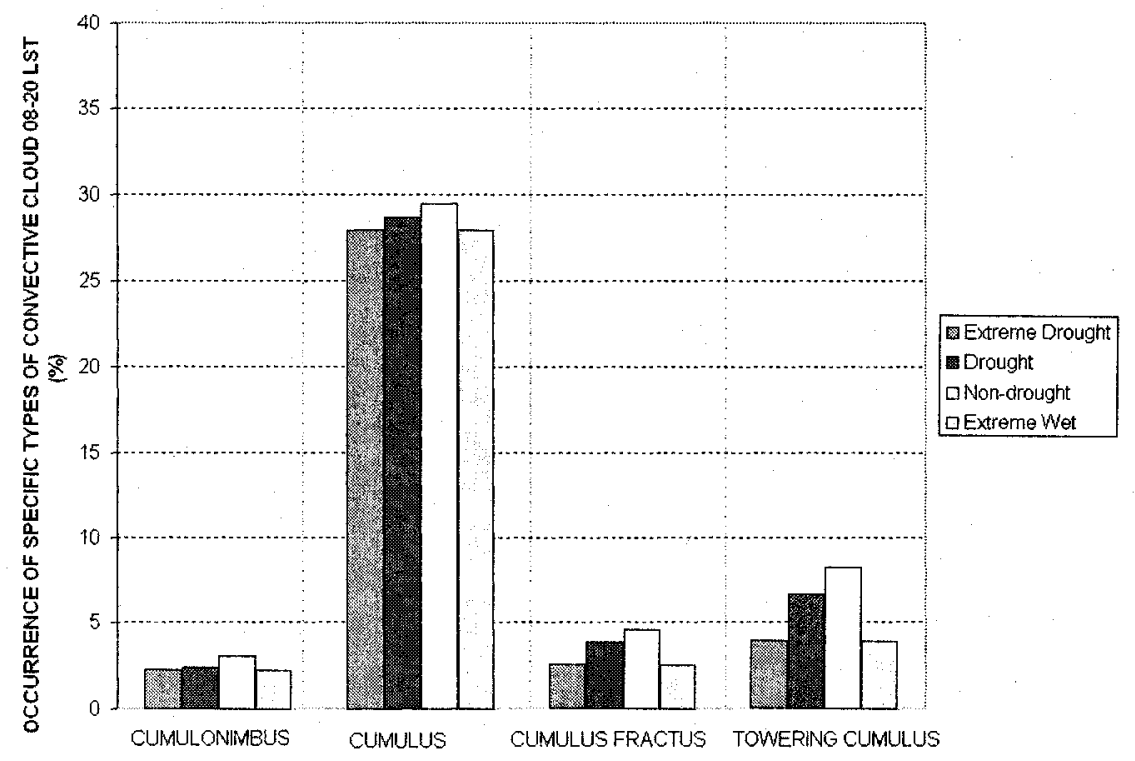

Figure 3-14: The percentage of time for each drought condition that the individual types of convective clouds from 08-20 LST were observed.

Figure 3-15 shows the percent of time that the specified convective clouds were observed between 21-07 LST. Cumulonimbus clouds are most frequently reported, accounting for more than $40 \%$ of the observations for extreme drought, drought, non-drought and extreme wet conditions. More cumulonimbus clouds are observed during extreme drought conditions than during the other three conditions. During extreme drought conditions cumulus clouds are observed more than $50 \%$ of the time when convective clouds are reported at night. The 
Chapter 3 - Characteristics of Temperature, Moisture, and Clouds

percentage of time that cumulus clouds are observed between 21-07 LST is less than those observed between 08-20 LST. Both towering cumulus and cumulus fractus clouds account for a greater percentage of the convective clouds observed from 21-07 LST than between 08-20 LST.

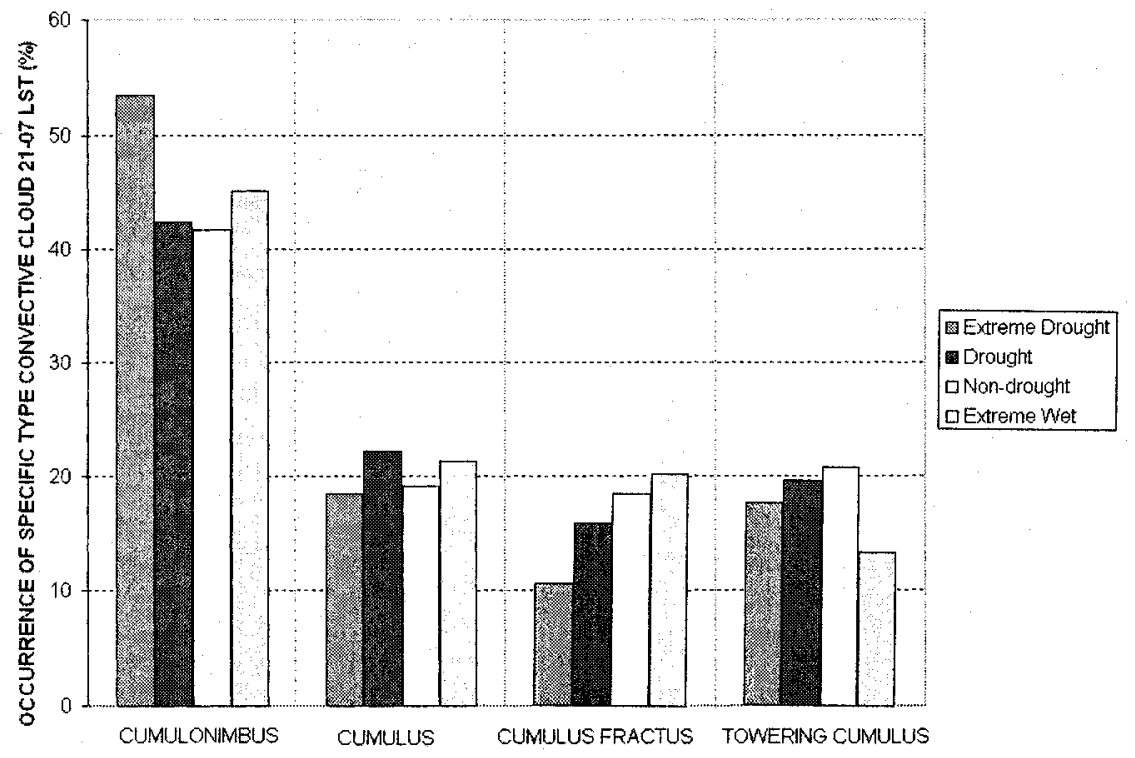

Figure 3-15: The percentage of time with the specified convective clouds occurring between 2107 LST.

\subsubsection{Ceiling}

Figure 3-16 depicts the average diurnal cycle of ceiling height $(\mathrm{m})$ with respect to ground level. Reports of unlimited ceilings were not accounted for in this analysis.

A similar trend is observed in the diurnal cycle of the ceiling for all four conditions. There is a distinct diurnal cycle of ceiling height with the highest ceilings occurring during late afternoon. In addition, the highest ceilings occur with increasingly dry conditions. The ceiling peaks at $3600 \mathrm{~m}$ during extreme drought conditions while only at $2700 \mathrm{~m}$ during extreme wet conditions. 
Chapter 3 - Characteristics of Temperature, Moisture, and Clouds

The lag that was observed between extreme drought and extreme wet conditions in Sections 3.3.1 and 3.3.2 is again evident in the ceiling data. The ceiling reaches a maximum height at 17 LST during extreme wet conditions and reaches a maximum height at 18 LST for extreme drought conditions and 19 LST during drought conditions.

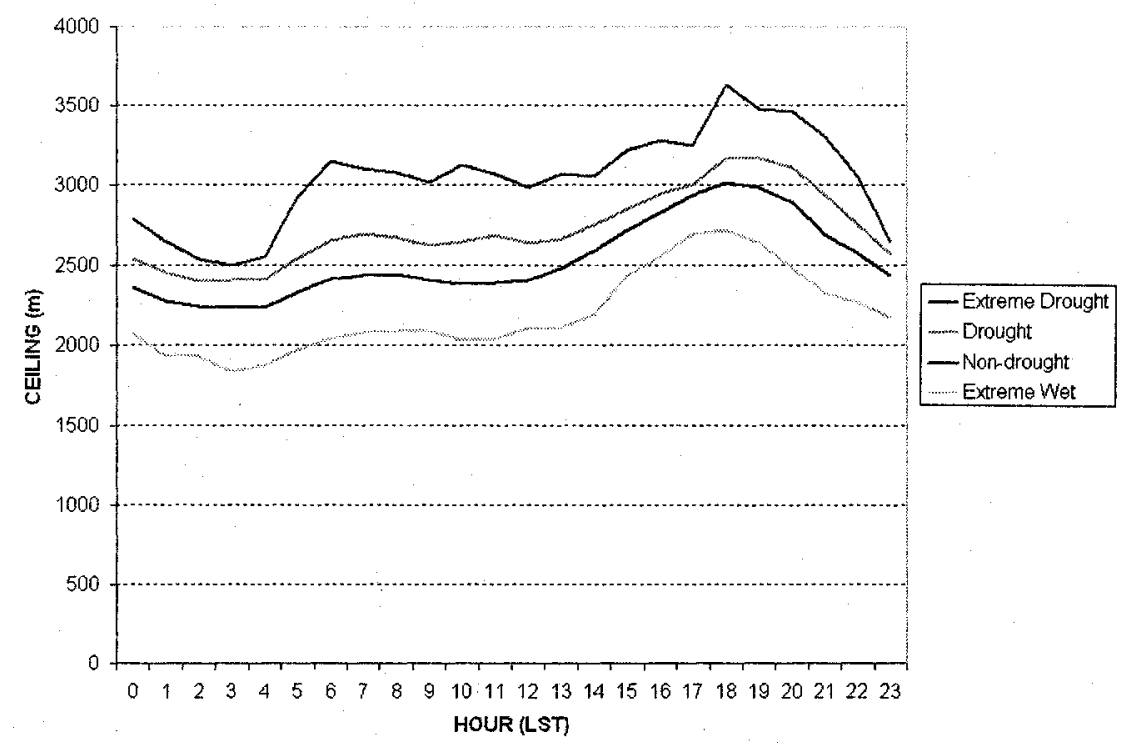

Figure 3-16: The diurnal cycle of ceiling.

\subsection{Synopsis}

The analysis of the surface parameters has shown that deviations are observed in both the overall averages and the diurnal cycle. Overall, temperatures are warmer, dew points are lower, and ceilings are higher during drought conditions. It was shown that temperatures increase by $1.0^{\circ} \mathrm{C}$ per step when progressing between each condition from extreme wet, non-drought, drought, and extreme drought conditions. As well, the dew point was $1.0^{\circ} \mathrm{C}$ lower during extreme drought and drought conditions as compared to nondrought and extreme wet conditions. The combination of drier and warmer nearsurface conditions resulted in a higher ceiling and fewer overcast conditions. As 
well, a reduction in the occurrence of low clouds during drought and extreme drought conditions was observed. However, little change was observed in the occurrence of both middle and convective clouds. The analysis of the convective clouds showed that cumulus clouds were the most often observed convective cloud. Convective clouds were typically observed between 21-07 LST. Deep convection, typified by cumulonimbus and towering cumulus clouds, was not observed as often during drought and extreme drought conditions in the analysis of the 00-23 LST observations.

Surface observations and photographs of the cloud field obtained during a field experiment in a drought stricken area further the analysis of the characteristics of temperature, moisture, and clouds. A discussion and analysis of the results from the field experiment are presented in Appendix $I$.

The analysis of the diurnal cycle revealed important patterns. There was a delay of 1-2 $\mathrm{h}$ in the occurrence of the highest temperature and highest ceiling. The maximum temperature and ceiling occurred later in the afternoon during increasingly dry conditions. The diurnal cycle of the dew point showed a similar trend, however the lowest dew points were observed earlier in the afternoon during extreme drought and drought conditions than during non-drought and extreme wet conditions.

These results confirm one portion of the positive feedback cycle that was shown in Figure 1-3. In a drought afflicted region temperatures are warmer, dew points are lower, and ceilings are higher. The remaining part of the feedback cycle, impacts to precipitation, will be analyzed in Chapter 4.

\subsection{Statistical Significance}

To this point all the results concerning the characteristics of drought over the Canadian Prairies have compared the averages for numerous surface parameters between drought, non-drought, extreme wet, and extreme drought conditions. To determine the significance of the difference between the diurnal 
Chapter 3 - Characteristics of Temperature, Moisture, and Clouds

cycle for drought and non-drought conditions, the difference of two means test was utilized. This test was applied to the diurnal cycles which were analyzed in Section 3.3. Only the drought and non-drought conditions were analyzed, as the data sets for the extreme drought and extreme wet conditions were not large enough.

To compute the Student T-distribution the variance, $\mathrm{s}^{2}$, was used to calculate the value of $t$. With the degrees of freedom value (df), the significance of the means at the $5 \%$ level was determined using the one-tailed $t$-distribution table. The one-tailed test is appropriate to use when it is known that the deviations will be in a particular direction, as is the case with the results of this thesis. With the one-tailed $t$-distribution table and the calculated df value it can be noted if the $t$ value is exceeded at the $5 \%$ level. If so, this indicates that the means are significantly different (Clarke and Cooke, 1998).

$$
\begin{aligned}
& s^{2}=\frac{1}{N-1} \sum\left(x_{i}-\bar{x}\right)^{2} \\
& |t|=\frac{\overline{\left(x_{1}-\overline{x_{2}}\right)}}{\sqrt{\frac{s_{1}^{2}}{N_{1}}+\frac{s_{2}}{N_{2}}}} \\
& \text { df }=\mathrm{N}_{1}+\mathrm{N}_{2}-2
\end{aligned}
$$

The two means test was applied to the cloud data. Cloud tenths were significantly different for the overcast, "broken", "few", and clear categories for 00-23 LST. The cloud type is significant for the hours of 00-23 LST for the categories that include low, middle, high, convective, and clear. The cloud type 
Chapter 3 - Characteristics of Temperature, Moisture, and Clouds

category including fog and other obscurities to vision did not have significant differences between the means for drought and non-drought conditions.

The diurnal cycle of the surface observations was investigated to determine whether there was significance between the curves for drought and non-drought conditions. Table 3-2 shows, for each parameter, the number of hours for which the results are significant. Significance is noted for each of these parameters indicating that the deviations between the diurnal cycles of drought and non-drought conditions are large enough to be studied. The parameters clearly linked with near-surface moisture show significance for all 24 hours. The significance for temperature, wind, and ceiling occurred late in the day, between 19-22 LST for ceiling and from 15-20 LST for wind. The only hours that were not significant for temperature were from 04-07 LST.

\begin{tabular}{|c|c|}
\hline Parameter & Hours of Significance \\
\hline Temperature & $20 / 24$ \\
\hline Dew Point & $24 / 24$ \\
\hline Relative Humidity & $24 / 24$ \\
\hline Dew Point Depression & $24 / 24$ \\
\hline Wind Speed & $8 / 24$ \\
\hline Ceiling & $14 / 24$ \\
\hline
\end{tabular}

Table 3-2: The number of hours that the deviations between the diurnal cycles of drought and non-drought were significant.

\subsection{Discussion}

A discussion is presented to explain some of the deviations, both within the overall averages and the diurnal cycle, observed between extreme drought, drought, non-drought, and extreme wet conditions.

First, the cloud type and fraction of cloud cover influence the surface temperature. Therefore the cooler temperatures during extreme wet conditions and warmer temperatures during extreme drought conditions may be correlated to 
the amount of cloud cover. It was shown in Section 3.3.6 that during extreme wet conditions there is an increased occurrence of completely overcast skies. Overcast skies and low clouds permit less radiation to reach the surface as more will be reflected by the cloud tops. The opposite case applies to drought conditions. The absence of completely overcast skies, shown in Section 3.3.6, would allow for more solar radiation to reach the surface, thus increasing surface temperatures.

A second item that may influence the surface temperatures is as follows. The surface temperature is correlated to the flux of sensible and latent heat and the increase in temperature can be described by analyzing the Bowen Ratio, $\beta$, the ratio of sensible heat to latent heat. During prolonged drought conditions the moisture within the ground decreases as there is only evapotranspiration depleting soil moisture and no precipitation to replenish the moisture. As the drought conditions worsen, there is an eventual decrease in the amount of surface evapotranspiration. The flux of latent heat is directly correlated to the amount of evapotranspiration and lower amounts of evapotranspiration indicate lower fluxes of latent heat. Assuming a constant value of shortwave radiation, surface temperatures will then increase since a reduction in evaporation requires an increased sensible heat flux (Oglesby and Erickson, 1989). The sensible heat flux from the surface to the atmosphere is greatest when the soil is the driest (Sellers, 1965). The increase in sensible heat will increase the surface temperature as is evidenced in the extreme drought and drought conditions.

The high percentage of time during which clear skies were reported and low percentage of time during which overcast skies were reported during drought, described in Section 3.3.6, is consistent with several ideas. First, during drought, predominantly subsiding motion is typical. The subsiding motion and overall dry soil does not allow lower level clouds and more widespread cloud cover to form (Wilhite, 2000). The decrease in the occurrence of low clouds may also be correlated to the warmer and drier near-surface conditions. Dey (1982) 
showed that a drier and warmer surface resulted in a higher lifting condensation level and thus no clouds could form at low levels. Second, given the larger dew point depression, there is a shorter amount of time during drought when clouds can occur.

It is important to note that the lowest cloud type was analyzed and there is uncertainty as to the whether the increase in high clouds such as cirrus can be attributed to the drought conditions or if the absence of the low level clouds allows the observer to see the high level clouds that before were obscured from view.

In addition to influencing the temperature, a decrease in soil moisture may impact convection. The presence of little deviation in the observation of convective clouds can be explained in part by a dry atmosphere and by the high flux of sensible heat that allows the convective boundary layer to deepen and aid in the formation of convective clouds (Rabin et al., 1990). In Chapter 2 it was shown that the structure of drought is spatially incoherent across the Prairies with extremely dry areas found adjacent to extremely wet areas. It has been shown that a variation in soil moisture may induce a local circulation which may cause cumulus convection events (Emori, 1998). The wet and dry conditions initiate intense soil moisture contrasts, evapotranspiration discontinuities, and differences in sensible heat flux. These deviations can force thermally induced circulations and cumulus convection (Emori, 1998).

Hanesiak et al. (2004) found that a dry atmosphere favored shallow convection and fair weather cumulus. This correlates with the results from Section 3.3.8 where it was shown that there is little change to the cumulus clouds during drought conditions. There are, however, fewer deep convective clouds that are formed during drought conditions. This is consistent with work done by Rabin et al. (1990). Hanesiak et al. (2004) found that deep convective clouds, cumulus congestus and cumulonimbus, only formed over areas with low Bowen ratios which are not common in regions afflicted by extreme drought. 
It was shown in Section 3.2 that on average winds are stronger during extreme drought and drought conditions than during non-drought conditions. The occurrence of a stronger average wind speed during drought is consistent with results of earlier work. Strong winds have been associated with past droughts including the dust bowl of the 1930's (Berton, 1991). Hanesiak et al. (2004) found a positive correlation between the depth of the convective boundary layer and the sensible heat flux. The larger flux of sensible heat during drought leads to a deeper convective boundary layer. The deeper convective boundary layer allows for more mixing within the atmosphere leading to increased wind speed at the surface as higher winds aloft are allowed to reach the surface. In addition, stronger winds cause more evaporation and increase the drying effects of drought, causing a positive feedback and enhanced drought conditions (Tannehill, 1947).

The higher ceiling during drought conditions is attributed to the drier and warmer surface conditions which force a higher cloud condensation level and thus a higher ceiling. The late day increase in ceiling height is correlated with the diurnal cycle of both temperature and dew point, with the daily high temperature and the daily low value of dew point reached in the late afternoon.

The increased height of the ceiling coupled with an increase in temperature and a decrease in dew point at the surface may have an impact on precipitation. The deeper sub-cloud layer coupled with the drier near-surface conditions will result in increased evaporation of precipitation, allowing less precipitation to reach the surface, thus perpetuating the drought. The characteristics of the occurrence of precipitation will be addressed in Chapter 4 and the evaporation of precipitation below cloud base will be addressed further in Chapter 5. 


\section{Chapter 4}

\section{Characteristics of the Occurrence of Precipitation}

This chapter will continue the investigation of the small scale characteristics of drought with a focus on the characteristics of the occurrence of precipitation. The overall average characteristics of the occurrence of precipitation will first be analyzed. This includes an analysis of the occurrence of thunderstorms, drizzle, and rain events. As well, the variation of thunderstorms, drizzle, and rain over the diurnal cycle will be examined. An analysis of the frequency and the duration of rain events will then be completed. Finally, there will be a discussion addressing the results presented in this chapter.

As discussed in Chapter 2, it should be again noted that corrected hourly precipitation data were not available for this project. Therefore, an analysis of precipitation from individual precipitation events could not be completed.

\subsection{Average Characteristics of Precipitation}

To this point, the analysis of the small scale structure of drought has focused on surface-observed temperature, moisture, wind, and clouds. As discussed in previous sections, these surface observations vary significantly between drought and non-drought conditions. The reduction of clouds and higher ceiling may result in fewer precipitation events and serve to prolong drought conditions. In this section, the impacts to the average characteristics of 
the occurrence of precipitation during extreme drought, drought, non-drought, and extreme wet conditions will be analyzed.

The study of the characteristics of precipitation includes the analysis of rain, frozen precipitation, rain showers, drizzle, and thunderstorms. Overall, precipitation (rain, rain showers, thunderstorms, drizzle, and frozen precipitation) is observed approximately $8.7 \%$ of the time over the course of the warm season.

Focusing on extreme drought, drought, non-drought, and extreme wet conditions, precipitation is observed fewer hours during dry conditions than during wet conditions. Precipitation is reported approximately $5.5 \%$ of the time during extreme drought conditions. During drought conditions precipitation is observed $7.0 \%$ of the time, during non-drought conditions it is observed $9.1 \%$ of the time, and during extreme wet conditions precipitation is observed $9.6 \%$ of the time.

The precipitation events can then be broken down into three subcategories: drizzle events, thunderstorms, and rain events. Each was previously defined in Chapter 2. The last category, rain, includes rain, rain showers, and frozen precipitation. However, frozen precipitation accounts for only $5.4 \%$ of the observations within the last category. Therefore, the latter category is referred to only as rain.

Figure 4-1 shows the average number of hours during the warm season with observations of drizzle, thunderstorms, and rain. It is noted that, when comparing the three precipitation categories, rain is most commonly observed, accounting for more than $70 \%$ of all observations of precipitation for each of the three conditions.

In addition, Figure 4-1 shows that fewer hours of rain are observed during drought conditions when compared to non-drought conditions. On average there are approximately $283 \mathrm{~h}$ of rain during extreme wet conditions and $270 \mathrm{~h}$ of rain during non-drought conditions accounting for approximately $7.6 \%$ and $7.3 \%$ of the warm season hours respectively. In contrast, $160 \mathrm{~h}$ of rain are observed 
during extreme drought conditions, $4 \%$ of the warm season hours, and $215 \mathrm{~h}$ of rain are observed during drought conditions, $6 \%$ of the warm season hours.

On average, warm season thunderstorms occur for $42 \mathrm{~h}$ during extreme wet conditions and for $39 \mathrm{~h}$ during non-drought conditions whereas thunderstorms are observed for approximately $31 \mathrm{~h}$ during drought conditions and for $30 \mathrm{~h}$ during extreme drought conditions. Thunderstorms are observed with rain at the observing site $60 \%$ of the time during extreme drought conditions, $62 \%$ of the time during drought and non-drought conditions, and $72 \%$ of the time during extreme wet conditions.

On average, drizzle is rarely reported over the Canadian Prairies. It is observed only $0.5 \%$ of the warm season hours. Drought and extreme drought conditions experience even fewer occurrences of drizzle as only $12 \mathrm{~h}$ are observed over the course of the warm season for these two conditions. Even during the extreme wet conditions, drizzle is observed during only $32 \mathrm{~h}$.

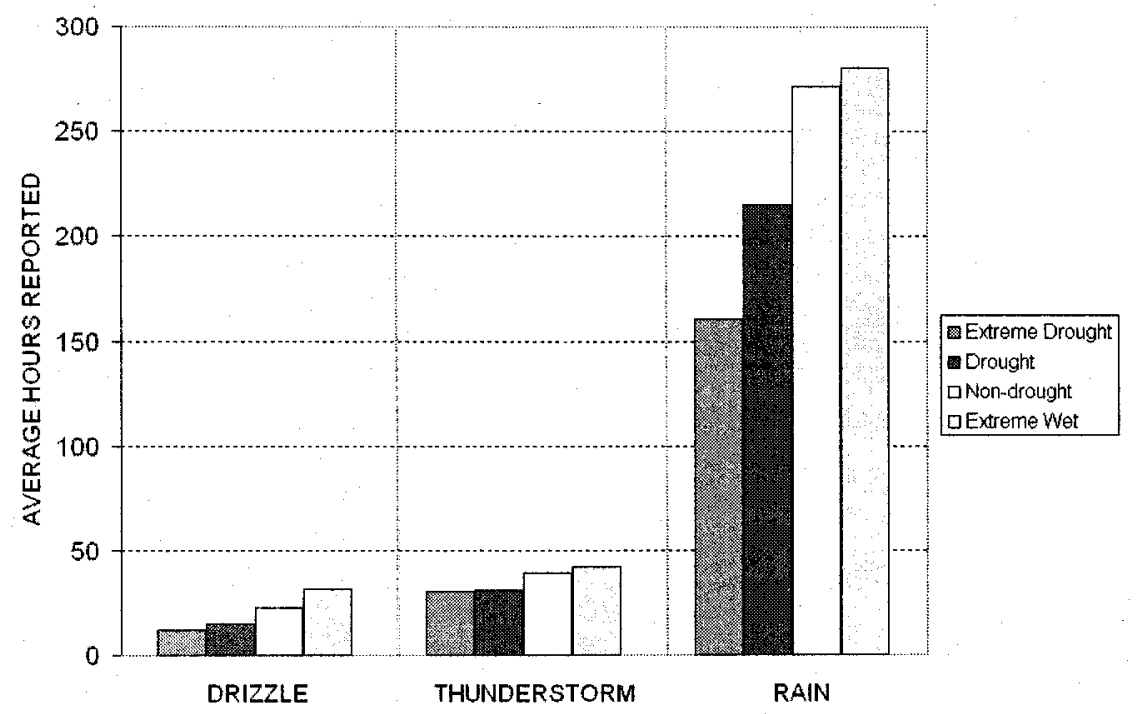

Figure 4-1: Average number of hours over the warm season with reports of drizzle, thunderstorms, and rain. 


\subsection{Diurnal Cycle of Precipitation}

The occurrence of precipitation is further analyzed in this section. An analysis of the diurnal cycle of rain, thunderstorms, and drizzle is presented to further demonstrate variability between extreme drought, drought, non-drought, and extreme wet conditions.

\subsubsection{Rain}

Figure 4-2 displays the diurnal cycle of rain. The average number of occurrences of rain for each hour over the May to September period is shown. To first order, the curves for all conditions show relatively little change over the diurnal cycle. In addition, at no point over the course of the diurnal cycle do any of the curves cross. However, there is a small increase in the frequency of rain toward the late afternoon and evening. A second peak, occurring during the overnight hours, is present within the diurnal cycle for extreme wet conditions.

There are more occurrences of rain reported throughout the entire diurnal cycle for the extreme wet conditions in comparison to the three other conditions. Fewer occurrences of rain for each of the $24 \mathrm{~h}$ are evident during extreme drought and drought conditions in comparison to non-drought and extreme wet conditions; this is consistent with Figure 4-1

A lag is apparent when comparing the gradual increase of reports of rain during the afternoon between extreme drought and extreme wet conditions. A marked increase is seen as early as 11 LST during extreme wet conditions whereas the afternoon increase does not occur until 14 LST when the Prairies are afflicted by extreme drought conditions although there was an earlier sharp peak at 09 LST. 


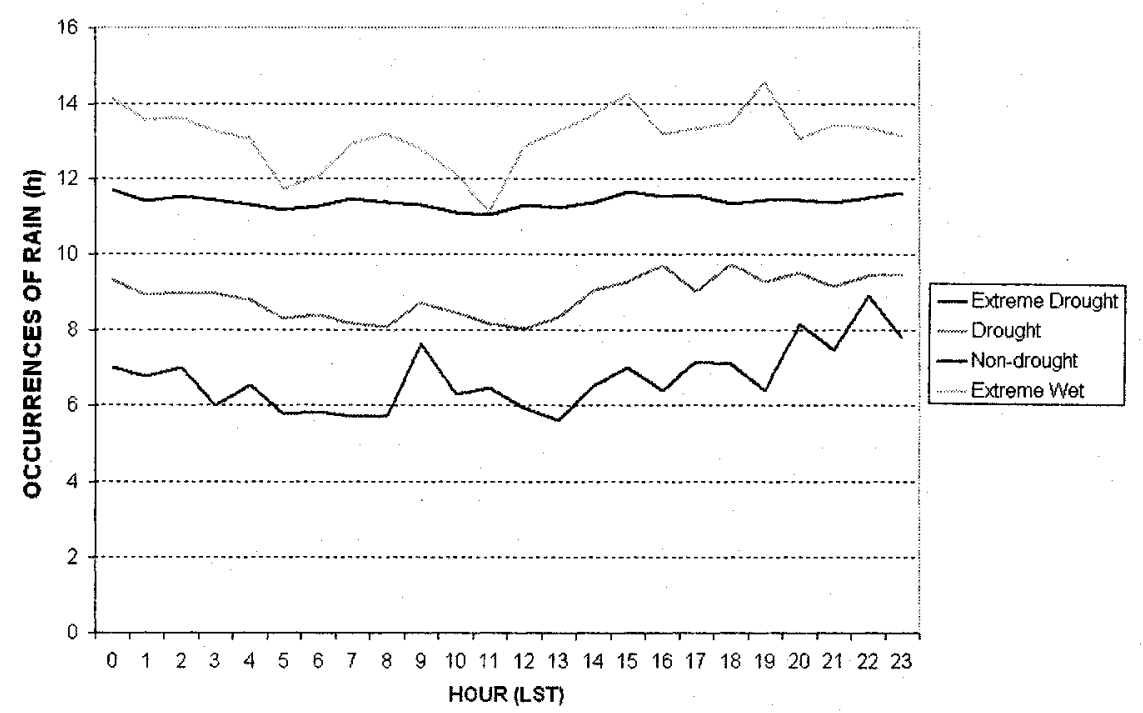

Figure 4-2: The diurnal cycle of rain for the specified condition with the average number of occurrences for each hour. The values refer to the average number of occurrences at a given location.

\subsubsection{Thunderstorms}

The diurnal cycle of the occurrence of thunderstorms is shown in Figure 4-3. Consistent with Figure 4-1, there are fewer occurrences of thunderstorms as drought severity increases. In addition, regardless of drought severity, there is a strong diurnal cycle with a peak occurring in the late afternoon or early evening. Extreme wet conditions have the highest peak but the lowest peak is not observed during extreme drought conditions, rather it is observed during drought conditions.

There are three embedded patterns within this general trend. First, the minimum occurrence of thunderstorms is delayed by $4 \mathrm{~h}$, from 08 LST to 12 LST, when comparing extreme wet and extreme drought conditions. Second, there is a delay in the time that the peak occurrence of thunderstorms is observed. Thunderstorms are recorded most often at 21 LST during extreme drought conditions and during extreme wet conditions thunderstorms occur $4 \mathrm{~h}$ earlier, at $17 \mathrm{~h}$ LST. Finally, it is important to note, that while the diurnal cycle follows 
relatively the same pattern, the peak itself exhibits different characteristics. During both extreme wet and extreme drought conditions the thunderstorms increase to a peak and quickly diminish in frequency. However, during drought and non-drought conditions the peaks are broader and flatter, extending for several hours.

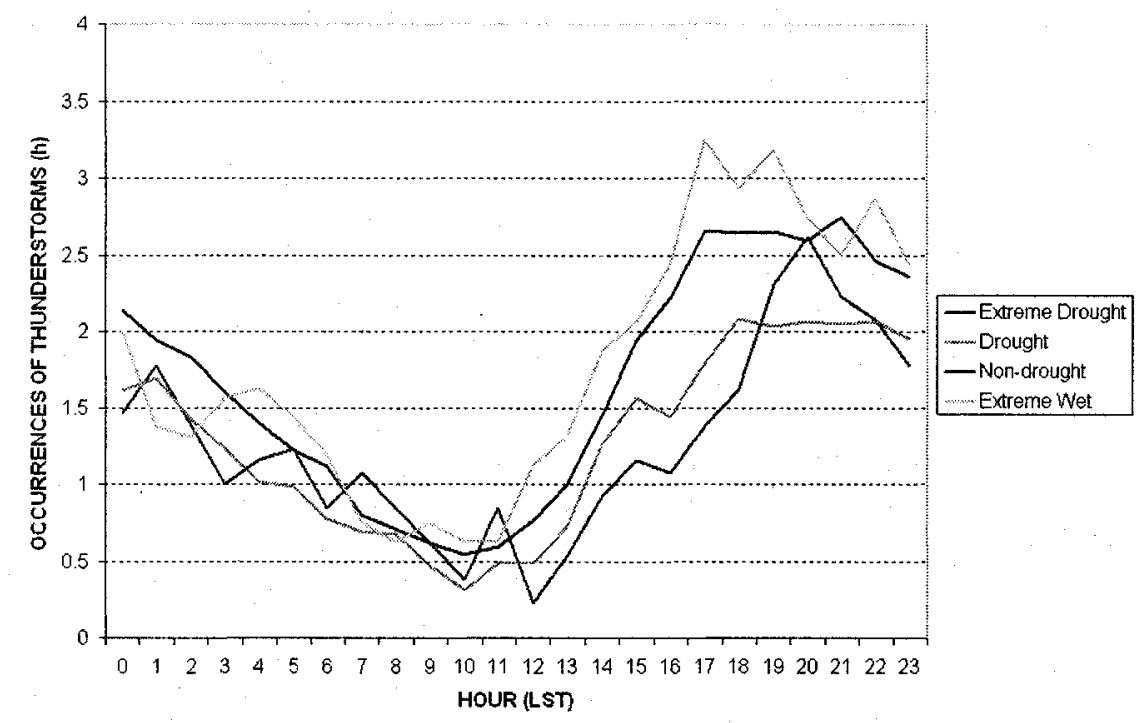

Figure 4-3: The diurnal cycle of thunderstorms with the average number of occurrences for each hour and the specified condition at a given site.

\subsubsection{Drizzle}

Figure 4-4 displays the diurnal cycle of drizzle. Similar trends are observed in the diurnal cycle for each of the four conditions. Drizzle occurs most frequently during the early morning hours around 07 LST. There is a decrease in its occurrence after 10 LST, with few reports of drizzle between 14 LST and 20 LST.

Drizzle is more commonly associated with extreme wet conditions. Fewer drizzle events are observed during drought conditions. This can be attributed to several factors including the increased height of the ceiling, fewer 
low clouds, and warmer and drier near-surface conditions. Further discussion is provided in Section 4.5.

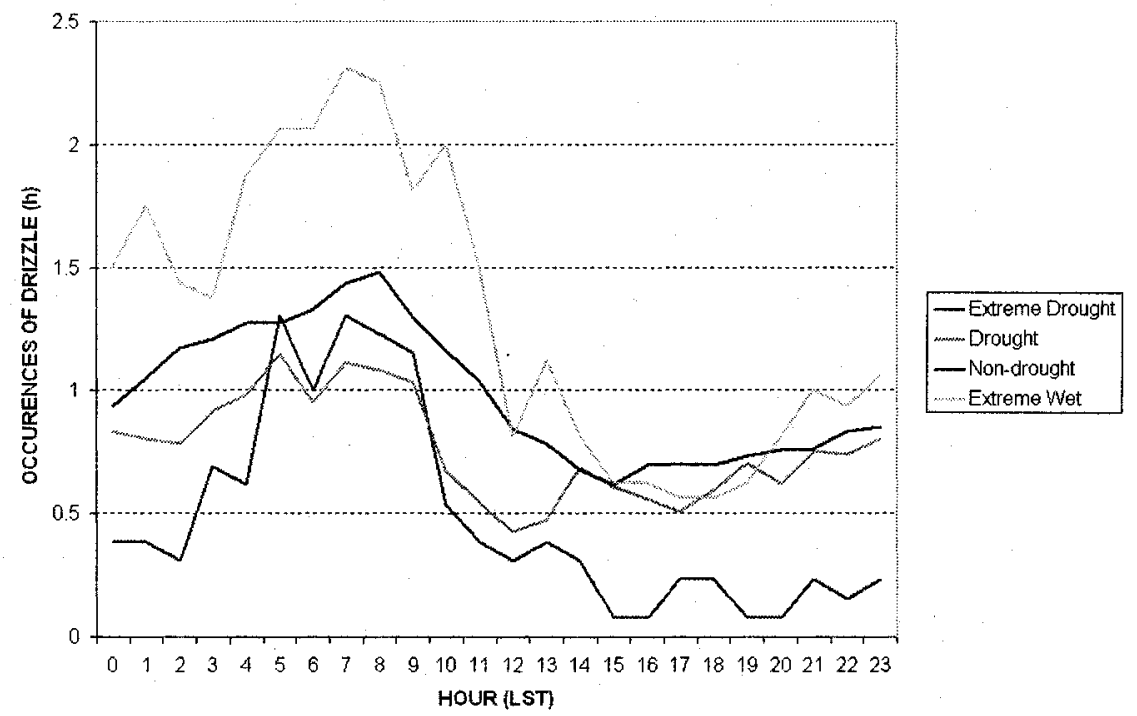

Figure 4-4: The diurnal cycle of drizzle with the average number of occurrences for each hour for the specified condition at a given site.

\subsection{Duration of Events and Time between Events}

In Sections 4.3.1 and 4.3.2 an analysis of the duration of rain events and the number of days between the occurrences of rain events is conducted. It is again noted that the observation of rain accounts for frozen precipitation as well as rain showers.

\subsubsection{Duration of Rain Events}

The hourly precipitation data were analyzed. For each warm season the duration of the rain events was tabulated and averages were then calculated to determine the number of rain events that were at least $1 \mathrm{~h}$ in duration. Figure 4-5 shows the average duration of the events for each of the four conditions. In 
general, the shape of the curves is very similar for all four conditions with the highest occurrence of low duration events and lowest occurrence of high duration events.

In particular, shorter duration precipitation events are correlated with increasingly dry conditions. Focusing on $1 \mathrm{~h}$ events, an average of 47 rain events are reported during each warm season for extreme wet and non-drought conditions whereas fewer occurrences, 44 and 38 , are observed during drought and extreme drought conditions respectively.

The standard deviation was then calculated for the $1 \mathrm{~h}$ events to find the extent of the outliers within the averages of the hourly data. Standard deviations of $14,6,6$, and 12 were found for extreme wet, non-drought, drought, and extreme drought conditions respectively. This indicates that $68 \%$ of the time one can expect that a warm season will average between $33-611-\mathrm{h}$ events for extreme wet conditions, 43 - 55 1-h events for non-drought conditions, 38 - 501 h events for drought conditions, and 26 - 50 1-h events for extreme drought conditions.

Relatively few rain events last longer than $1 \mathrm{~h}$. However, the trend that fewer occurrences of rain are correlated with drought conditions continues. Only 12 times during a warm season does rain last more than $2 \mathrm{~h}$ for extreme drought conditions as compared to 16 times for drought conditions and 19 times for nondrought and extreme wet conditions.

The longest duration of rain events was also analyzed and it was found that the longer lasting events were observed during increasingly wet conditions. On average, the longest rain events lasted $13 \mathrm{~h}$ during extreme drought conditions, $20 \mathrm{~h}$ during drought conditions, $24 \mathrm{~h}$ during non-drought conditions and $29 \mathrm{~h}$ during extreme wet conditions. 


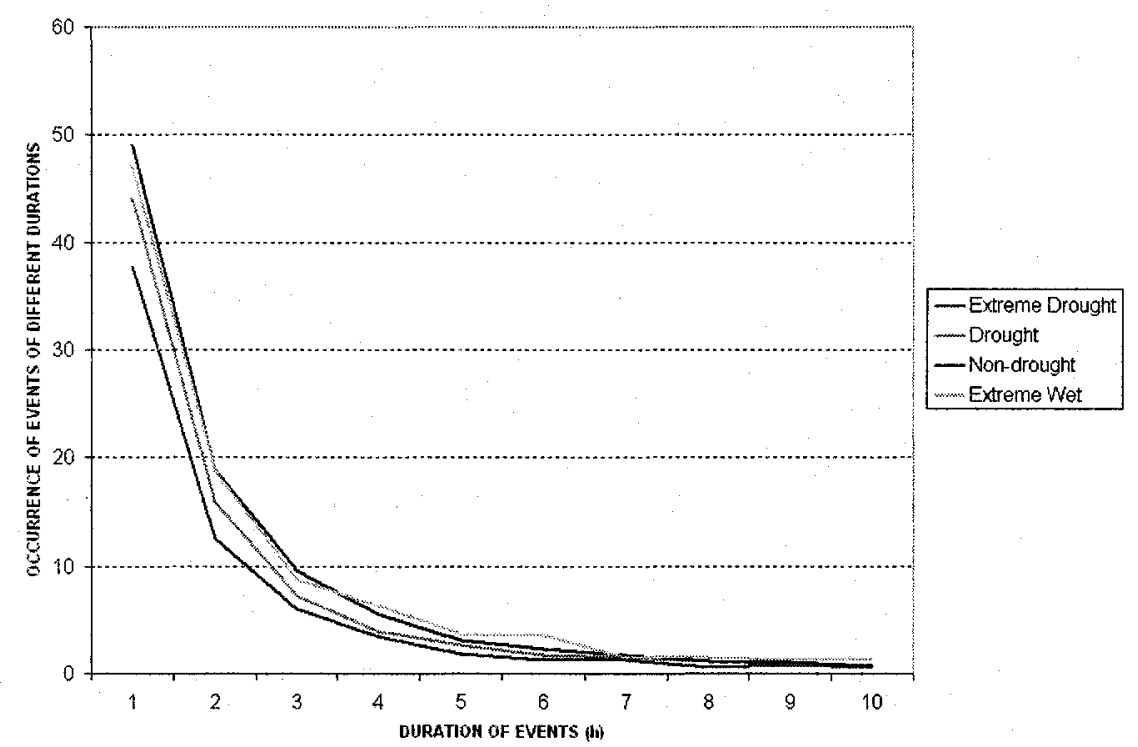

Figure 4-5: Average number of rain events as a function of their duration at a given location during the warm season.

\subsubsection{Time between Rain Events}

The amount of time that elapsed between rain events is shown in Figure 4-6. A similar pattern is noted for each of the four cases as most often rain events are separated by less than $24 \mathrm{~h}$. Longer periods of time between rain events are less frequent.

The results again indicate that there are more rain events observed during non-drought and extreme wet conditions. Reports of rain are separated by less than $24 \mathrm{~h}$ more often during extreme wet and non-drought conditions than during drought and extreme drought conditions. On average, rain events during extreme drought conditions are separated by less than $24 \mathrm{~h} 37$ times over the course of the warm season whereas this value increases to 49 times, 63 times, and 64 times during drought, non-drought, and extreme wet conditions respectively. 


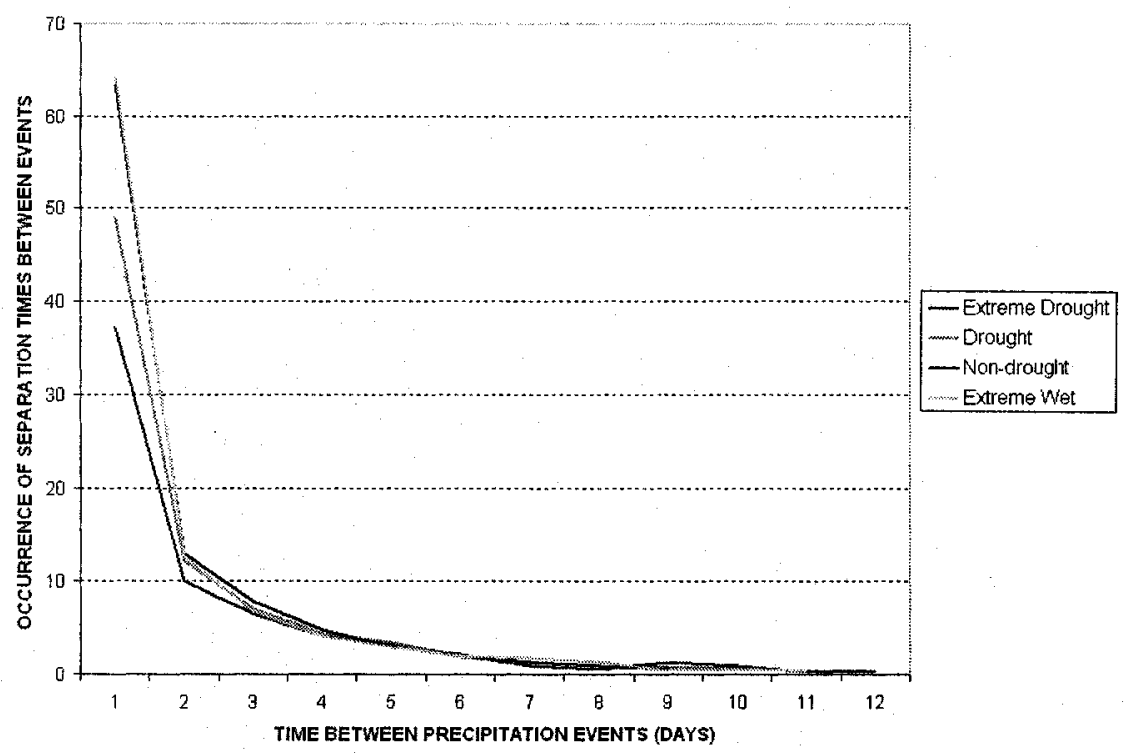

Figure 4-6: Average number of days between rain events at a given location during the warm season.

The standard deviations were once again calculated for the averages where the rain events were separated by less than $24 \mathrm{~h}$. The standard deviations found were $17,7,8$, and 21 for extreme drought, drought, non-drought, and extreme wet conditions respectively. This indicates that $68 \%$ of the time one can expect rain events to be separated by less than $24 \mathrm{~h}$ between 20 - 54 times during extreme drought conditions, 42 - 56 times during drought conditions, $55-71$ times during non-drought conditions, and 43 - 85 times during extreme wet conditions.

The longest period of time between rain events was then analyzed. On average the largest period between rain events is 17.5 days during extreme drought conditions, 14 days during drought conditions, 12.5 days during nondrought conditions, and 11.1 days during extreme wet conditions. 


\subsection{Synopsis}

Table 4-1 shows the overall warm season averages for characteristics of the occurrence of precipitation for extreme drought, drought, non-drought, and extreme wet conditions. For rain, thunderstorms, and drizzle, the total number of warm season occurrences are shown. In addition, the peak time of the occurrence of thunderstorms, the longest number of consecutive hours with rain reported, and the longest period of time between rain events are shown.

\begin{tabular}{|c|c|c|c|c|}
\hline & $\begin{array}{c}\text { Extreme } \\
\text { Drought }\end{array}$ & Drought & Non-drought & $\begin{array}{c}\text { Extreme } \\
\text { Wet }\end{array}$ \\
\hline $\begin{array}{c}\text { Occurrences of } \\
\text { Rain }\end{array}$ & $160 \mathrm{~h}$ & $215 \mathrm{~h}$ & $270 \mathrm{~h}$ & $283 \mathrm{~h}$ \\
\hline $\begin{array}{c}\text { Occurrences of } \\
\text { Thunderstorms }\end{array}$ & $30 \mathrm{~h}$ & $31 \mathrm{~h}$ & $39 \mathrm{~h}$ & $42 \mathrm{~h}$ \\
\hline $\begin{array}{c}\text { Occurrences of } \\
\text { Drizzle }\end{array}$ & $12 \mathrm{~h}$ & $12 \mathrm{~h}$ & $23 \mathrm{~h}$ & $32 \mathrm{~h}$ \\
\hline $\begin{array}{c}\text { Peak of } \\
\text { Thunderstorms }\end{array}$ & $21 \mathrm{~h} \mathrm{LST}$ & $18 \mathrm{~h} \mathrm{LST}$ & $17 \mathrm{~h} \mathrm{LST}$ & $17 \mathrm{~h} \mathrm{LST}$ \\
\hline $\begin{array}{c}\text { Longest } \\
\text { Duration Event }\end{array}$ & $13 \mathrm{~h}$ & $20 \mathrm{~h}$ & $24 \mathrm{~h}$ & $29 \mathrm{~h}$ \\
\hline $\begin{array}{c}\text { Longest Period } \\
\text { between Events }\end{array}$ & $17.5 \mathrm{days}$ & 14 days & 12.5 days & $11.1 \mathrm{days}$ \\
\hline
\end{tabular}

Table 4-1: Overall warm season averages for the four conditions studied.

The analysis of the characteristics of the occurrence of precipitation has shown that deviations are observed in both the overall averages and the diurnal cycle. Overall, fewer rain events are observed during extreme drought and drought conditions than during non-drought and extreme wet conditions. Rain events are observed approximately $40 \%$ and $20 \%$ less often during extreme 
drought and drought conditions respectively as compared to non-drought and extreme wet conditions. Similarly, drizzle and thunderstorms are observed less frequently during drought conditions as compared to non-drought conditions. In fact, at all hours rain and drizzle are more likely during non-drought and extreme wet conditions in comparison to extreme drought and drought conditions. There are relatively few deviations between the diurnal cycles of rain and drizzle for the four conditions. Thunderstorms show a strong diurnal cycle in all conditions, but their peaks and minimum values shift somewhat with each condition. The peak of the thunderstorms is delayed during extreme drought and drought conditions as compared to non-drought and extreme wet conditions.

The analysis of the duration and time between rain events confirmed that more rain events are observed during extreme wet and non-drought conditions. Most rain events did not last longer than $1 \mathrm{~h}$. Approximately $54 \%$ of all rain events were less than $1 \mathrm{~h}$ in duration during extreme drought conditions, $58 \%$ of all rain events were less than $1 \mathrm{~h}$ in duration during drought conditions, $64 \%$ of all rain events were less than $1 \mathrm{~h}$ in duration during non-drought conditions, and finally $66 \%$ of all rain events were less than $1 \mathrm{~h}$ in duration during extreme wet conditions. As well, $51 \%$ of the rain events are separated by less than $24 \mathrm{~h}$. In addition, rain events during extreme drought and drought conditions were separated by a longer period of time than rain events during non-drought and extreme wet conditions.

These results confirm to the extent possible with our available data, the remaining portion of the positive feedback cycle that was shown in Figure 1-3. In Chapter 3 it was shown that warmer temperatures, lower dew points, and higher ceilings were observed during drought periods. Chapter 4 continued the analysis of the positive feedback cycle with the study of the impacts to precipitation. Fewer rain events, thunderstorms, and drizzle events are observed during drought conditions, confirming the remaining portion of the cycle. 


\subsection{Discussion}

A discussion is presented to explain several of the deviations observed in both the overall averages and the diurnal cycles between extreme drought, drought, non-drought, and extreme wet conditions.

Overall, fewer rain events are associated with drought conditions than non-drought conditions. This is consistent with the meteorological definition of drought, defined as the degree and duration of a dry period. A similar trend is apparent for the occurrence of thunderstorms and drizzle.

The decrease in the number of rain events during drought can be linked to the following. The Prairies rely on both water vapor advected into the region and on local water vapor derived through evapotranspiration. Evapotranspiration typically decreases during drought coinciding with the overall dry surface including a decrease in transpiration from agriculture (Paulson et al., 1991). This was noted in this study in the low dew point observed during drought and extreme drought conditions. As well, it has been shown in previous drought studies that changes in the storm track cause storms to miss the Prairie region (Trenberth and Guillemot, 1996). The deviation in the storm track coupled with the decreased levels of evapotranspiration furthers the reduction of water vapor in the atmosphere thus limiting precipitation.

Recycled moisture accounts for a large fraction of the total rain that falls during the summer months over the Canadian Prairies (Raddatz, 2000). Oglesby (1991) showed that decreased precipitation during drought periods was correlated to both the reduction of local evaporation and ridging aloft. Ridging aloft may be induced by warm surface temperatures (Chang and Wallace, 1986).

Large deviations are noted within the diurnal cycle of thunderstorms, the most evident being the timing of the late day thunderstorms. It is noted that during drought conditions, the peak occurrence of thunderstorms is later in the day than for the other conditions. 
It is hypothesized that this delay is due to the following. Typically there are two mechanisms, thermodynamic and dynamic, that control convection. Dynamic forcing involves mass convergence within the planetary boundary layer. This analysis will focus on the thermodynamic, or the ability for the increased surface sensible heat flux to force thunderstorms (Wallace, 1975). The temperature reaches its maximum late in the day; coinciding with the largest flux of sensible heat. This may result in the delay of the initiation of thunderstorms. Similar trends were found by Hanesiak et al. (2004) who reported that, as root zone soil moisture declined over flat agricultural areas, the initiation of convection was delayed up to $7 \mathrm{~h}$. This was consistent with the idea that over regions where the Bowen ratio is high, the convective boundary layer is dry which does not allow convective clouds to form early in the day (Hanesiak et al., 2004).

Decreased occurrences of drizzle are observed during drought conditions. The decrease in the occurrence of drizzle coincides with the decreased occurrence of low level clouds and increased ceiling. Drizzle is initiated by lowlevel stratiform clouds, the absence of which inhibits the formation of drizzle and the higher ceilings may lead to its evaporation before reaching the surface. The evaporation of precipitation below cloud base will be addressed further in Chapter 5. 


\section{Chapter 5}

\section{Additional Features of Drought}

To this point, the analysis of the small scale structure of drought has focused on surface-observed temperature, moisture, wind, clouds, and precipitation. This chapter will address additional features associated with or influencing drought conditions, extending the discussion of the small scale characteristics of drought analyzed in Chapters 3 and 4 .

First, a quantitative study will be conducted on the effect of the increase in ceiling height and the decrease in atmospheric moisture on the evaporation of precipitation below cloud base. The occurrence of atmospheric aerosols (smoke, dust, and haze) during the four conditions and their effect on precipitation will then be analyzed. Finally, there will be a discussion concerning the correlation between cold season (October through April) and warm season (May through September) precipitation.

\subsection{Evaporation below Cloud Base}

In comparison to non-drought conditions, during drought conditions the ceiling is higher, surface temperatures are warmer, and the surface dew point is lower. Consequently, precipitation occurring during drought conditions is more likely to evaporate before reaching the surface. In this section, initial estimates are made to quantify the effect of an increased ceiling and warmer and drier surface conditions on precipitation. 
The distance a drop can fall below the cloud base before evaporation is strongly dependent on the radius of the drop. This distance is also affected by the temperature and relative humidity of the ambient air. Using the ClausiusClapeyron equation, an equation can be derived to determine the correlation between the drop radius, the cloud base, and potential evaporation. In particular, Ludlam (1980) derived an equation to calculate the distance a drop can fall before complete evaporation.

$$
z=10^{6} \int_{0}^{r}\left(\frac{V r}{C_{v}}\right) d r
$$

In Equation 5.1, $\mathrm{r}$ is the radius of the raindrop in $\mathrm{cm}, \mathrm{z}$ is the distance between the cloud base and the surface in $\mathrm{cm}, \mathrm{V}$ is the fall speed in $\mathrm{cm} \mathrm{s}^{-1}$, and $\mathrm{C}_{v}$ is the ventilation coefficient. For this study and following Ludlam (1980), the fall speed is approximated as $\left(8 \times 10^{3} \mathrm{r}\right) \mathrm{cm} \mathrm{s}^{-1}$ and the ventilation coefficient is estimated to be $\left(\mathrm{r} \times 10^{2}\right)$.

Equation 5.1 assumes a value of $-3 \times 10^{-6} \mathrm{~g} \mathrm{~cm}^{-3}$ for the difference between the atmospheric vapor density and the saturation vapor density (Ludlam, 1980). In the lower atmosphere, this vapor density difference corresponds to an average difference of approximately $2.78 \mathrm{~g} \mathrm{~kg}^{-1}$ between the atmospheric mixing ratio and the saturation mixing ratio.

For this study, Equation 5.1 was first modified to consider the lower atmospheric conditions over the Prairies rather than the conditions assumed in Equation 5.1. This is done by multiplying Equation 5.1 by the ratio of the originally assumed mixing ratio $\left(2.78 \mathrm{~g} \mathrm{~kg}^{-1}\right)$ over the average mixing ratio for the Prairies. Incorporating the average mixing ratio difference between the ceiling and the surface, $\Delta w$, Equation 5.1 becomes

$$
z=\left(\frac{2.78 \times 10^{6}}{\Delta w}\right) \int_{0}^{r}\left(\frac{V r}{C_{v}}\right) d r
$$


Equation 5.2 can be integrated to find the radius of a drop $(\mathrm{cm})$ that the drop must exceed to reach the surface in an unsaturated environment.

$$
r=\sqrt{\left(\frac{z \times \Delta w}{1.11 \times 10^{8}}\right)}
$$

This equation was applied to the four conditions of extreme drought, drought, non-drought, and extreme wet to determine the diameter that the drop must exceed in order for it to reach the surface. The average surface temperature and dew point for each condition, from Section 3-2, are utilized to calculate the difference between the surface atmospheric mixing ratio and the saturation mixing ratio. For this analysis, the observed mixing ratio difference at the surface was then divided by two to estimate the average difference between the surface and the ceiling and this difference was incorporated into Equation 5.3. The average ceiling for each of the four conditions, shown in Table 5.1, is considered for the value of $\mathrm{z}$. The diameter that the drop must exceed to allow the drop to reach the surface prior to evaporation was then calculated for each of the four conditions. The results are shown in Table 5.1.

\begin{tabular}{|c|c|c|c|}
\hline & $\begin{array}{c}\text { Average Mixing } \\
\text { Ratio Difference }\end{array}$ & Average Ceiling & Diameter \\
\hline Extreme & $3.2 \mathrm{~g} \mathrm{~kg}^{-1}$ & $3000 \mathrm{~m}$ & $1.9 \mathrm{~mm}$ \\
\hline Drought & $2.8 \mathrm{~g} \mathrm{~kg}^{-1}$ & $2700 \mathrm{~m}$ & $1.7 \mathrm{~mm}$ \\
\hline Non-drought & $2.3 \mathrm{~g} \mathrm{~kg}^{-1}$ & $2500 \mathrm{~m}$ & $1.4 \mathrm{~mm}$ \\
\hline Extreme Wet & $1.9 \mathrm{~g} \mathrm{~kg}^{-1}$ & $2200 \mathrm{~m}$ & $1.3 \mathrm{~mm}$ \\
\hline
\end{tabular}

Table 5-1: The average mixing ratio difference between the surface and the cloud base, the ceiling, and the minimum diameter that the drop diameter must exceed to allow a drop to reach the surface. 
The minimum diameter required for the raindrop to reach the surface without evaporating increases with an increase in the ceiling and an increase in the mixing ratio difference. The minimum diameter needed for a raindrop to reach the surface is approximately $0.6 \mathrm{~mm}$ larger during extreme drought conditions in comparison to extreme wet conditions.

Equation 5.3 was then applied to the hourly data to calculate the diurnal cycle of the minimum diameter required for the raindrop to reach the ground without evaporating. The diurnal cycle is shown in Figure 5-1.

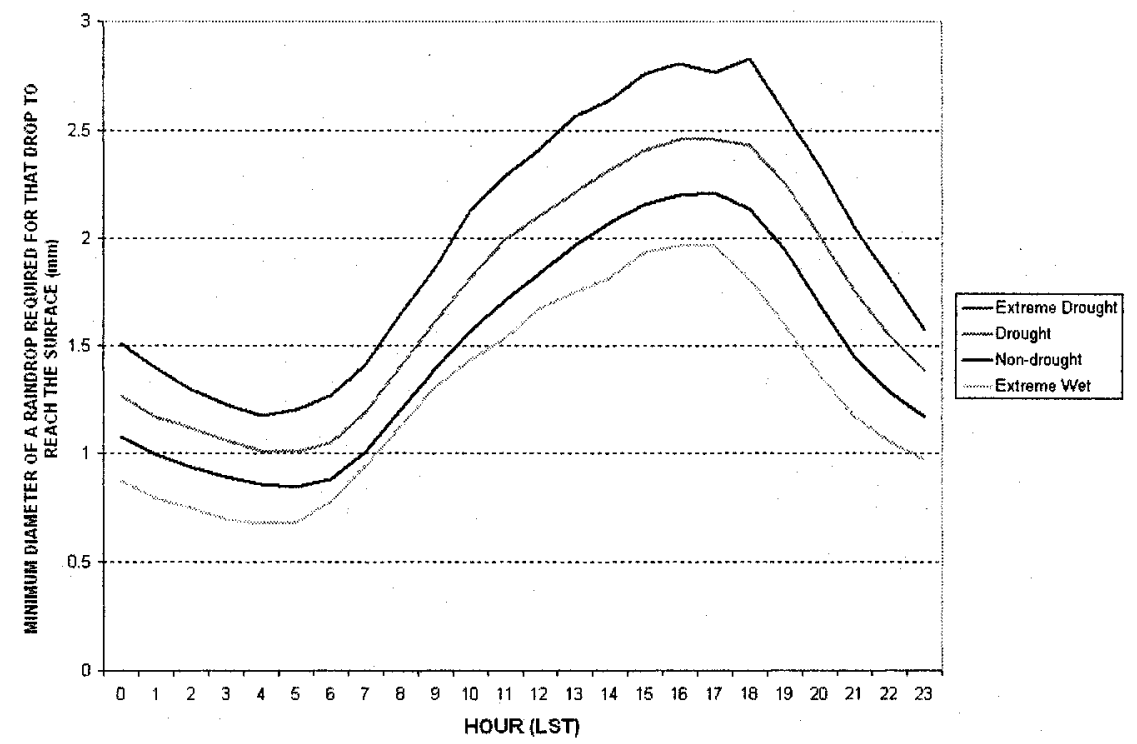

Figure 5-1: The diurnal cycle of the diameter a raindrop must exceed to reach the surface in the specified condition.

Figure 5-1 shows that the four curves follow a similar trend with the smallest required diameter observed early in the morning and the largest required diameter observed during the late afternoon. It is evident that larger diameters are correlated with drier surface conditions, as the largest required diameters are observed during extreme drought conditions and the smallest required diameters are observed during extreme wet conditions for each of the 24 hours. Over the course of the diurnal cycle, the required diameter of the raindrop increases by 1.6 
$\mathrm{mm}$ during extreme drought conditions, $1.4 \mathrm{~mm}$ during drought conditions, 1.3 $\mathrm{mm}$ during non-drought conditions, and $1.3 \mathrm{~mm}$ during extreme wet conditions.

As evident from Equation 5.3, both changes in the ceiling height and moisture in the lower atmosphere will have a significant impact on the probability that the falling precipitation will reach the ground. Collectively, these factors act to further perpetuate the drought conditions.

\subsection{Reduction of Visibility}

\subsubsection{Introduction}

To this point, the analysis of the small scale structure of drought has focused on surface-observed temperature, moisture, wind, clouds, and precipitation. As discussed in previous sections, these conditions vary significantly between drought and non-drought conditions. The variations of the surface-observed parameters may also be linked with changes to visibility. For example, due to stronger winds and a great likelihood of forest fires during drought, there may be deviations in the occurrence of dust, smoke, and haze.

Previous studies have reported on these features. More dust storms and forest fires were reported over the Prairies during the drought of 1988 (Wilhite, 2000). As well, Wheaton (1990) showed that there was a correlation between drought, the PDI, and the number of dust storms over the Canadian Prairies with dust storms reported more frequently during drought episodes.

\subsubsection{Analysis}

To further address visibility related features, an analysis of the observations of haze, smoke, and dust was conducted. For this study, the number of warm season occurrences of these three variables was calculated for each station. These data were then grouped into the four conditions of extreme 
drought, drought, non-drought, and extreme wet. The average number of obscurities reported for each condition per year was then calculated.

Figure 5-2 shows the average number of warm season observations of haze, smoke, and dust. Overall, smoke and dust are the most commonly reported obscurities; there are few reports of haze.

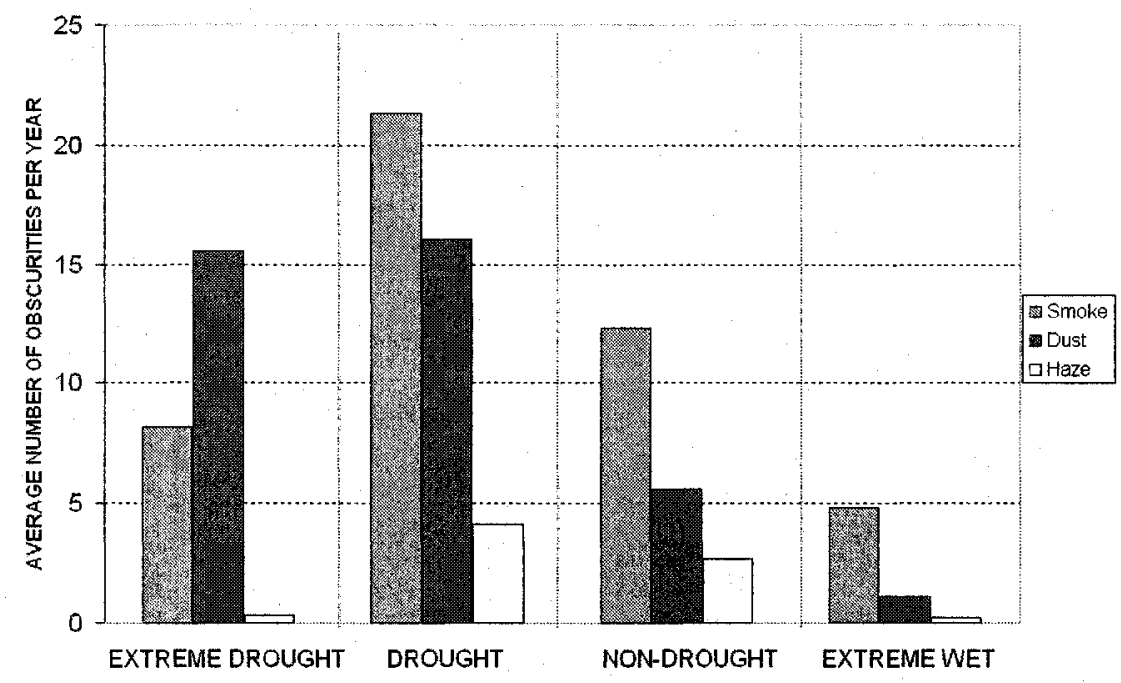

Figure 5-2: Average number of observations of smoke, dust, and haze during the warm season for each of the four conditions.

Figure 5-2 shows that dust is observed more frequently when drought conditions are present. During extreme drought and drought conditions, dust is observed 15 and 16 times, respectively, whereas it is observed 5 times during non-drought conditions and only once during extreme wet conditions. The increased occurrence of dust during drought is mainly attributed to the surface conditions. Surface temperatures are warmer and surface moisture is lower during extreme drought and drought conditions as compared to non-drought and extreme wet conditions indicating lower amounts of soil moisture and thus drier soil. In addition, stronger surface winds are observed during extreme drought and drought conditions as compared to non-drought conditions. It is more likely that with increased winds the drier topsoil will be mixed into the air. Thus, the 
number of occurrences of dust increases as drought severity increases; this is consistent with previous studies (Wheaton, 1990). The reports of smoke vary between the four conditions. During extreme drought conditions smoke is typically observed 8 times during the warm season in contrast with 21 reports during drought conditions, 12 observations during non-drought conditions, and 5 reports during extreme wet conditions. It is important to note that there were fewer reports of smoke during extreme drought conditions than during drought conditions. The reason for this is not clear, but it may be attributed to the fact that fires may not have occurred within the drought region and the winds carried the smoke into the region. Therefore, the wind direction and origin of the smoke would impact which of the stations observed smoke regardless of whether or not the station was afflicted by drought conditions.

There are negligible differences in the occurrence of haze when comparing drought and non-drought conditions although the greatest number of reports of haze occurs during drought conditions. Haze is formed from suspended particles that may or may not have been moistened; nonetheless, they have not been activated (Rogers and Yau, 1989). Haze is removed from the atmosphere as a result of precipitation scavenging. With less precipitation, it is not surprising that haze is more common during drought conditions. Unfortunately, no references concerning haze over the Canadian Prairies could be found in the literature to further pursue this issue.

Collectively, the increased reports of smoke and dust and to a lesser extent, haze, imply that the atmosphere contains more aerosols during extreme drought and drought conditions than during non-drought and extreme wet conditions. Assuming this is the case, the increased number of atmospheric aerosols may have implications on the precipitation efficiency.

In the atmosphere, dust and smoke particles serve as cloud condensation nuclei (Rogers and Yau, 1989). The more frequent observations of these particles would increase the number of cloud droplets, decreasing their average 
size. Smaller drops are less efficient in producing rain (Twomey and Squires, 1959). Thus, the decrease in the drop radius may result in an increased inability of rain formation due to the difficulty of droplet coalescence (Namias, 1983).

Therefore, during drought conditions, at least two factors act to decrease the occurrence of precipitation. Here, it was implied that the production of precipitation would be less efficient. As discussed in Section 5.1, even if the drop was able to coalesce, the smaller raindrop would be more likely to evaporate below the cloud base. Thus, precipitation may be inhibited during drought conditions due to both the increased number of cloud condensation nuclei as well as the increased height of the cloud base over a drier sub-cloud layer.

\subsection{The Correlation between Cold Season and Warm Season Precipitation}

In reference to precipitation, there was a focus on the occurrence of precipitation during the warm season (May through September). In addition, the question of whether precipitation observed in the previous cold season (October through April) has an impact on the following warm season precipitation should be addressed.

"Drought begets drought" (Namias, 1960). Through feedbacks, precipitation deficits during one season can affect precipitation in subsequent seasons. This section will address the strength of the relationship between cold season (October through April) precipitation and the precipitation during the following warm season (May through September). Conclusions of previous studies will first be given followed by the methodology and the results of this study. Finally, a discussion will be presented addressing the factors that may influence the strength of correlation between cold season precipitation and the precipitation during the following warm season. 


\subsubsection{Previous Studies}

Previous studies have analyzed the influence of winter and spring precipitation on subsequent summer precipitation. In general, persistence rules dictate that warm, dry springs will be followed by both hot and dry summers (AES, 1986). Namias (1960) found that dry conditions in the spring favor the formation of anticyclonic pressure conditions, a common large-scale feature associated with drought. The correlation between cold season and warm season precipitation was studied by Oglesby (1991) who determined that a late spring precipitation anomaly could carry over to the summer months and induce drought. Shabbar et al. (1997) concluded that runoff and soil moisture are adversely affected by extremely dry winters. Drier soil results in less evaporation and dry conditions during the spring make drought more favorable due to the dependence on local evaporation (Trenberth et al., 2003).

It is hypothesized that cold season (October through April) precipitation influences the subsequent warm season (May through September) precipitation for the following reasons. At the time of the spring thaw, the depth of the snowpack dictates the amount of water that will be released into the area. A smaller winter snowpack will negatively impact the soil moisture. The subsequent dry soils may lead to warmer temperatures, previously discussed in Chapter 3. Thus, the amount of cold season precipitation contained in the snowpack may influence the surface temperature and moisture leading to higher ceilings and fewer clouds. In addition, since local moisture sources are a significant source of summer precipitation, it follows that the summer precipitation should be less.

However, the correlation between cold season and warm season precipitation is complex and previous studies have shown conflicting results. Studies have shown that several severe summer droughts were preceded by a wet winter whereas others were preceded by a dry winter. Nkemdirim and Weber 
(1998) investigated the drought of 1936 and the droughts of the 1980's over the Canadian Prairies. They found the droughts of the 1980's were typically plagued by dry winter and spring months during which the average winter precipitation was as much as $30-35 \%$ below normal. In contrast, the winter prior to the drought of 1936 had record snowfall and abundant spring soil moisture.

\subsubsection{Current Study}

For this analysis, the period from late fall through early spring (October through April) is referred to as the cold season, and the period from late spring through early fall (May through October) is referred to as the warm season. The monthly precipitation data, obtained from Environment Canada, were analyzed to determine the correlation between cold season and warm season precipitation. The overall 49 year average monthly precipitation was calculated for each station and subsequent cold season and warm season precipitation averages were also calculated. From this, the percentage of normal precipitation was calculated for each cold season and warm season for each station. A product moment correlation was then applied to the precipitation anomalies and the resultant correlation coefficient analyzed. Correlation coefficients range from -1 to 1 . A value of 1 indicates the strongest correlation, a value of 0 indicates no correlation, and a value of -1 implies a negative correlation indicating that the warm season was drier than the cold season.

The correlation coefficient was first calculated between the entire cold season (October through April) and warm season (May through October). The resultant coefficient of -0.05 indicates that there is essentially no overall correlation between cold season and warm season precipitation.

The study was then focused on the drought years and the correlation coefficient between cold season and warm season precipitation was calculated for only the drought years. The correlation between cold season and warm season precipitation is 0.04 for the drought years, indicating there is essentially no 
correlation between the entire cold season and warm season precipitation during drought conditions. Due to the length of the cold season and warm seasons, it is unlikely that precipitation deficits in October, for example, would have an impact on precipitation in the following September. Therefore, further analysis was conducted.

The cold season (October through April) was broken down into three groups, October through November, December through February, and March through April. In addition, each month of the warm season (May through September) was also individually studied. Precipitation averages and subsequent percentages of normal precipitation values were calculated for each station and for each of the three groups of the cold season and the five warm season months. The correlation coefficient between the percentage of normal precipitation for October/November, December/February, and March/April and each of the five warm season months from May through September was then calculated. The correlation coefficients for the 49 years are shown in Table 5-2.

\begin{tabular}{|c|c|c|c|c|c|}
\hline & May & June & July & August & September \\
\hline October/November & 0.04 & 0.01 & -0.01 & 0.03 & -0.14 \\
\hline December/February & -0.02 & 0.02 & -0.02 & 0.01 & -0.05 \\
\hline March/April & 0.04 & -0.01 & 0.01 & 0.03 & -0.09 \\
\hline
\end{tabular}

Table 5-2: Correlation coefficients between cold season and warm season precipitation anomalies for the 49 year period.

From Table 5-2, it is evident that the correlation coefficients do not show strong correlation when all 49 years are studied. Little to no correlation is evident between any of the periods during the cold season and warm season.

The correlation coefficients were then calculated for only the drought conditions and are shown in Table 5-3. Stronger correlations were seen in the drought data in comparison to the correlations for the entire 49 year period shown in Table 5-2. In particular, a higher correlation, 0.37, is noted between 
March/April and June. The correlation between the October/November anomaly and the May anomaly is 0.10 , the correlation between December/February and May is 0.05, and the correlation between March/April and May is 0.15. In summary, the strongest correlations were found between the late winter/early spring precipitation anomalies and the late spring/early summer precipitation anomalies.

\begin{tabular}{|l|l|l|l|l|l|}
\hline & May & June & July & August & September \\
\hline October/November & 0.10 & -0.22 & 0.11 & 0.19 & -0.15 \\
\hline December/February & 0.05 & -0.10 & -0.10 & -0.19 & 0.28 \\
\hline March/April & 0.15 & 0.37 & 0.07 & -0.19 & -0.17 \\
\hline
\end{tabular}

Table 5-3: Correlation coefficients between cold season and warm season precipitation anomalies during drought years.

\subsubsection{Factors Influencing the Correlation between Cold Season and Warm Season Precipitation}

There are numerous factors that may influence the strength of the correlation between cold season and warm season precipitation. These include assumptions concerning precipitation, the sublimation of the snowpack, and the occurrence of chinook winds. These factors may be the cause of the weak correlation observed between the cold season and warm season precipitation.

First, the precipitation data is not gridded and it is assumed that the precipitation is produced in a vertical column. This fails to account for the advection of moisture which is often of paramount importance. In addition, the convective precipitation during the warm season is spotty in nature. This leads to precipitation in one location while nothing is reported a short distance away. The assumption is also made that all the precipitation during the cold season falls as snow which does not melt until spring. The correlation between cold season and warm season precipitation is influenced by the amount of snowfall received over 
the cold season and the percent of the snowpack that is melted due to liquid precipitation and winter thaws.

In addition, during the cold season months there can be tremendous amounts of sublimation in the Prairie region. Over Saskatoon 44-77\% of the snowpack is lost due to sublimation during the cold season (Pomeroy et al., 1993). The higher values are in general linked with stronger winds since this leads to greater sublimation.

Finally, winter thaws impact the depth of the snowpack. Chinook winds, strong warm winds that bring unseasonable warmth to the interior sections of Canada, mainly affecting Alberta, are one frequent phenomenon that results in the melting of the snowpack allowing evaporation to occur (Nkemdirim, 1996). A chinook wind typically results in temperature increases of $20.0^{\circ} \mathrm{C}$ in less than a few hours, melting much of the snowpack. Since the ground is frozen, none of the water from the snowpack would be able to enter the soil (Nkemdirim, 1996). This will subsequently deprive the rivers and soil of spring runoff.

The results of this study showed slight correlation between the late spring and early summer precipitation anomalies. It was observed that the highest correlations, although still small, were between late spring and early summer precipitation. This is consistent with previous studies as most have concluded that spring precipitation dictates the probability and extent of drought conditions in the following summer (Trenberth et al., 2003; Shabbar et al., 1997; Oglesby, 1991)

The study of precipitation and drought was furthered in this section where an analysis was conducted on the impact of cold season precipitation on the following warm season precipitation. It is noted that the relation between the cold season and the following warm season precipitation is quite complex. Comparing only the precipitation anomalies between the cold season and warm season does not account for the occurrence of chinook winds, sublimation of snow, and assumptions concerning precipitation. Thus, the amount of measured 
Chapter 5- Additional Features of Drought

precipitation may not directly impact the correlation between the cold season and warm season precipitation. It should be recognized that these were preliminary results using station information; a full examination of this issue over the Prairies could lead to other results. 


\section{Chapter 6}

\section{Conclusions}

\subsection{Thesis Summary}

The Canadian Prairies are very susceptible to droughts and over the last century severe drought has frequently plagued the region. The consequences of drought are extensive with impacts affecting many sectors including agriculture, water resources, and the environment. The large economic impact of drought and the knowledge that it repeatedly occurs over the Canadian Prairies makes the study of Canadian Prairie drought essential.

In this thesis a study of the characteristics of the structure of drought over the Canadian Prairies was completed. The main objectives of this thesis included the investigation of the small scale characteristics of drought and the identification and comparison of these characteristics across varying degrees of drought severity. The general approach for this thesis was to quantify key aspects of Figure 1-3 and other associated features through an analysis of surface temperature, moisture, cloud properties (type, coverage, and height) and impacts to precipitation. In particular, the warm season, May through September, was examined between 1953 and 2001.

First, 10 observational sites across the Canadian Prairies were chosen. Hourly surface observations from 1953-2001 were then obtained from Environment Canada for each site. The 49 warm seasons between 1953 and 
2001 were divided into drought and non-drought conditions based on the average warm season Palmer Drought Index (PDI) values and precipitation anomalies. The categories of extreme drought conditions and extreme wet conditions were then organized as subsets of the drought and non-drought conditions. Focusing on the warm season, drought conditions were also classified as extreme drought conditions if the PDI was less than -4 and non-drought conditions were also classified as extreme wet conditions if the PDI was greater than +4 . The subsequent categories of extreme drought, drought, non-drought, and extreme wet conditions were studied.

An initial analysis of the characteristics of temperature, moisture, and clouds was completed. The analysis of these surface parameters showed deviations between extreme drought, drought, non-drought, and extreme wet conditions for both the overall averages and the diurnal cycle. Overall, temperatures were warmer, dew points were lower, and ceilings were higher during extreme drought and drought conditions as compared to non-drought and extreme wet conditions. It was shown that temperatures increase by $1.0^{\circ} \mathrm{C}$ per step when progressing between extreme wet, non-drought, drought, and extreme drought conditions. As well, the dew point was $1.0^{\circ} \mathrm{C}$ lower during extreme drought and drought conditions as compared to non-drought and extreme wet conditions. The combination of drier and warmer surface conditions resulted in a higher ceiling and fewer overcast conditions. As well, a reduction in the occurrence of low clouds was observed during drought and extreme drought conditions. However, little change was observed in the occurrence of both middle and convective clouds. The additional analysis of the convective clouds showed that cumulus clouds were the most commonly observed type. Convective clouds were typically observed between 21-07 LST.

The analysis of the diurnal cycle of the surface parameters revealed important patterns. There was a delay of 1-2 $\mathrm{h}$ in the occurrence of the highest temperature and highest ceiling. The maximum temperature and ceiling occurred 
later in the afternoon during increasing dry conditions. The diurnal cycle of the dew point showed a similar trend, the lowest dew points were observed later in the afternoon during extreme drought and drought conditions than during extreme wet and non-drought conditions. A decrease of near-surface moisture and consequent decrease in evapotranspiration allowed the dew point to decrease further during drought conditions and thus the lowest dew points were observed later in the day during drought conditions than wet conditions.

The analysis of the characteristics of the occurrence of precipitation showed that deviations were observed in both the overall averages and the diurnal cycle. Overall, fewer precipitation events were observed during extreme drought and drought conditions than were observed during non-drought and extreme wet conditions. Rain events were observed $40 \%$ and $20 \%$ less often during extreme drought and drought conditions respectively as compared to nondrought and extreme wet conditions. Similarly, drizzle and thunderstorms were observed less frequently during the drier conditions as compared to wetter conditions. In fact, rain and drizzle were more likely during non-drought and extreme wet conditions at all hours. There were relatively few deviations between the diurnal cycles of rain and drizzle for the four conditions. Thunderstorms showed a strong diurnal cycle for all four conditions, but their peaks were delayed during extreme drought conditions when compared to extreme wet conditions. The delay is due to thermodynamic mechanisms; one factor controlling convection. During drought conditions the maximum temperature is recorded later in the day than during non-drought conditions. This causes a later day flux of sensible heat and may result in the delay of initiation of thunderstorms.

The analysis of the duration and time between rain events confirmed that more rain events were observed during extreme wet and non-drought conditions. Most rain events were less than $1 \mathrm{~h}$ in duration for each of the four conditions. Approximately $54 \%$ of all rain events were less than $1 \mathrm{~h}$ during extreme drought 
conditions, $58 \%$ of all rain events were less than $1 \mathrm{~h}$ during drought conditions, $64 \%$ of all rain events were less than $1 \mathrm{~h}$ during non-drought conditions, and finally $66 \%$ of all rain events were less than $1 \mathrm{~h}$ during extreme wet conditions. As well, $51 \%$ of all rain events were separated by less than $24 \mathrm{~h}$. In addition, the average longest period of time between rain events was observed during extreme drought (17.5 days) and drought conditions (14 days) as compared to nondrought (12.5 days) and extreme wet conditions (11.1 days).

Further analysis was conducted on precipitation related factors and visibility. Calculations showed that the increased ceiling and decreased relative humidity resulted in a greater amount of evaporation of precipitation below cloud base. It was estimated that the diameter of the raindrop must be $0.6 \mathrm{~mm}$ larger during extreme drought conditions when compared to extreme wet conditions to allow the raindrop to reach the surface prior to evaporation. Also, there were more occurrences of obstructions to visibility during extreme drought and drought conditions. Reports of dust increase with increasing drought severity and smoke has been reported more often during drought conditions than other conditions. The increased occurrences of dust and smoke during drought should result in an increased amount of cloud condensation nuclei. As a result, smaller droplets should be formed and the precipitation efficiency may decrease. As well, a study was conducted to determine the correlation between cold and warm season precipitation during drought. In the analysis of only the drought years, the strongest correlation was observed between late spring (March and April) and early summer precipitation (May or June) although even this correlation was weak.

Overall, with reference to Figure 6-1, the following can now be concluded regarding the drought characteristics over the Canadian Prairies. In general, the conceptual picture was validated and values associated with each aspect of the feedback process are shown in Table 6-1. 


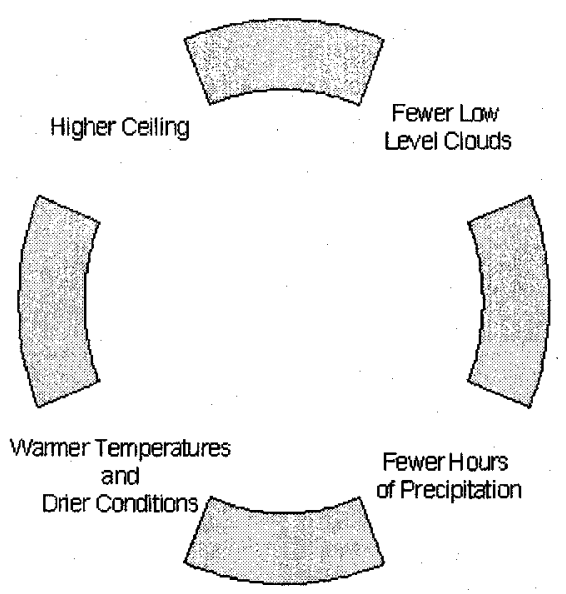

Figure 6-1: Positive feedback process associated with drought. The figure is similar to Figure 13 ; however it has been updated with some of the results from this thesis.

Drought is defined by a deficit of precipitation as compared to a climate normal and typically results in drier soil. Subsequent feedbacks include an increase of surface temperature and a decrease of near-surface moisture. Warmer surface temperatures and drier surface conditions cause the height of the ceiling to increase. Deviations are reported in the type of lowest cloud reported. Significantly fewer low level clouds are observed during drought conditions. Simultaneously, drought conditions report fewer occurrences of overcast skies and more frequent occurrences of clear skies. Each of the above factors influences precipitation. As the height of the ceiling increases and the dew point decreases the potential for the raindrops to evaporate below the cloud base increases. Raindrops must be larger in order to reach the surface prior to evaporation. This combined with fewer low level clouds and a higher ceiling results in less precipitation reaching the surface. In addition, dust and smoke are observed more frequently during extreme drought and drought conditions resulting in an increased number of cloud condensation nuclei and smaller drops. Thus, precipitation may be inhibited during drought conditions due to both the increased number of cloud condensation nuclei as well as the increased height of 


\begin{tabular}{|c|c|c|c|c|}
\hline & $\begin{array}{l}\text { Extreme } \\
\text { Drought }\end{array}$ & Drought & Non-drought & $\begin{array}{c}\text { Extreme } \\
\text { Wet }\end{array}$ \\
\hline Temperature & $17.0^{\circ} \mathrm{C}$ & $16.0^{\circ} \mathrm{C}$ & $15.0^{\circ} \mathrm{C}$ & $14.0^{\circ} \mathrm{C}$ \\
\hline Dew Point & $6.0^{\circ} \mathrm{C}$ & $6.0^{\circ} \mathrm{C}$ & $7.0^{\circ} \mathrm{C}$ & $7.0^{\circ} \mathrm{C}$ \\
\hline Ceiling & $3000 \mathrm{~m}$ & $2700 \mathrm{~m}$ & $2500 \mathrm{~m}$ & $2200 \mathrm{~m}$ \\
\hline Clear Skies & $16 \%$ & $14 \%$ & $13 \%$ & $17 \%$ \\
\hline Overcast Skies & $16 \%$ & $16 \%$ & $19 \%$ & $23 \%$ \\
\hline High Clouds & $14 \%$ & $12 \%$ & $10 \%$ & $9 \%$ \\
\hline Middle Clouds & $29 \%$ & $28 \%$ & $26 \%$ & $24 \%$ \\
\hline Low Clouds & $18 \%$ & $20 \%$ & $24 \%$ & $25 \%$ \\
\hline Convective Clouds & $22 \%$ & $25 \%$ & $28 \%$ & $26 \%$ \\
\hline Occurrences of Rain & $160 \mathrm{~h}$ & $215 \mathrm{~h}$ & $270 \mathrm{~h}$ & $283 \mathrm{~h}$ \\
\hline $\begin{array}{l}\text { Occurrences of } \\
\text { Thunderstorms }\end{array}$ & $30 \mathrm{~h}$ & $31 \mathrm{~h}$ & $39 \mathrm{~h}$ & $42 \mathrm{~h}$ \\
\hline $\begin{array}{c}\text { Occurrences of } \\
\text { Drizzle }\end{array}$ & $12 \mathrm{~h}$ & $12 \mathrm{~h}$ & $23 \mathrm{~h}$ & $32 \mathrm{~h}$ \\
\hline $\begin{array}{l}\text { Minimum Diameter } \\
\text { of Raindrop }\end{array}$ & $1.9 \mathrm{~mm}$ & $1.7 \mathrm{~mm}$ & $1.4 \mathrm{~mm}$ & $1.3 \mathrm{~mm}$ \\
\hline Reports of Dust & $15 \mathrm{~h}$ & $16 \mathrm{~h}$ & $5 \mathrm{~h}$ & $1 \mathrm{~h}$ \\
\hline Reports of Smoke & $8 \mathrm{~h}$ & $21 \mathrm{~h}$ & $12 \mathrm{~h}$ & $5 \mathrm{~h}$ \\
\hline Reports of Haze & $0.3 \mathrm{~h}$ & $4 \mathrm{~h}$ & $3 \mathrm{~h}$ & $0.2 \mathrm{~h}$ \\
\hline
\end{tabular}

Table 6-1: Overall warm season averages for the four conditions studied. 
the cloud base over a drier sub-cloud layer. Consequently, the drought perpetuates and the cycle continues until precipitation is produced over the drought area, eliminating the precipitation deficit. This typically occurs when the anticyclone moves or when precipitation is produced as a result of enhanced buoyant energy (AES, 1986; Giorgi et al., 1996).

\subsection{Concluding Remarks}

Drought is of widespread concern across many areas of the world. The study of drought has not been confined to the Prairies and Great Plains of North America. Extensive studies have been conducted on drought in parts of Australia, Europe, and Africa (Wilhite, 2000). Nazemosadat and Ghasemi, (2004) quantified the impact of warm and cold phases of ENSO on drought in Iran. In Romania, low amounts of precipitation are correlated to the positive phase of the North Atlantic Oscillation (Stefan et al., 2004). Suppiah (2004) found a relation between the Southern Oscillation and drought in Austrailia. Consistent with the study of drought across the Prairies, a majority of this research has focused on the teleconnections and the effects of the drought on the economy, agriculture, and hydrology.

To date, there is little skill in the prediction of drought (Wilhite, 2000). This is attributed to the insufficient understanding of drought and the numerous definitions and indices used to define and detect it. Bonsal and Lawford (1999) showed that specific synoptic conditions, such as anomalous anticyclones, typify drought although feedback mechanisms such as those which were discussed in this thesis act to define the detailed characteristics of drought. Models must be able to predict these anticyclones given certain sea surface temperatures and other associated teleconnections before significant achievements can be made concerning the prediction of drought and they also must account for regional feedbacks that lead to the exact structures. 
In the future, changes to the hydrologic cycle due to global warming may make drought more recurrent in many areas. So far studies concerning the future of drought have been inconclusive. Evidence is present for both increased and decreased precipitation across the Canadian Prairies (Dai and Trenberth, 1998; Gan, 1998). Climate models have predicted drier midlatitude continental conditions and the IPCC reported in 1990 that with a doubled $\mathrm{CO}_{2}$ atmosphere there may be a decrease of soil moisture across the Prairies (IPCC, 1990; Ogelsby, 1991). Effects of climate change may be seen in the hydrologic cycle. This arises in part because winter precipitation may not fall entirely as snow and any snowpack that does form would melt more quickly. Thus this would leave less water available during the summer (Watson et al., 1998). Other climate change studies have suggested that future warming would bring more intense drought. This is due to the higher temperatures which cause enhanced evaporation and this coupled with a longer warm season would result in more droughts (Williams et al., 1998).

This thesis provided an analysis of drought characteristics over the Canadian Prairies. There are many areas of study remaining. First, in many regions surface-based observations are not available. Studies could concentrate on furthering the use of satellite derived data to monitor and study droughts in such regions. Additionally, drought afflicted regions are often bordered by wet regions. Studies could focus on this border and the interaction between the two areas. In addition, studies could address the nature of single catastrophic storms which often terminate droughts. Other studies could be conducted on the accuracy of forecasts during drought as models tend to over predict precipitation within drought regions. Finally, studies could focus on drought prediction and how drought will change with future climate change.

Future study of drought is essential because of drought's severe economic and environmental effects. Thus, not only the Canadian Prairies but areas around 
Chapter 6 Conclusions

the globe would benefit from such studies. It is important to understand not only how drought develops and evolves now, but how it may change in the future. 


\section{Appendix I}

This Appendix describes the results of a field experiment conducted in Edmonton, Alberta on May 26, 2004. The main objective of the field experiment was to photograph and analyze the cloud cover in a drought stricken region. At the time of the field experiment, the Edmonton area was afflicted by extreme drought and had been under drought conditions since 1999.

\section{A.1 Experimental Design}

For this field experiment, a tripod and digital camera were utilized at the Environment Canada surface observing site near the Edmonton International Airport. Multiple photographs, giving a complete $360^{\circ}$ prospective, were taken every 30 minutes between 12 LST and 15 LST. Surface observations taken by the field observer in Edmonton were obtained for each of the hours the photographs were taken. In Section A.3 several of the cloud photographs are shown and the corresponding hourly surface observations are given. Each of the photographs shown was taken in a north-easterly direction.

\section{A.2 Synoptic Conditions}

Figure A-1 displays the rawinsonde observation recorded just after the experiment period ended, at 18 LST on May $26^{\text {th }}$. An analysis of the skew-T diagram gives the following information. The surface was both very dry and warm as evidenced by a near-surface dew point depression of almost $20^{\circ} \mathrm{C}$. This resulted in a higher ceiling. There is relatively little change of wind with height. Upon analyzing the skew- $T$ to find the stability of the atmosphere, it was found 
that at 18 LST the atmosphere was marginally unstable with a small value of CAPE (convective available potential energy).

Figure A-2 displays the synoptic conditions as shown by the surface analysis at 12 LST on May 26, 2004. A low pressure system was centered over northern Alberta with a trough extending southeastward through Alberta. The low pressure system allowed for northwesterly flow into the Edmonton area.

No precipitation was recorded at the Edmonton observing station on the $26^{\text {th}}$; however distant showers were reported several times throughout the afternoon.

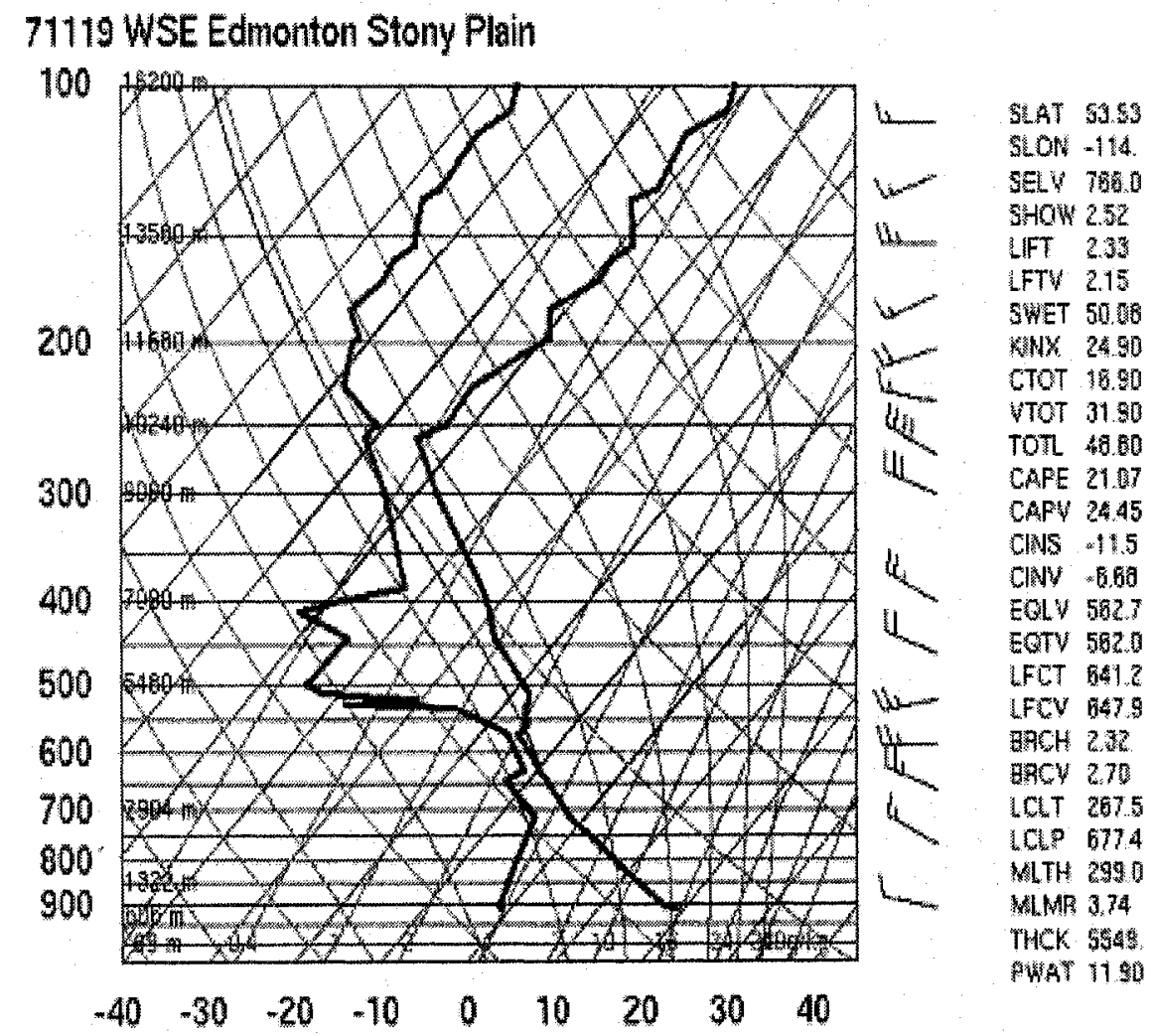

00227 May 2004

Figure A-1: Sounding at 18 LST on May 26, 2004 for Edmonton, Alberta. 


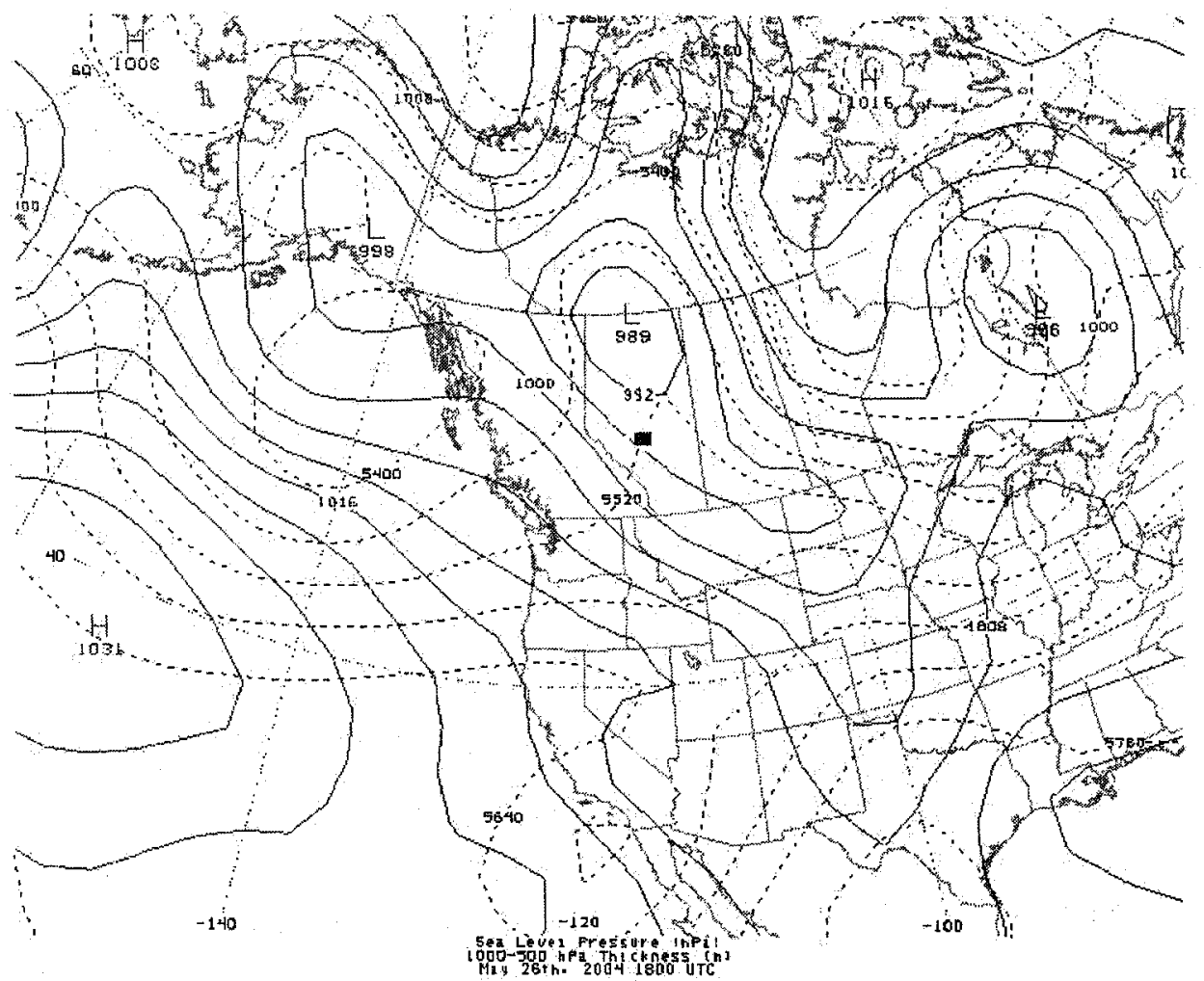

Figure A-2: Sea level pressure and 1000-500 hPa thickness 12 LST on May 26, 2004. Edmonton, Alberta is identified by a red dot.

\section{A.3 Photographs}

The following sections show four of the photographs taken during the field experiment between 12 LST and 15 LST.

\section{A.3.1 12 LST}

Figure A-3 shows the cloud field at 12 LST, at which time clouds covered $4 / 10$ of the sky. The lowest cloud base was recorded at $1600 \mathrm{~m}$. The temperature was $17.1^{\circ} \mathrm{C}$ and the dew point was $4.1^{\circ} \mathrm{C}$. Winds were from 310 degrees at $22 \mathrm{~km} / \mathrm{h}$, gusting to $33 \mathrm{~km} / \mathrm{h}$. 


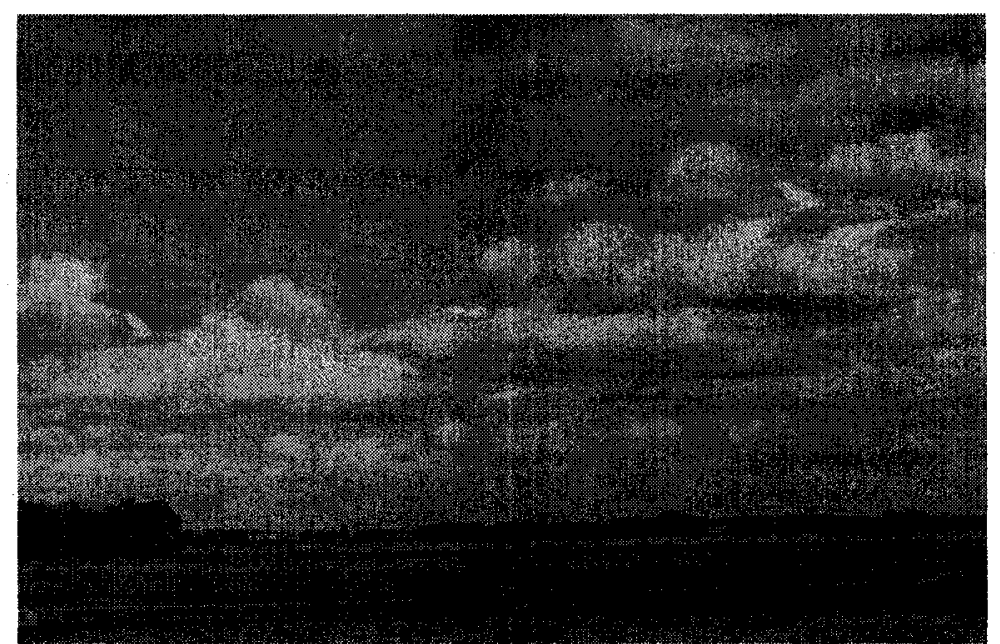

Figure A-3: Observed cloud field at 12 LST.

\section{A.3.2 13 LST}

Figure A-4 shows a photograph of the clouds taken at 13 LST. More clouds are evident at this hour, and they covered 5/10 of the sky. At the 13 LST observation, the temperature had increased to $19.3^{\circ} \mathrm{C}$ and the dew point had decreased to $2.8^{\circ} \mathrm{C}$ causing the ceiling to increase to $1900 \mathrm{~m}$. The wind was still from 300 degrees at $26 \mathrm{~km} / \mathrm{h}$. Distant showers were reported at this hour.

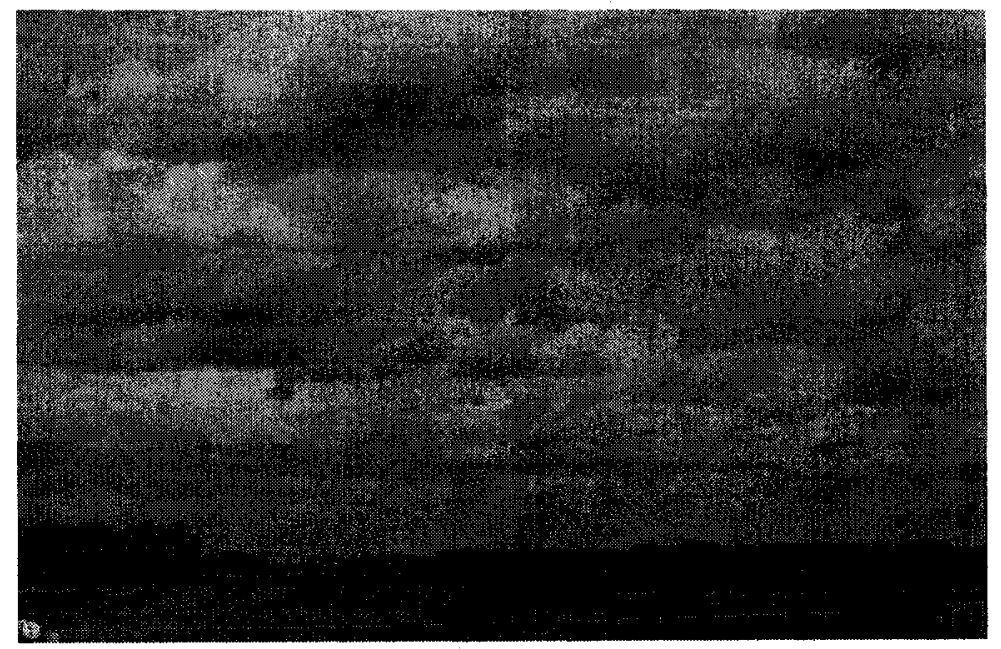

Figure A-2: Observed cloud field at 13 LST. 
Appendix I

\title{
A.3.3 14 LST
}

Figure A-5 displays the photograph of the cloud field at 14 LST. At this time distant showers were reported. However, at the observing site no showers were observed and the clouds were reported to cover $5 / 10$ of the sky. The lowest cloud base had risen to $2000 \mathrm{~m}$. The dew point was recorded at $3.0^{\circ} \mathrm{C}$ and the temperature was $19.0^{\circ} \mathrm{C}$. The wind was from 300 degrees at $28 \mathrm{~km} / \mathrm{h}$.

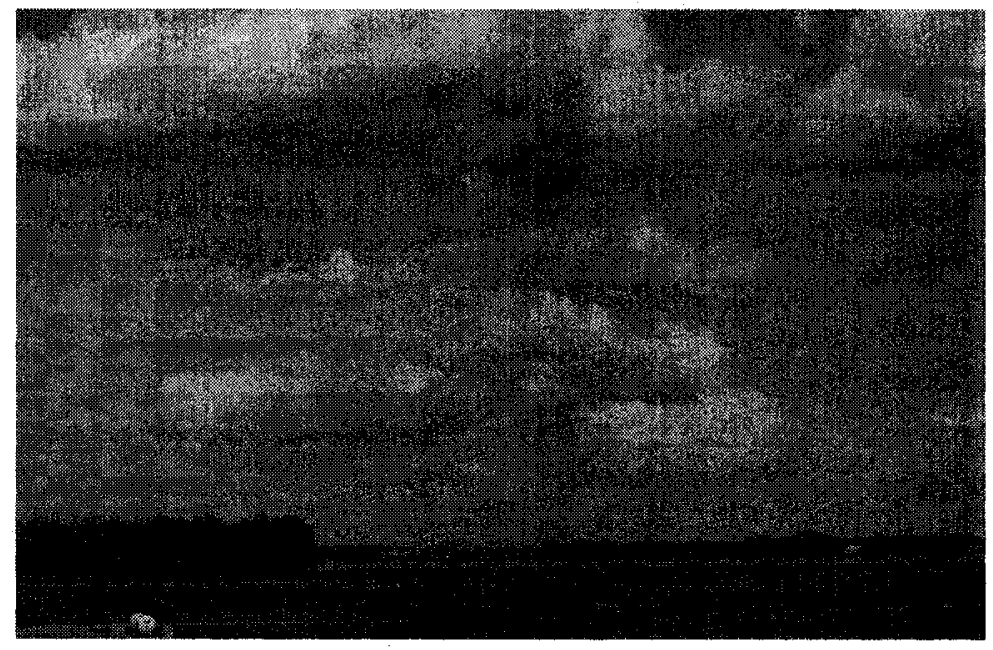

Figure A-3: Observed cloud field at 14 LST.

\begin{abstract}
A.3.4 15 LST
Figure A-6 shows the clouds at the 15 LST observation. At this time the lowest cloud base was recorded at $2000 \mathrm{~m}$. The clouds covered $5 / 10$ of the sky. Temperature was $19.0^{\circ} \mathrm{C}$. The dew point was $3.0^{\circ} \mathrm{C}$. The winds were $26 \mathrm{~km} / \mathrm{h}$ from 300 degrees.
\end{abstract}




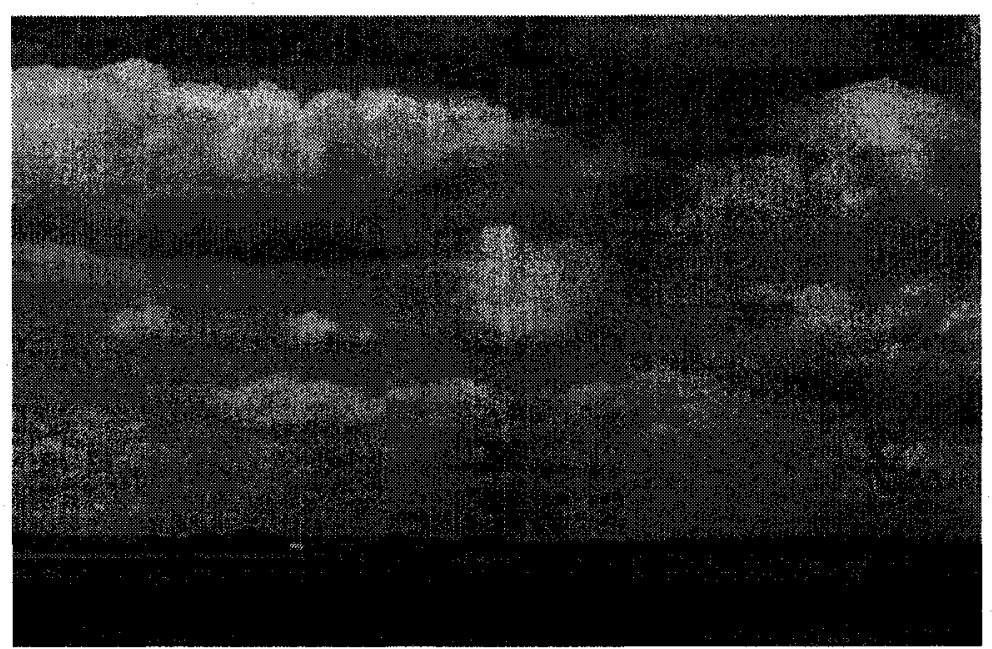

Figure A-4: Observed cloud field at 15 LST.

\section{A.2 Remarks}

The field experiment confirmed the results that were obtained throughout the analysis of the hourly surface observations for this thesis. While the Edmonton area was afflicted by drought, there was still moisture present. Clouds were formed through convective processes during the day. The drought conditions and drier soil were evidenced in the high dew point depression. As the afternoon progressed, further warming of the surface led to a higher cloud base which limited precipitation efficiency. This is similar to the results that were seen in the study of the hourly surface observations and that were analyzed and discussed in Chapters 3, 4, and 5. 


\section{Bibliography}

AES Drought Study Group, 1986: An Applied Climatology of Drought in the Canadian Prairie Provinces. Report No. 86-4, Canadian Climate Centre, Downsview, ON 197 pp.

Akinremi O., S. McGinn, and A.G. Barr, 1996: Evaluation of the Palmer Drought Index on the Canadian Prairies. Journal of Climate, 9, 897-905.

Berton, P., 1991: The Great Depression. McClelland and Stewart, 202 pp.

Bonsal, B., X. Zhang, and W.D. Hogg, 1999: Canadian Prairie Growing Season Precipitation Variability and Associated Atmospheric Circulation. Climate Research, 11, 191-208.

Bonsal, B., A.K. Charkravarti, and R.G. Lawford, 1993: Teleconnections Between North Pacific SST Anomalies and Growing Season Extended Dry Spells On The Canadian Prairies. International Journal of Climatatology, 13, 865-878.

Bonsal, B. and R. Lawford, 1999: Teleconnections between El Nino and La Nina Events and Summer Extended Dry Spells on the Canadian Prairies. International Journal of Climatology, 19, 1445-1458.

Chang, Fong-Chiau, and J. Wallace, 1986: Meteorological Conditions during Heat Waves and Droughts in the United States Great Plains. Monthly Weather Review, July 1987, 1253-1269.

Clarke, G.M. and D Cooke, 1998: A Basic Course in Statistics. Arnold, 672 pp.

Dai, A. and K. Trenberth, 1998: Global Variations in Droughts and Wet Spells: 1900-1995. Geophysical Research Letters, 25, 3367-3370.

Dey, B., 1982: Nature and Possible Causes of Droughts on the Canadian Prairies - Case Studies. International Journal of Climatology, 2, 233-249.

Emori, S., 1998: The Interaction of Cumulus Convection with Soil Moisture Distribution: An Idealized Simulation. Journal of Geophysical Research, 103, 8873-8884.

Environment Canada (EC), 1977: MANOBS, Manual of Surface Weather Observations. Ottawa, Environment Canada. 
Bibliography

Environment Canada (EC), 2003: Natural Disasters on the Rise. Science and the Environment Bulletin, 35.

Environment Canada (EC), 2004: Personal Communication. Edmonton, Alberta.

Gan, T.Y., 1998: Paleoclimatic trends and possible climatic warming in the Canadian Prairies. Water Resources Research, 34, 3009-30015.

Giorgi, F., L. Mearns., C. Shields, and L. Mayer, 1996: A Regional Model Study of the Importance of Local versus Remote Controls of the 1988 Drought and the 1993 Flood over the Central United States. Journal of Climate, 9, 1150-1162.

Gutman, G., 1990: Towards Monitoring Droughts from Space. Journal of Climate, 3, 282-295.

Hahn, C., S. Warren, and J. London, 1995: The Effect of Moonlight on Observation of Cloud Cover at Night, and Application to Cloud Climatology. Journal of Climate, 8, 1429-1446.

Hanesiak, J., R. Raddatz, and S. Lobban, 2004: Local Initiation of Deep Convection on the Canadian Prairie Provinces. Boundary-Layer Meteorology, 110, 455-470.

Heim, R. Jr., 2002: A Review of Twentieth Century Drought Indices Used in the United States. Bulletin of the American Meteorological Society, 83, 1149-1165.

Hoerling, M. and A. Kumar, 2003: The Perfect Ocean for Drought. Science, 299, 691-694.

International Panel on Climate Change (IPCC), 1990: Climate Change, the IPCC scientific assessment. World Meteorological Organization/United Nations Environment Programme, 365 pp.

Kogan, F., 1995: Droughts of the Late 1980's in the United States as Derived from NOAA Polar-Orbiting Satellite Data. Bulletin of the American Meteorological Society, 76, 655-668.

Laird, K., B. Cumming, S. Wunsam, J. Rusak, R. Oglesby, S. Fritz, and P. Leavitt, 2003: Lake Sediments record large-scale shifts in moisture regimes across the northern Prairies of North America during the past two millennia. Proceedings of the National Academy of Sciences, 100, 24832488 . 
Bibliography

Liu, J., R. Stewart, and K. Szeto, 2004: Moisture Transport and Other Hydrometeorological Features Associated with the Severe 2000/01 Drought over the Western and Central Canadian Prairies. Journal of Climate, 17, 305-319.

Longley, R., 1972: The Climate of the Prairie Provinces. Crown, 79 pp.

Ludlam, F.H., 1980: Clouds and Storms: The Behavior and Effect of Water in the Atmosphere. The Pennsylvania State University Press, 405 pp.

Maybank, J., B. Bonsal, K. Jones, R. Lawford, E.G. O'Brien, E.A. Ripley, and E. Wheaton, 1995: Drought as a Natural Disaster. Atmospheric-Ocean, 33, 195-222.

Mekis, E. and W. Hogg, 1999: Rehabilitation and Analysis of Canadian Daily Precipitation Time Series. Atmosphere-Ocean, 37, 53-85.

Namias, J., 1960: Factors in the initiation, perpetuation, and termination of drought. In Pub 51. Association of Scientific Hydrology. Commission of Surface Waters.

Namias, J., 1983: Some Causes of United States Drought. Journal of Climate and Applied Meteorology, 22, 30-39.

Natural Resources Canada (2004). Retrieved August 31, 2004, from http://atlas.gc.ca/site/index.html.

Nazemosadat, M., and A. Ghasemi, 2004: Quantifying the ENSO-Related Shifts in the Intensity and Probability of Drought and Wet Periods in Iran. Journal of Climate, 17, 4005-4018.

Nkemdirim, L. 1996: Canada's Chinook Belt. International Journal of Climatology, 16, 441-462.

Nkemdirim, L., and L. Weber, 1998: Comparison between the Droughts of the 1930's and the 1980's in the Southern Prairies of Canada. Journal of Climate, 12, 2434-2450.

Oglesby, R.J., 1991: Springtime Soil Moisture, Natural Climatic Variability, and North American Drought as Simulated by the NCAR Community Climate Model 1. Journal of Climate, 4, 890-897. 
Bibliography

Oglesby, R., and D. Erickson, 1989: Soil Moisture and the Persistence of North American Drought. Journal of Climate, 2, 1362-1380.

Paulson, R.W., Chase, E.B., Roberts, R.S., and Moody, D.W., 1991: National Water Summary 1988-89--Hydrologic Events and Floods and Droughts: U.S. Geological Survey Water-Supply Paper 2375, p. 99-104.

PFRA, Prairie Farm Rehabilitation Administration, 1998: Drought in the Palliser Triangle (A provisional primer). Regina: Agriculture and Agrifood Canada, $58 \mathrm{pp}$.

Philips, D., 1990: The Climates of Canada. Minister and Supply and Services Canada, $176 \mathrm{pp}$.

Pomeroy, J.W., D.M. Gray, and P.G. Landine, 1993: The Prairie Blowing Snow Model: characteristics, validation, operation. Journal of Hydrology, 144, 165-192.

Quiring, S., and T. Papakryiakou, 2003: An evaluation of agricultural drought indices for the Canadian Prairies. Agricultural and Forest Meteorology, 118, 49-62.

Rabin, R.M., Stadler, S., Wetzel P.J., Stensrud, D.J. and Gregory, M., 1990: Observed Effects of Landscape Variability on Convective Clouds. Bulletin of the American Meteorological Society, 71, 272-280.

Raddatz, R.L., 2000: Summer Rainfall recycling for an agricultural region of the Canadian Prairies. Canadian Journal of Soil Science, 80, 367-373.

Rogers, R.R. and M.K. Yau, 1989: A Short Course in Cloud Physics. Butterworth-Heinemann, $290 \mathrm{pp}$.

Sellers, W., 1965: Physical Climatology. The University of Chicago Press, 272 pp.

Shabbar, A., B. Bonsal, and M. Khandekar, 1997: Canadian Precipitation Patterns Associated with the Southern Oscillation. Journal of Climate, 10, 3016-3027.

Stefan, S., M. Ghioca, N. Rimbu, and C. Boroneant, 2004: Study of meteorological and hyrdological drought in Southern Romania from observational data. International Journal of Climatology, 24, 871-881. 
Bibliography

Stewart, R. and J. Burford, 2002: On the features of clouds occurring over the Mackenzie River Basin. Journal of Geophysical Research, 107, AAC 181-18-13.

Suppiah, R., 2004: Trends in the Southern Oscillation phenomenon and Australian rainfall and changes in their relationship. International Journal of Climatology, 24, 261-290.

Tannehill, I., 1947: Drought its Causes and Effects. Princeton University Press, $264 \mathrm{pp}$.

Trenberth, K., and G. Branstator, 1992: Issues in Establishing Causes of the 1988 Drought over North America. Journal of Climate, 5, 159-172.

Trenberth, K., and C. Guillemot, 1996: Physical Processes Involved in the 1988 Drought and 1993 Flood in North America. Journal of Climate, 9, 12881298.

Trenbeth, K., A. Dai, R. Rasmussen, and D. Parsons, 2003: The Changing Character of Precipitation. Bulletin of the American Meteorological Society, 84, 1205-1217.

Twomey, S., and P. Squires, 1959: The Influence of cloud nucleus on the microstructure and stability of convective clouds, Tellus, 11, 408-411.

Wallace, J.M., 1975: Diurnal Variations in Precipitation and Thunderstorm Frequency over the Conterminous United States. Monthly Weather Review, 103, 406-419.

Watson, R., M. Zinyowera, and R. Moss, 1998: The Regional Impacts of Climate Change: An Assessment of Vulnerability. Cambridge University Press, $517 \mathrm{pp}$.

Webb, R.S., C.E. Rosenzweig, and E.R. Levine, 1993: Specifying land surface characteristics in general circulation models: Soil profile data set and derived water-holding capacities. Global Biogeochemical Cycles, 7, 97108.

Wheaton, E.E., 1990: Frequency and Severity of Drought and Dust Storms. Canadian Journal of Agricultural Economics, 38, 695-700.

Wilhite, D., W. Easterling, and D. Wood, 1987: Planning for Drought: Toward a Reduction of Societal Vulnerability. Westview Press, 583 pp. 
Bibliography

Wilhite, D., 2000: Drought A Global Assessment, Volume 1. Routledge, 396 pp.

Williams, G.D.V., Fautley, R.A., Jones, K.H., Stewart, R.B., and Wheaton, E.E. 1988: Estimating effects of climate change on agriculture in Saskatchewan, Canada. The Impact of Climatic Variations on Agriculture, Volume 1, Assessments in Cool temperature and cold regions, Boson MA: Kluewer Academic Publishers

WMO, 1956: International Cloud Atlas Volume 1. World Meteorological Organization, $155 \mathrm{pp}$.

Woodhouse, C., and J. Overpeck, 1998: 2000 Years of Drought Variability in the Central United States. Bulletin of the American Meteorology Society, 79, 2693-2714.

Worldwatch Institute, 2003: Vital Signs. W.W. Norton and Company, 153 pp. 